\title{
A Practical Approach for Social Life Cycle Assessment in the Automotive Industry
}

\author{
Hannah Karlewski ${ }^{1, *}$, Annekatrin Lehmann ${ }^{1}$, Klaus Ruhland ${ }^{2}$ and Matthias Finkbeiner ${ }^{1}$ \\ 1 Chair of Sustainable Engineering, Technische Universität Berlin, Straße des 17. Juni 135, \\ 10623 Berlin, Germany \\ 2 Group Environmental Protection, Daimler AG, 70546 Stuttgart, Germany \\ * Correspondence: slca@karlewski.de
}

Received: 31 March 2019; Accepted: 13 June 2019; Published: 16 August 2019

\begin{abstract}
Identifying social impacts along the life cycle of their products is becoming increasingly important for companies. Social Life Cycle Assessment (SLCA) as a possible tool has not been conducted so far within industries with complex international supply chains using mainly companyspecific data. As a novelty, this work presents a practical SLCA approach along with the first case studies for the automotive industry, based on a previously developed indicator set and an extensive data collection. Social data was collected from companies along the life cycle of two specific car components, while analyzing data availability, validity and comparability. To obtain product references, both a top-down and a bottom-up approach for quantitative indicators based on time effort and data availability on the process level were devised. Also, two options were developed for how qualitative indicators (e.g., written principles for Corruption) can be applied together with quantitative performance indicators (e.g., number of accidents). The general practical applicability of the approach could be demonstrated by four quantitative and seven qualitative indicators. It is a first step towards analyzing the social performance of products with complex supply chains on a company level. Remaining challenges include social data availability and quality and obtaining data at the process level (allocation). These should be addressed in future studies.
\end{abstract}

Keywords: social life cycle assessment; automotive industry; case study; social data collection

\section{Introduction}

The analysis of social topics during the production, use and disposal of products is becoming increasingly important for companies in terms of their social responsibility towards a sustainable development. End consumers are also paying more and more attention to these social topics (e.g., [1-4]), also sensitized by numerous news in media. There have been reports in the last years mainly in the textile and IT industries about social abuses like child labor, forced labor, poor wages and harassment by supervisors (e.g., [5-10]). Also, the disposal of European electronic waste in Africa and its social impacts is mentioned regularly (e.g., [11-13]). The automotive industry has been in focus as well [14,15]. One way to assess social aspects of a product along its entire life cycle, from resource depletion to disposal, is offered by the Social Life Cycle Assessment (SLCA) method (e.g., [16]).

\subsection{The Status in Research}

The publication of the Guidelines for Social Life Cycle Assessment (SLCA) of Products (hereinafter: Guidelines) [16] and their corresponding Methodological Sheets for Subcategories in Social Life Cycle Assessment (hereinafter: Methodological Sheets) [17] marked a significant milestone. Therefore, it has been a major basis for this work. However, the huge amount and the diverse topics of the publications in this field indicate that there are still a variety of challenges in SLCA. Before the Guidelines were 
published, there were already studies on SLCA, but the focus was more on developing methods and approaches. One example is the Product Sustainability Assessment-Methodology (PROSA) [18], which also contains an approach for SLCA. The extensive set of social aspects and indicators from PROSA has also been considered in this work. The results of a case study about notebooks are however more qualitative due to the deficiency of quantitative product-based data [19]. Further studies exist, for example for the salmon and milk industry [20,21], for waste management [22] or for comparisons between detergents [23]. In the latter study a method for social aspects not relating to a product but describing an attribute of a process (like a fair-trade certification) was developed. In this method called the Life Cycle Attribute Assessment (LCAA) the indicators are related to a share of a product life cycle (e.g., percent or working hours) (see also reference [24]). It has been applied in a case study with greenhouse tomatoes [25] and is used in this work for qualitative and semi-quantitative indicators.

After 2009, the focus of case studies turned more towards the application of the Guidelines. There are examples in the electronic industry [26-28], the textile industry [29], the energy sector [30-33], the building industry [34-36], agriculture [37-43], manufacturing [44], mining [45], mobility [46], water resources management [47], the tourism industry [48] and the waste management industry [49-51].

Because the Guidelines do not describe a binding way of proceeding, the case studies differ often mainly in the method or the scope of SLCA (see also reference [52]). In addition, there are still studies that do not follow the Guidelines (e.g., [53-58]).

While some authors calculate the social impacts as being analogous to those of a Life Cycle Assessment (LCA, thus being compatible with Life Cycle Sustainability Assessment (LCSA)) based on the functional unit of a product system (e.g., [43,59]), others describe these impacts more qualitatively (e.g., [28]). Some of the studies use only generic data (e.g., [26,29]), while others collect company-specific data for key processes (e.g., [37]). Noticeably more and more studies use the term SLCA, although no product system is considered, but company assessments are carried out with the social aspects of the Guidelines (e.g., [48,50,52]).

In summary, the case studies in many publications focus primarily on products which either have a less complex life cycle within one country or only a reduced number of stakeholders, life cycle phases, mass and energy flows or social aspects compared to the suggestions of the Guidelines. Slowly more and more parameters have been included in the case studies and more complex products are being considered. One extensive study for example has been published by Martinéz-Blanco et al. [43].

Regarding impact assessment, color or point scales are frequently used which indicate different risks or performance in relation to reference values (e.g., [27,36,38,51]). Based on the Guidelines Parent, Cucuzzella and Revéret [60] described this approach as a task force approach (type 1 of impact assessment) in contrast to impact assessment using impact paths (type 2) [61,62].

In the beginning, theoretical studies on SLCA focused more on the development of methods, the fundamental considerations on possible challenges and the differences to LCA. Since then, studies have increasingly focused on the further development of SLCA such as in the field of impact assessment (e.g., $[63,64])$. In general, however, the status and further procedure of the SLCA method itself are also discussed (e.g., [65-68]).

While the goal in many studies on SLCA has been to establish a process reference (micro level), an evaluation at the company level (meso level) would also be conceivable [69]. Because many social aspects of companies are addressed at the organizational level, the Organizational LCA (OLCA; the abbreviation is used analogously to SLCA as in reference [70]) could be a promising approach for which a Guidance on Organizational Life Cycle Assessment [71] and the ISO/TS standard 14072 [70] were published some years ago [72]. Like the LCA, it analyzes various environmental impacts, but extends the life cycle approach to organizations. In reference [73] the authors propose a framework for Social Organizational LCA (SOLCA). 


\subsection{The Status in Industry}

As a result of the developments described at the beginning of this chapter, companies are increasingly also taking social aspects into account with their suppliers. However, these actions have so far been addressed primarily within Sustainable Supply Chain Management and have not been related to the life cycle of a product (e.g., [74]). But there are more and more approaches in the industry as well.

One example is BASF. Its eco-efficiency method was supplemented by social aspects in 2005 and has since been called SEE (Socio-Eco-Efficiency) Balance (see references [75,76]). Based on experiences with the SEEBalance method, BASF developed a method for measuring and evaluating sustainability in agriculture in 2012-AgBalance [77]. BASF was also part of a Working Group on Life Cycle Metrics in the chemical industry, which developed a first attempt of a guideline to measure and report social impacts of chemical products during their life cycles [78].

Several companies that have joined forces to form the Roundtable for Product Social Metrics published a Handbook for Product Social Impact Assessment at the end of 2014. The Handbook proposes a practical method for companies to analyze social aspects of products during their life cycles [79]. The latest Handbook is from September 2018 [80,81].

In the automotive industry there were two $\mathrm{PhD}$ theses which addressed social aspects. At Daimler, Karlewski developed a practical SLCA approach [82] (this article is based on parts of this thesis), while at BMW Tarne assessed SLCA as part of LCSA [83-86]. Another company that deals with social aspects of products in the automotive industry is Ford. In this approach called the Product Sustainability Index (PSI), the social aspects are- together with the other dimensions of sustainability-considered in the development of a car. As in LCSA, the ecological aspects are covered by LCA, while the economic aspects are represented by Life Cycle Costing (LCC). However, in the PSI, the social aspects are only considered in the use phase. This includes vehicle safety for occupants and pedestrians as well as mobility capacity. Vehicle noise and substance management (interior air quality) can also be taken into account [87]. However, there is no scientific derivation of the social aspects.

\subsection{Research Needs}

The publication of the Guidelines was an important step towards the standardization of SLCA. It further progressed SLCA activities in research and industry. While in the beginning the focus had been mainly on theoretical work and rather basic case studies, researchers started to include more complex products, more stakeholders and life cycle phases and more detailed mass and energy flows in the last years. In general, when comparing SLCA to LCA, there is still a great need for more standardized methods and indicators and for further case studies [62,88-91].

In particular, analyses in business environments that assess the relevance and feasibility of SLCA are still rare (see reference [92]). This also affects the questions for which social data are available from several, possibly internationally operating, companies, and which data can be compared between different companies. SLCA studies with mainly company-specific data have not been conducted so far in industries with complex international manufacturing and supplier structures. Previous studies have mainly used generic data, such as data from the Social Hotspot Database (SHDB) [93]. Using company-specific instead of generic data is advantageous because it makes the results more meaningful and accurate. Also, social impacts in the use phase of a product and their consideration in SLCA have been hardly investigated. Besides, there is still a need for research in the field of impact assessment of SLCA, such as for the standardization of reference points or impact pathways. Further challenges exist when integrating SLCA into LCSA.

SLCA should be adapted to the respective industry, for example by including stakeholders or analyzing the specific impact of the product $[89,94,95]$. This has not yet been done systematically in the automotive industry. Similarly, there is neither a theoretical derivation of the social properties of cars, nor any consideration of these properties within the framework of SLCA.

In summary, SLCA studies are needed, which consider as many of the following points as possible: 
- consideration of the entire life cycle of a product,

- priority use of company-specific data in industries with complex, international manufacturing and supplier structures,

- inclusion not only of material but also of energy flows, and

- compatibility of SLCA with LCA and LCC in the context of an LCSA.

In addition, the following topics give rise to more detailed investigations:

- availability and comparability of social data in the context of different, internationally operating companies,

- consideration of social impacts in the use phase of a product, and

- further development of impact assessment.

For the application of SLCA in the automotive industry, research is also needed regarding:

- analysis and development of social aspects and indicators considering the characteristics of the automotive industry,

- involving stakeholders from the automotive industry in prioritizing and evaluating social aspects, and

- theoretical derivation of social car properties.

\subsection{Objectives of This Paper}

Based on the research needs, the central question addressed in this paper was how (and indeed if) SLCA in the automotive industry-as an example of an industry with complex, international manufacturing and supplier structures-based on company data can be conceptualized and conducted in case studies. Therefore, the main goal was the development of a practical SLCA approach including its application with case studies of two car components (inner part of the rear door, made of steel in the case of one component and aluminum in the other). Furthermore, a short overview about the results of the social data collection being the basis for the developed method is given. The focus was on company-specific data for gaining insight into which data is available at company/organizational level and which can be used for SLCA.

\section{Materials and Methods}

The method that was used to develop a practical SLCA approach is described in Section 2.1. The social data collection (Section 2.1.1) was the basis for calculating the reference values (Section 2.1.2) and the social data (Section 2.1.3). The way the applicability of the SLCA approach was tested in case studies is explained in Section 2.2. The SLCA approach itself although including some methodological parts is presented as a result in Section 3, because its development was one of the main objectives of this work.

\subsection{Practical Approach for SLCA in the Automotive Industry}

To develop an SLCA approach for the automotive industry, social aspects and indicators were devised considering the characteristics of this industry. The procedure was described comprehensively in a previous publication [82] and is shown in Figure 1 (the individual steps of the figure are shown bold hereafter). As there was no automotive-specific social aspect set, which could be used for an SLCA approach in the automotive industry, social aspects were derived from the Guidelines and their Methodological Sheets. Additional sources included the Global Reporting Initiative guidelines (GRI guidelines) [96], PROSA, SEEBalance and internal discussions at Daimler. This set of social aspects was analyzed in order to determine how the aspects could be specifically adjusted and fitted to the structure of suppliers and the international nature of the automotive industry, including the present and future material composition of an automobile. They were classified into life cycle-oriented and 
end consumer-oriented social aspects. The former concerns the behavior of companies involved in the life cycle of the vehicle towards their stakeholders (society, business partners and competitors, employees, local community), while the latter refers to the behavior of an automotive company towards the end consumers and to social car properties, i.e., the use phase of a car. In this paper, only the life cycle-oriented social aspects are addressed. For the prioritization and evaluation of the social aspects, a survey of more than 400 stakeholders of Daimler was conducted. The development of indicators used to characterize the social aspects included consultation with experts of Daimler, along with extensive research into the literature. To categorize the indicators, a new systematic approach was deduced from the PLAN, DO, CHECK, ACT (PDCA) management cycle. The PDCA indicators describe management processes and are used to analyze whether a company has defined (written) principles for the respective social aspect (PLAN), has developed measures/systems to implement the principles (DO), has introduced control measures to monitor the implementation (CHECK) and has established processes to react to violations (ACT). The performance indicators represent measurable parameters of the social aspects. On the basis of these social aspects and indicators, a data collection form was designed (see Appendix A, Table A1). To analyze the data availability, validity and comparability between companies, social data along the entire life cycle of five different automobile parts, as well as for a whole car during the use phase at Daimler, were collected. Additionally, the challenges involved in such primary data collection were investigated. The results of the data collection were the basis for the development of the calculations for an approach using SLCA in the automotive industry. Subsequently, the applicability of the approach was analyzed by conducting case studies.

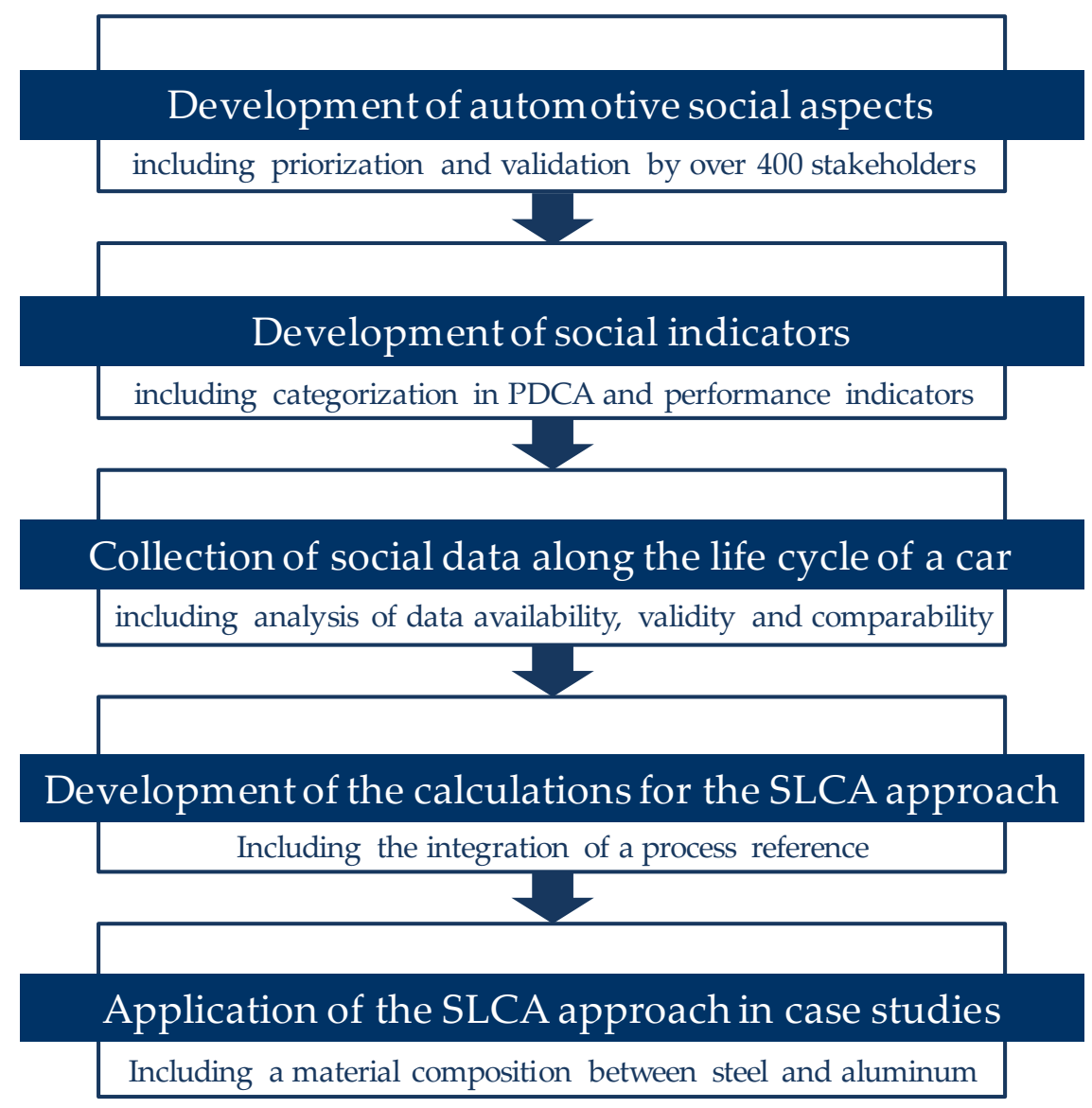

Figure 1. Overview of the procedure for developing an SLCA approach in the automotive industry. The development of automotive social aspects and indicators is comprehensively explained in reference [82]. This paper addresses the data collection and the final calculations of the SLCA approach, including case studies. 
This paper focuses on the presentation of the data collection and the final calculations of the SLCA approach including case studies.

\subsubsection{Collection of Social Data along the Life Cycle of a Car}

In order to gain experience regarding the data availability of the social aspects and indicators on organizational/company level as well as the methodological approach and to get social data as a basis for the calculations of the SLCA approach, exemplary social data along the life cycle of a car were collected. The Guidelines and others (e.g., $[73,97]$ ) also see the necessity for company-specific data, but at the same time advise to use generic data because of time and cost efficiency. In this work, we used intentionally only company-specific data. The results are presented in Section 3.1.1.

The focus of the social data collection was on the following questions:

- Which of the social aspects and indicators are available in the different companies or communicated?

- What are the challenges in data collection?

Three criteria were decisive in the selection of companies for data collection:

1. considering the entire life cycle of a car,

2. covering a large proportion of the materials contained in a car; and

3. including materials that have already been the focus of attention in other sectors regarding their social impacts (such as textiles or platinum metals).

As shown in Table 1 the data collection was divided in four phases:

In the supply chain (phase 1), the respective manufacturers and suppliers of various materials were examined. Due to the large number of individual parts of an automobile, the components considered were selected on the basis of the material composition of a Mercedes-Benz vehicle [98]. A total of five direct material or component suppliers (and their upstream chains) were surveyed: steel, textile, biopolymer, platinum metals and aluminum. The aim was to map the main flows of materials and energy. Individual processes were neglected for reasons of confidentiality and simplification.

For the car production (phase 2) in two of the five data surveys (biopolymer and platinum metals), the direct supplier delivers the finished component to Daimler, where it is installed in the car. For the other three (steel, aluminum, textiles) the component is produced at Daimler. Daimler was therefore surveyed, independent of the material.

The social data collection in phase 3 was carried out at one dismantling and one shredder company in Germany. In addition, an officially registered recycling company in Ghana was surveyed. Since many smaller and unregistered companies are common in this sector in Ghana, the company represents only a small formal part of this sector.

The term energy (phase 4) refers to electricity, process energy and fuel. Social data were collected from an electricity producer and a mineral oil company (including - if available — the companies in the upstream chain) as an example. This means that the specific energy suppliers of the individual companies are not represented.

In addition to the gathering of social data, company data like the number of employees (i.e., working hours) and mass and energy flows were also collected.

In total, 22 companies were analyzed regarding social aspects. A large portion of these companies (14) are globally active, with 7 in one country in Europe and 1 in Africa. Based on the number of employees, most of these companies are large companies (with more than 500 employees), while 5 are medium-sized companies. No small companies were surveyed (company size structure was judged according to reference [99]). The companies were contacted by telephone or e-mail. If possible, the company was visited on site to present the topic and aim of the data collection through a presentation and discussion. Web conferences were organized with most of the remaining companies. In additional telephone calls, the data collection form and the procedure were discussed. For 6 companies, only 
sustainability reports and/or homepages could be analyzed, while for the others direct contact was possible.

Table 1. Overview of the materials (or energy) and life cycle stages considered in the data collection process. The life cycle stages considered are marked with $\mathrm{x}$. The color fields illustrate the four phases according to which the various processes are presented in this chapter (middle blue = phase 1, dark blue $=$ phase 2, light blue $=$ phase 3 , grey $=$ phase 4 )

\begin{tabular}{c|c|c|c|c|c|c}
\hline Materials/Energy & $\begin{array}{c}\text { Resource } \\
\text { Depletion }\end{array}$ & Tier 1-Tier n & $\begin{array}{c}\text { Car } \\
\text { Production }\end{array}$ & Car Use & Dismantling & Shredder \\
\hline Steel & $\mathrm{x}$ & $\mathrm{x}$ & $\mathrm{x}$ & & $\mathrm{x}$ & $\mathrm{x}$ \\
\hline Textile & $\mathrm{x}$ & $\mathrm{x}$ & $\mathrm{x}$ & & $\mathrm{x}$ & $\mathrm{x}$ \\
\hline Biopolymer & $\mathrm{x}$ & $\mathrm{x}$ & $\mathrm{x}$ & & $\mathrm{x}$ & $\mathrm{x}$ \\
\hline Platinum metals & $\mathrm{x}$ & $\mathrm{x}$ & $\mathrm{x}$ & & $\mathrm{x}$ & $\mathrm{x}$ \\
\hline Aluminum & $\mathrm{x}$ & $\mathrm{x}$ & $\mathrm{x}$ & & $\mathrm{x}$ & $\mathrm{x}$ \\
\hline Energy & $\mathrm{x}$ & $\mathrm{x}$ & $\mathrm{x}$ & $\mathrm{x}$ & $\mathrm{x}$ & $\mathrm{x}$ \\
\hline
\end{tabular}

\subsubsection{Calculation of the Reference Values}

Social data require a process reference for use in SLCA that is analogous to LCA. Ideally, they can be collected directly from the company, including the process reference (referred to as the bottom-up approach in this work). However, this is not always possible for various reasons (see Section 3.1.1), often the social data are only available at the company level [16,97]. Therefore, this paper describes also an alternative procedure for calculating the process reference (referred to as the top-down approach in this work). After defining and quantifying the functional unit, it is important to specify the reference flows [16]. In Environmental LCA databases, precise process references exist which can be used for determining the material and energy flows of the considered components (see step 1 in Figure 2). Because the databases use mass and energy units, it is necessary to link them to the social data by using an activity variable. The activity variable working hours was chosen in this work as the reference variable, since many social aspects are associated with it. Alternatively, other reference values, such as turnover, number of units or mass, can also be selected [16]. For some processes, the activity variable working hours can be taken from the LCA database GaBi within the framework of the Life Cycle Working Environment (LCWE) approach [100]. For example, Martinéz-Blanco et al. [43] use this data source. However, the information relates mainly to the US economy and cannot be used for any other country. Also, for some processes the individual process steps are not listed in detail. In this work the working hours of the companies (step 2 in Figure 2) were related to the mass and energy data of the company (step 3, Figure 2) and offset with the mass and energy flows of the components' life cycles in order to be able to indicate the contribution of a company to a process step or component (steps $4 \mathrm{a}$ and $4 \mathrm{~b}$, Figure 2). With the help of the calculated reference values, the social data collected at company level for use in SLCA could be converted at the product level. A similar approach was used by e.g., [101]. These calculations are shown in the context of the presentation of the approach in Section 3.1.2 and with application examples in Section 3.2.1. The transfer from the component level to the car level is discussed in Section 3.3.5.

\subsubsection{Calculations with the Social Data}

The following steps in Figure 2 show how the social data can be prepared for SLCA. Step 5 identifies the social aspects and indicators to be included in SLCA. In the steps $6 \mathrm{a}$ and $6 \mathrm{~b}$, the performance and PDCA indicators are calculated, for which the use in SLCA is then presented in step 7. Step 6a differs between the bottom-up and the top-down approach (see Section 2.1.2). The underlying calculations are described in Section 3.1.3, the application with case studies is shown in Section 3.2.2. 


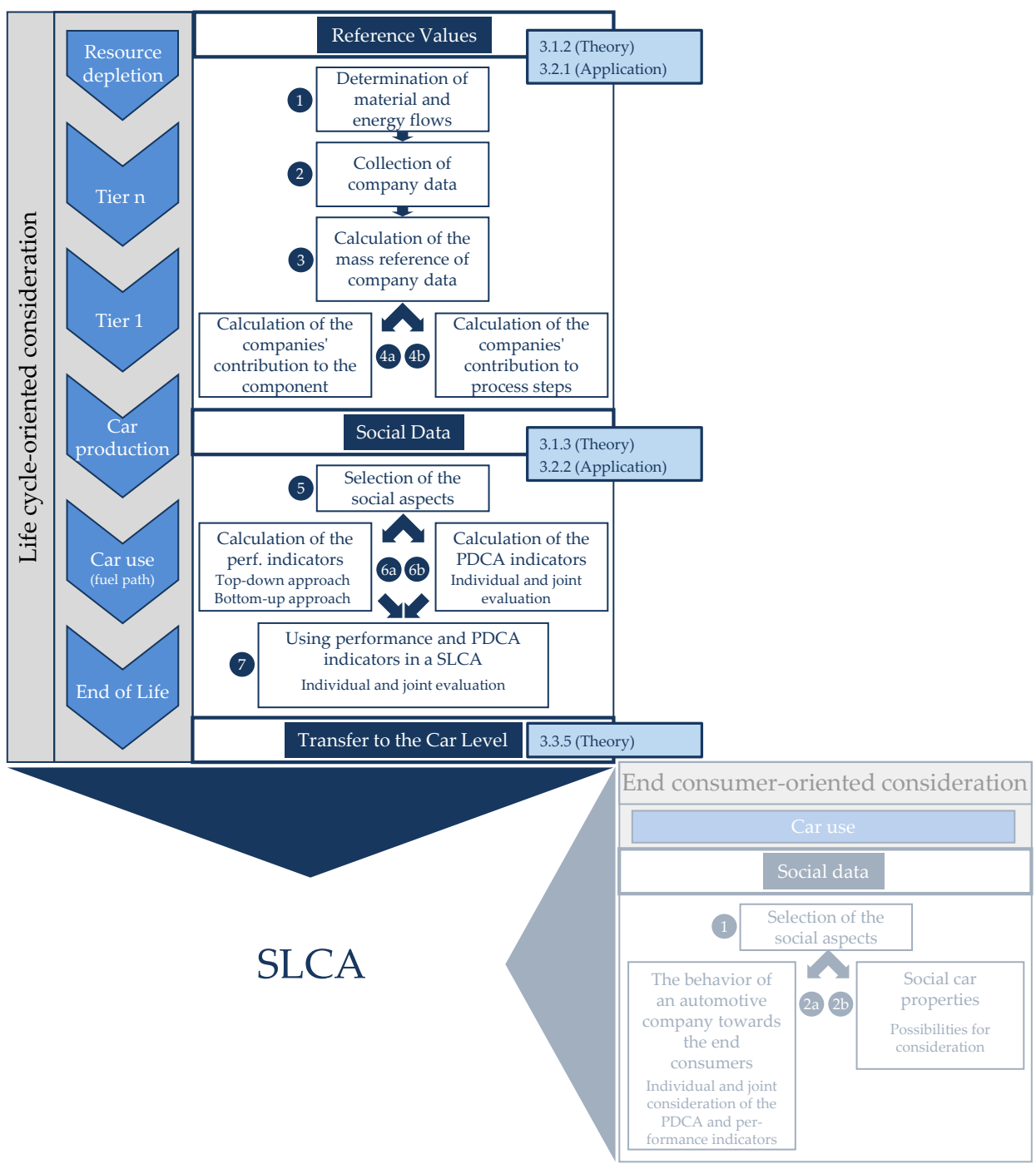

Figure 2. Overview of the approach for SLCA in the automotive industry. The life cycle-oriented approach is shown on the left side and is explained in Sections 2.1.2 and 2.1.3. The end consumer-oriented approach is shown on the right and is addressed in reference [82].

\subsection{Application of the SLCA Approach in Case Studies}

The company responses to the data collection form were applied to the developed calculations of the SLCA approach to test the general practical applicability of the method (Section 3.2). In order to show the possibility to support decisions in the product development, a material comparison between steel and aluminum was carried out.

The mass and energy flows of the components' life cycles were taken from GaBi [102] (22nd service pack) and ecoinvent data sets [103] (Version 2.2). Additional sources were references [104,105]. Detailed information and assumptions are given in Appendix B.1.

\section{Results}

Based on the results of the social data collection, an approach of a practical SLCA method for the automotive industry was developed and is presented in Section 3.1 (see reference [82] for more details about the end consumer-related social aspects). The applicability of the SLCA approach was examined in case studies and is shown in Section 3.2. The results are used to analyze and discuss the central question about the feasibility of a practical SLCA method in an industry with complex international 
supply chains and company-specific data in Section 3.3. Since the data used are related to individual components, the transfer to the car level is also discussed in Section 3.3.5.

\subsection{Practical Approach for SLCA in the Automotive Industry}

\subsubsection{Collection of Social Data along the Life Cycle of a Car}

It was possible to gain life cycle-oriented, company-specific social data from resource depletion to disposal for two specific components (inner part of the rear door, made of steel in the case of one component and aluminum in the other). This data was used to further develop an approach for a practical SLCA method in the automotive industry (see Sections 3.1.2 and 3.1.3). When considering PDCA and performance indicators together, the data availability was high for almost half of the life cycle-oriented social aspects (see Figure 3). The highest response rates were recorded for the social aspects Public Commitment to (Social) Sustainability (1), Corruption (3), Behavior in Competition (6), Social Responsibility (9), Freedom of Association (10), Hours of Work (13), Forced Labor (14), Health and Safety (16), Social Benefits/Social Security (17), Dialogue with the Local Community (23), Indigenous Rights (25) and Access to Immaterial and Material Resources $(27,28)$ (red mark in Figure 3). For these, the data availability within the framework of this work is described as good. On the social aspect of Technological Development (4), there were also many answers regarding the performance indicators; PDCA indicators were not asked here. The latter also applies to the social aspect of Economic Development (2). There was no feedback on the PDCA indicators for Armed Conflicts. In principle, more social data could be obtained on PDCA indicators than on performance indicators. For the PDCA indicators, feedback on control mechanisms (CHECK) or processes to respond to non-compliance (ACT) was lower than on the written principles (PLAN) and implementation measures (DO) of the social aspects.

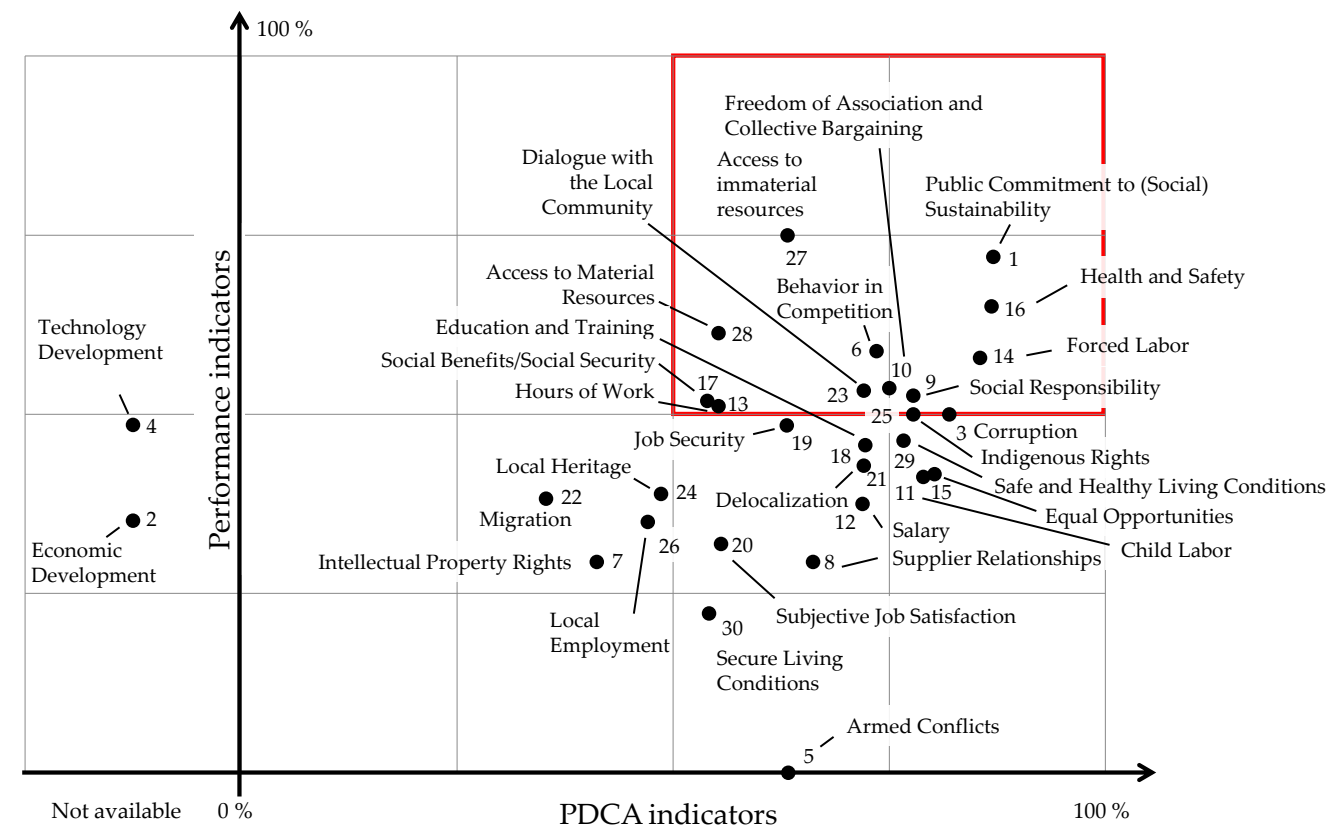

Figure 3. Evaluation of the PDCA and performance indicators regarding data availability in the surveyed companies. The answers to the social PDCA and performance indicators were set in relation to the maximum possible answers. The values in this figure are given as percentages. The social aspects within the square marked in red had good data availability in the primary data collection (response rate over 50\%). No PDCA indicators were asked for the social aspects 2 and 4.

Table 2 summarizes the companies' assessments of the comparability of different companies regarding the PDCA and the performance indicators, as well as their meaningfulness in general. 
Table 2. Overview of the social aspects with their corresponding numbers and an assessment of the social indicators in terms of their comparability between different companies and their meaningfulness. For the PDCA indicators, + means that the companies considered an assessment and comparison to be possible, - means that the feedback was negative or critical in this respect and 0 was given if the feedback was very different. For the performance indicators, + means that the companies considered an assessment and comparison of at least one performance indicator to be possible, - means that the feedback was more negative or critical for all performance indicators and 0 means that the feedback was ambiguous. No PDCA indicators were asked for the social aspects 2 and 4 .

\begin{tabular}{|c|c|c|c|c|c|c|c|}
\hline No. & Social Aspect & PDCA & Perf & No. & Social Aspect & PDCA & Perf \\
\hline 1 & $\begin{array}{l}\text { Public Commitment to (Social) } \\
\text { Sustainability }\end{array}$ & + & - & 16 & Health and Safety & + & 0 \\
\hline 2 & Economic Development & & - & 17 & Social Benefits/Social Security & + & 0 \\
\hline 3 & Corruption & + & - & 18 & Education and Training & + & + \\
\hline 4 & Technology Development & & - & 19 & Job Security & 0 & + \\
\hline 5 & Armed Conflicts & - & - & 20 & Subjective Job Satisfaction & 0 & 0 \\
\hline 6 & Behavior in Competition & + & + & 21 & Delocalization & 0 & + \\
\hline 7 & Intellectual Property Rights & - & 0 & 22 & Migration & 0 & 0 \\
\hline 8 & Supplier Relationships & - & - & 23 & $\begin{array}{l}\text { Dialogue with the Local } \\
\text { Community }\end{array}$ & - & - \\
\hline 9 & Social Responsibility & + & 0 & 24 & Local Heritage & - & - \\
\hline 10 & $\begin{array}{l}\text { Freedom of Association and } \\
\text { Collective Bargaining }\end{array}$ & 0 & 0 & 25 & Indigenous Rights & 0 & + \\
\hline 11 & Child Labor & + & 0 & 26 & Local Employment & - & - \\
\hline 12 & Salary & + & 0 & 27 & Access to Immaterial Resources & - & - \\
\hline 13 & Hours of Work & + & + & 28 & Access to Material Resources & - & + \\
\hline 14 & Forced Labor & + & - & 29 & $\begin{array}{l}\text { Safe and Healthy Living } \\
\text { Conditions }\end{array}$ & - & - \\
\hline 15 & Equal Opportunities & + & + & 30 & Secure Living Conditions & - & 0 \\
\hline
\end{tabular}

Accordingly, the PDCA indicators and the performance indicators of the social aspects Economic Development (2), Technological Development (4), Behavior towards Suppliers (8), Dialogue with the Local Community (23), Local Heritage (24) and Safe and Healthy Living Conditions (29) were assessed by the companies as unsuitable $(-,-)$ in terms of comparability and meaningfulness. The social aspects of Behavior in Competition (6), Hours of Work (13), Equal Opportunities (15) and Education and Training (18) were considered positively by the companies, as were the PDCA and performance indicators $(+,+)$.

There are various reasons for the different evaluations that occurred in the other social aspects. For example, companies rated some social aspects in general and the corresponding PDCA indicators as being basically positive but evaluated the performance indicators as difficult to measure or not (yet) meaningful $(+,-)$. Additionally, one social aspect in general and the corresponding PDCA indicators were regarded as being difficult to compare between companies, but the performance indicators were considered to represent a sub-area of the social aspect well $(-,+)$. Neutral evaluations $(0)$ indicate that the feedback did not allow for a clear trend.

In addition to the evaluation of the social indicators, all challenges that arose during the company-specific data collection process are described in the following section. These are taken up again in Section 3.3.

\section{Challenges in the primary data collection}

- Obtaining data at the process level

The goal of an SLCA is to collect social data for the individual processes along the life cycle of a product. Information on mass and energy flows is important for this, but companies often do not publish it for reasons of confidentiality. The data are usually only available at the organizational level, 
which is why an allocation must be carried out. At this point, the question arises regarding what proportion of the data must be allocated to administration and what proportion of administration must be allocated to the product under consideration. The allocation is getting even more complex if several products are developed or produced at one location or if the development or production extends over several locations (see Figure 4). The LCA still faces challenges with regard to allocation as well [106].

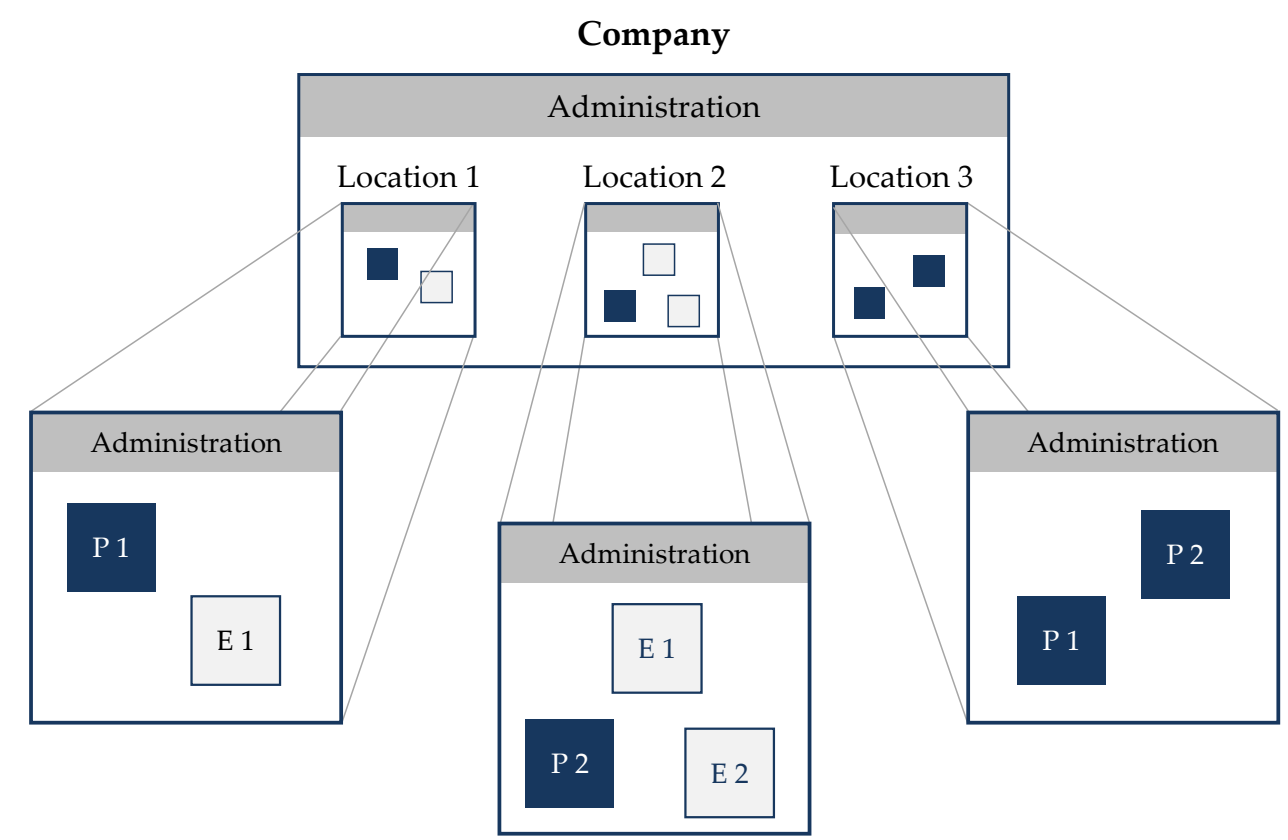

Figure 4. Exemplary representation of a company with three locations, two products and production and development areas. The company is expected to have three locations. The production (P) of product 1 (P1) and/or 2 (P2) and/or the development (E) of product 1 (E1) or 2 (E2) takes place at the respective locations.

Furthermore, most of the social aspects of companies are mainly surveyed at the organizational level and can only be related to processes with difficulty. After discussions with several companies regarding the feasibility of the social aspects developed in reference [82], it is theoretically possible to collect data at the process level on the following social aspects: Economic Development, Social Benefits/Social Security, Salary, Hours of Work, Health and Safety, Equal Opportunities, Freedom of Association and Collective Bargaining, Education and Training, Job Security, Child Labor and Forced Labor. However, even with these social aspects, in practice they may either not be considered at the process level or the information at the process level may be subject to confidentiality.

If social data have not been specifically recorded for a process in a company, they could be related to the process with a suitable activity variable, such as working hours. However, these are also often confidential.

- Obtaining location information with company data

Many of the indicators, such as the social aspects Salary or Hours of Work, can only be evaluated if the local situation or the cultural background of the social data is known. In the published data, there is usually no reference to the place of production, or the companies only provide social data as an average at organizational level-although they often operate at several locations in different countries (see Figure 4). Even if the company allows the publication of social data of individual sites in principle, there is often no central office, especially in large companies, to coordinate the data of the different sites. For example, each location must be requested individually, which involves a great deal of effort. Thus, an evaluation of indicators with a local reference is very difficult or even impossible in these cases. 


\section{- Definition of cut-off-criteria}

In the upstream chain, only components consisting of one material each were examined in this primary data collection. Nevertheless, many of them turned out to be very complex during the data collection due to the diverse material flows. An analysis of all specific energy flows in the upstream chain would have greatly increased the complexity of this process. Therefore, cut-off criteria had to be defined. Some of these were defined a priori (for example, in the biopolymer example, only direct suppliers whose materials account for more than 5 percent by weight of the component were considered). In other cases, the cut-off criteria had to be selected during the process if, for example, the materials contained (as in the case of the textile fabric finisher) were confidential. For the energy flows, one mineral oil producer and one electricity producer (including —if available — the companies in the upstream chain) were analyzed as examples.

In future studies, especially for products with complex material and energy flows, criteria must also be defined in order to be able to implement the data collection in a foreseeable timeframe. These should be harmonized and standardized so that the results are transparent and comparable. Confidentiality of processes can be a major obstacle.

- Comparability of social data between different companies

Apart from cultural differences in the evaluation of social indicators, there are also significant differences between companies in the definition and reporting of social indicators. For example, the indicator number of accidents per year appears at first glance to be clearly defined. However, companies report very different accident data (e.g., number of accidents compared to number of accidents with one day lost). This challenge can also be observed in the comparison of different sustainability reports for other indicators.

In guidelines for sustainability reporting, such as the GRI guidelines, many indicators are not sufficiently precise to guarantee comparability between companies. A stronger focus should be placed in future on the concretization and standardization of indicators. However, this is also a major challenge, as many companies have already well established, often significantly different, data collection systems.

- Collection of company-specific social data in the supply chain

In some cases, the social data collection was not possible down to resource depletion, as some companies only knew their direct suppliers or bought raw materials on stock exchanges. For this reason, the social risks in the upstream chains of the biopolymer material were examined using the SHDB as an example. The results were not integrated into the discussion of the indicators as they refer to risks for social aspects in specific countries or industries and cannot be applied directly to suppliers. The different types of data collection and evaluation prevent the comparability of the results.

In addition, many companies are very reluctant to publish social data. Due to the lack of influence of the OEM over the entire life cycle, an obligation of these companies is not feasible in all cases and it is also questionable whether such an obligation would lead to reliable results. Collecting social data in ways other than direct contact or use of published documents is not possible in the context of corporate relationships. In addition, many companies do not consider data from the media or from NGO investigations to be independent.

\section{- Collection of deviations from legal regulations}

When a company is asked about for example the minimum wage or the maximum weekly working time, it will only answer something different from the legally required regulations if it can give more positive values. This means that no negative deviations can be identified. In addition, it is often not possible to answer questions on country-specific laws, as most companies provide only information at the organizational level. 
- Concerns of companies about the collection of social data

The companies contacted were often skeptical about social data collection at the beginning, as many social data are confidential. However, in this work, the reluctance of companies usually subsided after reference was made to the research character of the work. In addition, companies were assured that their data would be treated accordingly and that the responses would have no impact on business relations. In principle, however, the success of a data collection depends strongly on the reasons and the argumentation.

- Effort of companies in completing the data collection form

The data collection form was very detailed in this work, as it was intended to be used to analyze the social aspects and indicators on which companies provide feedback. However, this fact led to the disadvantage that some companies did not complete the questionnaire at all or only did so partially due to a lack of capacity. Above all, the time required for collection and preparation of the data represented a high expenditure for the companies.

- Translation of the data collection form

When collecting data from companies from different countries and cultures, it is very important to adapt the different translations accordingly, maybe even working with native speakers.

\subsubsection{Calculation of the Reference Values}

Social data need a process reference for use in SLCA. If this requirement cannot be fulfilled during data collection (top-down approach), the mass and energy flows of the components' life cycle and the company data have to be offset against each other in order to be able to indicate the contribution of a company to a process step or component (see steps 1-4b, Figure 2).

\section{Step 1: Determination of the material and energy flows of the component}

After defining the functional unit, the material and energy flows are, for example, taken from LCA databases or directly collected at companies from the life cycle of the component under consideration. This results in the relevant material composition and energy consumption for each life cycle phase. In addition, further (actual or generic) companies relevant for the primary data collection can be determined.

If a company carries out several process steps and the social data are only available at the company level, the process steps must be combined into one at this point. In this case, the social effects of the process steps cannot be calculated individually.

\section{Step 2: Collection of company data}

The following data of the participating companies are collected in addition to the social data:

- mass of their products per year and

- number of employees.

The total number of working hours of the companies per year can be calculated from the number of employees (for example based on reference [107]). 


\section{Step 3: Calculation of the mass reference of company data}

From the previous calculations, the hours worked per company for each kilogram produced can be calculated using the following formula:

$$
e_{\mathrm{x}}=\frac{H_{\mathrm{x}}}{M_{\mathrm{x}}}
$$

$\mathrm{x}$ : Company A, B, C, ..

$e_{\mathrm{x}}$ : Hours worked per kilogram by company $\mathrm{x}$.

$M_{\mathrm{x}}$ : Total mass of production of $\mathrm{x}$ per fiscal year.

$H_{\mathrm{x}}$ : Total working hours of $\mathrm{x}$ per fiscal year.

The working hours per company per kilogram can be used to calculate the working hours per company per component or also broken down by process steps (steps $4 \mathrm{a}$ and $4 \mathrm{~b}$ ), depending on the issue at hand.

\section{Step 4a: Calculation of the companies' contribution to the component}

Using the factor $\frac{H_{\mathrm{x}}}{M_{\mathrm{x}}}$ and the material and energy flows from step 1, the working hours per company for the component (see Figure 5) can now be calculated using the following formula:

$$
h_{\mathrm{x}}=e_{\mathrm{x}} \times m_{\mathrm{x}}
$$

$\mathrm{x}$ : Company A, B, C, ..

$h_{\mathrm{x}}$ : Working hours for the component per company $\mathrm{x}$.

$m_{\mathrm{x}}$ : Mass of the component relevant to the company $\mathrm{x}$.

$e_{\mathrm{x}}$ : Working hours per kilogram of the company.

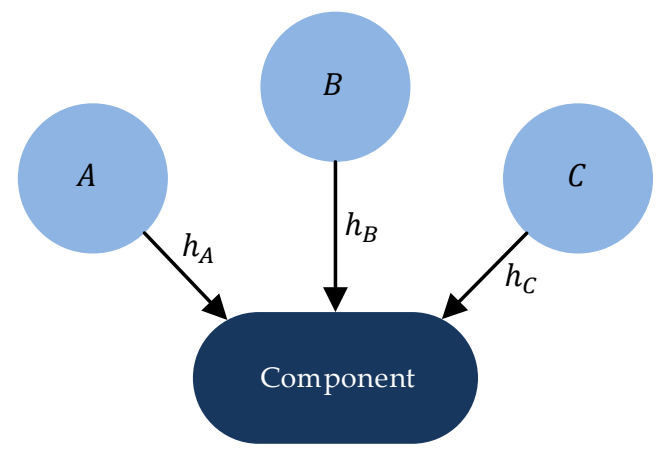

Figure 5. Representation of the hours worked per component by companies A, B, C $\left(h_{A}, h_{B}, h_{C}\right)$.

\section{Step 4b: Calculation of the companies' contributions to individual process steps}

The working hours of the companies per component cannot only be given over the entire life cycle of the component under consideration, but also per process step of the component:

$$
h_{\mathrm{x}, \mathrm{n}}=\frac{H_{\mathrm{x}}}{M_{\mathrm{x}}} \times m_{\mathrm{x}, \mathrm{n}}
$$

x: $\quad$ Company A, B, C, ...

$\mathrm{n}$ : Process step $\mathrm{n}$.

$h_{\mathrm{x}, \mathrm{n}}$ : Working hours for the company component $\mathrm{x}$ in process step $\mathrm{n}$.

$m_{\mathrm{x}, \mathrm{n}}$ : Mass of the component relevant to the company $\mathrm{x}$ in process step $\mathrm{n}$.

$H_{\mathrm{x}}$ : Total working hours of $\mathrm{x}$ per fiscal year.

$M_{\mathrm{x}}$ : Total mass of production of $\mathrm{x}$ per fiscal year. 
Social indicators can now be related to the calculated working hours per company. In most cases, the company carrying out the respective step as well as at least one energy company contribute to a process step.

\subsubsection{Calculations with the Social Data}

The collected social data can be related to a component or the individual process steps with the aid of the reference values according to the following approach (see steps 5-7, Figure 2):

\section{Step 5: Selection of the social aspects}

Ideally, in an SLCA, a company should consider at least those social aspects as being very important to the company's stakeholders. However, only social aspects can be analyzed for which data is available from companies along the life cycle. The comparability between companies and the meaningfulness of the social aspects are other important points. In addition, the process reference of the indicators should also be considered in an SLCA, analogous to the LCA (see Section 3.1.2).

In order to consider all the importance classifications of the social aspects, these could be included in the framework of the impact assessment as measures of weighting (in contrast, in reference [108], the weighting component is considered more as part of the evaluation). For this purpose, the LCA contains the optional component weighting, which should not be applied, however, due to the evaluations carried out in a publication aiming at comparative statements. If this is nevertheless desired, it is recommended to add statements on uncertainty and sensitivity [109]. However, a company can also include the prioritization of social aspects in its interpretation of the results of an SLCA.

\section{Step 6a: Calculation of the performance indicators}

The performance indicators can be represented by two different approaches. The top-down approach is discussed below, followed by the bottom-up approach.

\section{Top-down approach}

With the top-down approach, the respective social indicators and the total working hours per company are recorded and related to the working hours per process step:

$$
I_{x, \mathrm{n}}=\frac{I_{\mathrm{x}}}{H_{\mathrm{x}}} \times h_{\mathrm{x}, \mathrm{n}}
$$

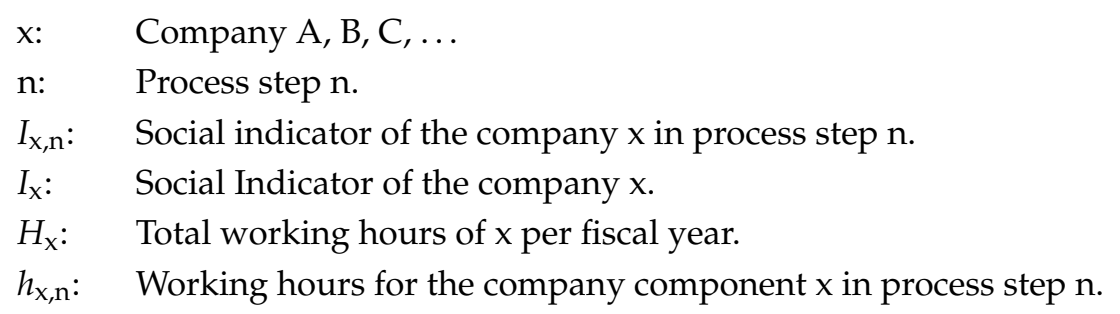

For calculating the respective social indicator per component, the individual process steps must be summed up. Since the social indicators in this approach are averaged across all processes of a company, it is possible that single processes are misrepresented. In addition, Equation (1) shows that the top-down approach can only be used to depict mass-dependent processes. If the functional unit in an SLCA or social indicators are independent of mass, i.e., depend on other factors, such as the number of units, this can lead to incorrect results of the top-down approach. Thus, in some cases, the bottom-up approach may offer advantages.

\section{Bottom-up approach}

For the bottom-up approach, the social data are recorded specifically for each process step of the component, i.e., indicator per functional unit. This allows a mass-independent calculation of 
the indicator. Since the calculation must be carried out specifically for each process step, no general formulas can be specified here. However, in Section 3.2.2, some examples are shown for component manufacturing and dismantling.

In order to be able to compare the result of an indicator of the bottom-up approach with the result of the same indicator of the top-down approach, an estimate for the administrative part can be added. The company is divided into three areas: production, development and administration. It is assumed that the hours worked in administration are equally divided between the hours worked in production and the hours worked in development.

The calculation of the working time required for a production hour in administration can be calculated using the following formula:

$$
T_{\mathrm{V}}=h_{\mathrm{V}} \times \frac{\frac{h_{\mathrm{P}}}{h_{\mathrm{P}}+h_{\mathrm{E}}}}{h_{\mathrm{P}}}=\frac{h_{\mathrm{V}}}{h_{\mathrm{P}}+h_{\mathrm{E}}}
$$

$T_{\mathrm{V}}$ : Administration working time in hours per production hour.

$h_{\mathrm{V}}$ : Working hours administration.

$h_{\mathrm{P}}$ : Working hours production.

$h_{\mathrm{E}}$ : Working hours development.

\section{Step 6b: Calculation of the PDCA indicators}

The PDCA indicators can be evaluated individually or collectively. These two options are discussed below. In addition, different reference values are addressed.

\section{Individual evaluation of the PDCA indicators}

The answers Yes, No and not relevant or no answer to the individual PDCA indicators from the primary data collection can be assigned to the working hours of the respective company and aggregated over the entire life cycle. This procedure was developed based on the LCAA $[23,24]$. The answers of the companies that do not provide any information in the primary data collection or that evaluate the social aspect as not relevant for them should be specifically examined. On the one hand, it is possible that this indicator is not communicated in public reports. On the other hand, the company can deliberately not respond. In the latter case, it can be assumed that the company does not address the indicator. If a company indicates that a social aspect is not relevant to it, it should be checked whether this answer is realistic. Social risk databases such as the SHDB can be used for this purpose. If the risk in the country in which the company operates is high for the social aspect, then the company should be analyzed in more detail during the evaluation. The evaluation and comparison with a social risk database can also be carried out for the other answers.

This approach offers the possibility of integrating social aspects that can only be measured to a limited extent by performance indicators, such as Forced Labor, into an SLCA. These social aspects would then only be included in the evaluation through PDCA indicators. In principle, a similar procedure would be suitable for qualitative performance indicators.

\section{Joint evaluation of the PDCA indicators}

In addition to the evaluation of individual indicators, all PDCA indicators can also be calculated together. For this purpose, the results of the percentage evaluation of the individual PDCA indicators can be averaged. With this procedure, however, the distribution between the individual indicators and the participating companies cannot be read off from the result (exception: 0 and $100 \%$ ). For example, it is not possible to distinguish whether a few companies in the product's life cycle have not implemented any PDCA indicators or whether many companies do not address individual indicators. To avoid this, the respective process steps and indicators would have to be specifically analyzed. Alternatively, individual PDCA indicators can also be defined as being mandatory. In order to give a Yes rating to working hours, a company would have to meet the defined indicators. 
For both the individual and the joint evaluation of the PDCA indicators, the calculations can be performed not only per company, but also per process step. The working hours calculated from Equation (3) can be used. In addition, as an alternative to working hours, the indicators can also be related to other parameters, such as turnover. This depends on the parameter with which the indicator is related. For the written principles of the social aspect Corruption, for example, it is possible to relate these to both working hours and turnover.

\section{Step 7: Using performance and PDCA indicators in an SLCA}

Below are several ways to apply the performance and PDCA indicators in an SLCA. They can be used in conjunction with each other or individually.

\section{Individual use of the indicator types}

If the indicator types are not to be offset against each other, they can be included directly and individually in the SLCA (results in step 6).

\section{Joint use of the indicator types}

The following two options for the joint use of performance and PDCA indicators are outlined below.

\section{Definition of scores for the indicators}

The performance indicators can be scored for the allocation of performance and PDCA indicators. For example, the desired value of a performance indicator is $100 \%$ and the undesired value is $0 \%$. A score of $50 \%$ could be defined by the industry average. For the PDCA indicators, either the percentage coverage of hours worked can be used directly as a score, or the same score as for the performance indicators can be used. For an overall result of the various indicators of a social aspect, the scores can be averaged. This is of course also possible for performance indicators among themselves. The result of the evaluation can be compared with alternative scenarios (e.g., other suppliers, other materials or the predecessor model of a car).

A disadvantage of this procedure is on the one hand that the evaluation can be specified again in each investigation. It must be ensured that comparability between companies is possible. On the other hand, a bad result of a performance indicator could be compensated for by a good result of the PDCA indicators.

\section{Determination of PDCA indicators as a condition for performance indicators}

PDCA indicators can be used as a condition for the evaluation of performance indicators. Only the systematic approach of the PDCA indicators can ensure that the performance indicators are measured correctly, and that the results can be interpreted. A possible realization would be the integration of the PDCA indicators into the actual functional unit, such as $160,000 \mathrm{~km}$ driven by a car. The integration of additional properties into the functional unit was proposed by Lehmann [47] as part of implementation criteria for technologies. If two cars are now compared, all flows and indicators evaluated for the two cars are related to this functional unit. However, this also means that the comparison can only be carried out if the participating companies comply with all (or previously selected) PDCA indicators of the respective social aspect. The implementation could be established through audits or questionnaires. A disadvantage of this method is that companies that have not implemented a PDCA approach for a social aspect cannot be included in the assessment. Companies could also use this approach to require a systematic procedure for certain social aspects as a condition from their suppliers. This would be independent of the performance indicators.

\subsection{Application of the SLCA Approach in Case Studies}

In the primary data collection described in Section 3.1.1, it was possible to collect social data for the two materials steel and aluminum along the entire life cycle from resource extraction to shredding (and exemplarily for one mineral oil producer and one electricity producer each, including the companies in 
the upstream chain). The developed SLCA approach described above is applied to the two materials in the following. For a better comparison, the component inner part of the rear door of a B-Class is considered for both materials (see Figure 6).

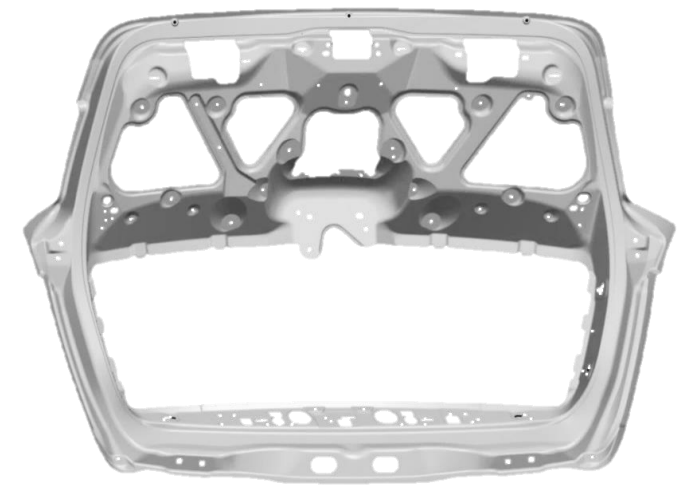

Figure 6. 2-D data model of the inner part of the rear door of a B-Class. The figure was taken from the Product Data Management Model of Daimler for the B-Class (W 246).

\subsubsection{Calculation of the Reference Values}

\section{Step 1: Determination of the material and energy flows of the component}

The steel component was assumed to weigh $5.90 \mathrm{~kg}$, the aluminum component $4.13 \mathrm{~kg}$ (internal concept comparison). The respective material and energy flows were mapped using life cycle assessment data records, which were taken from GaBi [102] (22nd Servicepack) and ecoinvent data sets [103] (Version 2.2). In the case of aluminum, an EAA study [104] was also used. Further data about recycling were taken from reference [105].

In the use phase, a fuel reduction factor of 0.31 per $100 \mathrm{~kg}$ and $100 \mathrm{~km}$ and a service life of $160,000 \mathrm{~km}$ was assumed. The functional unit was therefore the inner part of the rear door of a B-Class made of steel or aluminum, which is installed in a car with 160,000 $\mathrm{km}$ of mileage at the given fuel reduction factor.

From the information described, the relevant material composition and energy consumption were determined for each life cycle phase.

In the further course of the calculations, the process steps were assigned to the various companies, as the social data were recorded at company level. The following process steps resulted for the steel component: mineral oil production (extraction and production of diesel and process energy), electricity production, hard coal mining (for electricity), hard coal mining (for coke), manganese ore mining, iron ore mining, steel coil production (process from production of pig iron, via crude steel and slabs to steel coil, coke production process), component production, dismantling and shredding.

A company carries out several process steps for the aluminum component (bauxite mining to ingot production). These process steps were combined into one (ingot production). This resulted in the following process steps for this component: mineral oil production (extraction and production of diesel and process energy), electricity production, coal mining (for electricity), ingot production, aluminum sheet production, component production, dismantling and shredding.

No company-specific data were available for some individual processes, so only energy flow data were considered for them. The processes are: ferromanganese production (steel), anode production and floating and sinking plant (aluminum). This was also done in the same way for the recycling production waste process for both materials. In order to present the energy companies, one mineral oil producer and one electricity producer were interviewed as examples. Detailed information and assumptions regarding the case studies are given in Appendix B.1.

\section{Step 2: Collection of company data}

The following general data were collected from the companies participating in the life cycle: the mass of their products per year, the number of employees and the turnover. From the number 
of employees, the number of working hours per company and year could be calculated (based on reference [107]); 1450 working hours per year and employee were assumed for German companies and 1765 for the other companies.

\section{Step 3: Calculation of the mass reference of company data}

In order to be able to compare the data of all companies on the basis of the same unit, all energy data were also converted to kilograms. Each $\mathrm{kWh}$ of electricity was assigned the mass corresponding to the amount of hard coal needed to produce it. For the conversion of mineral oil, the lower calorific value $42.8 \mathrm{MJ} / \mathrm{kg}$ was used [110].

The factor $\frac{H_{\mathrm{x}}}{M_{\mathrm{x}}}(1)$ is shown for all companies of the steel component on the left and for all companies of the aluminum component on the right in Figure 7. For both the steel component and the aluminum component, the most hours worked per mass produced are allocated to the company producing the part.

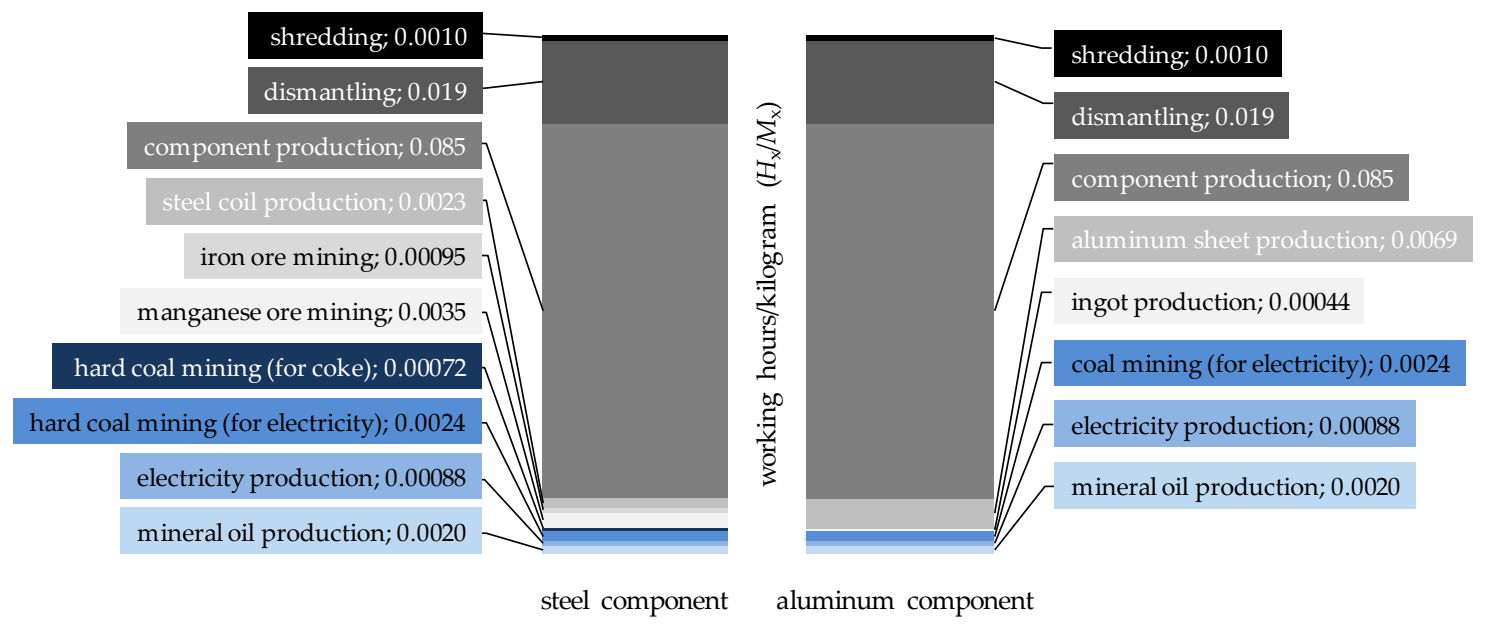

Figure 7. Working hours per kilogram of produced mass of the companies of the steel component (left) and the aluminum component (right).

\section{Step 4a: Calculation of the companies' contribution to the component}

Using the factor $\frac{H_{\mathrm{x}}}{M_{\mathrm{x}}}$ and the material and energy flows, it was possible to calculate the working hours $h_{\mathrm{x}}$ per company for the two components (see Figure 8 ). The total number of hours worked for the steel component was 0.64 and for the aluminum component 0.61 . For both components the most working hours were incurred during component production (steel: $0.50 \mathrm{~h}$, aluminum: $0.35 \mathrm{~h}$ ). An important factor here is the proportion of manual work compared with automated processes. The difference between aluminum and steel results from the different weight of the two components and is discussed again in Section 3.2.2. For aluminum, more working time was required for dismantling, as the proportion of dismantled components is higher than for steel due to the material value. The working hours required for power generation and supply were less important for the steel component than for the aluminum component, but the mineral oil consumption was higher. The reasons for these differences can be clearly seen in a breakdown by process steps (see step $4 b$ ).

\section{Step 4b: Calculation of the companies' contributions to individual process steps}

The working hours of the respective companies per process step are shown in Figure 9 for steel and aluminum as Sankey diagrams (for detailed values, see Appendix B.2). The working hours of the energy flows are shown separately from the working hours generated during material processing. 

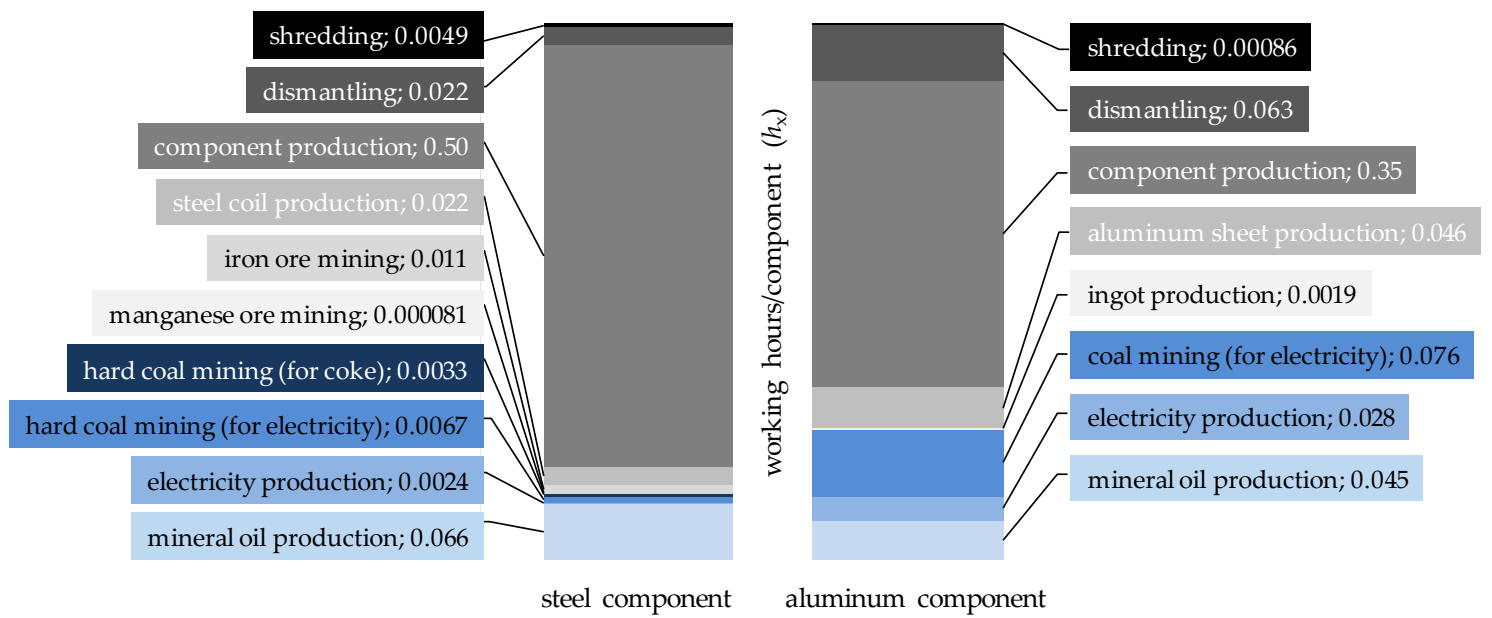

Figure 8. Working hours per company for the steel component (left) and for the aluminum component (right).

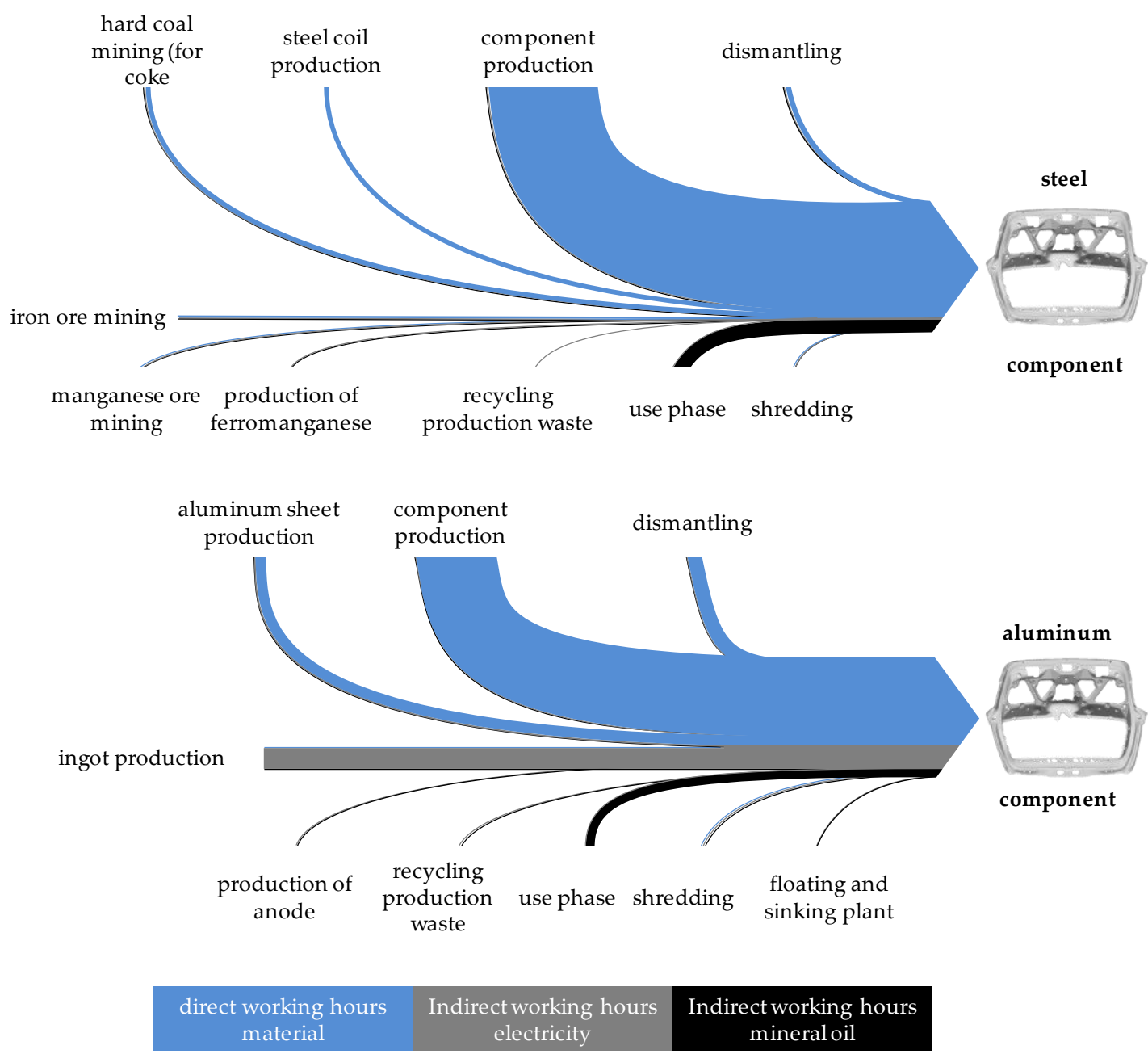

Figure 9. Sankey diagram of working hours for each process step of the steel component (top) and the aluminum component (bottom). Direct working hours are incurred directly by the company where the process is carried out. Indirect working hours are incurred during energy generation and are assigned to the respective process step. The line thicknesses are proportional to the number of working hours per process step. The working hours of the electricity flow for the steel component are not visible in the figure due to their small quantity. 
Figure 8 shows that the working hours caused by electricity consumption are significantly higher for aluminum than for steel. The Sankey diagrams indicate that the reason for this was the large amount of electricity required to producing ingots. The mineral oil consumption for both components was mainly caused during the use phase. The reduced consumption was noticeable here due to the lower weight of the aluminum part.

\subsubsection{Calculations with the Social Data}

\section{Step 5: Selection of the social aspects}

The results of the importance ranking of the social aspects (see reference [82]) and the availability of data (see Section 3.1.1) can be seen in Figure 10. Good data availability was found in the primary data collection for the social aspects within the square marked in red. The very important social aspects were drawn in dark blue. The following social aspects were therefore the most important in this work, both in terms of importance and data availability:

- Health and Safety (16),

- $\quad$ Forced Labor (14) and

- $\quad$ Freedom of Association and the Right to Collective Bargaining (10).

Since the social aspect Corruption (3) was on the red mark, it was also included in this list.

In addition, the companies' assessment of the comparability of different companies was analyzed regarding the PDCA and the performance indicators and their meaningfulness in general (see Section 3.1.1). The PDCA indicators for the social aspects of Forced Labor, Health and Safety and Corruption were rated as positive by the companies surveyed in terms of their meaningfulness and comparability. However, this was only the case for some of the performance indicators for the social aspects of Health and Safety and Freedom of Association and the Right to Collective Bargaining.

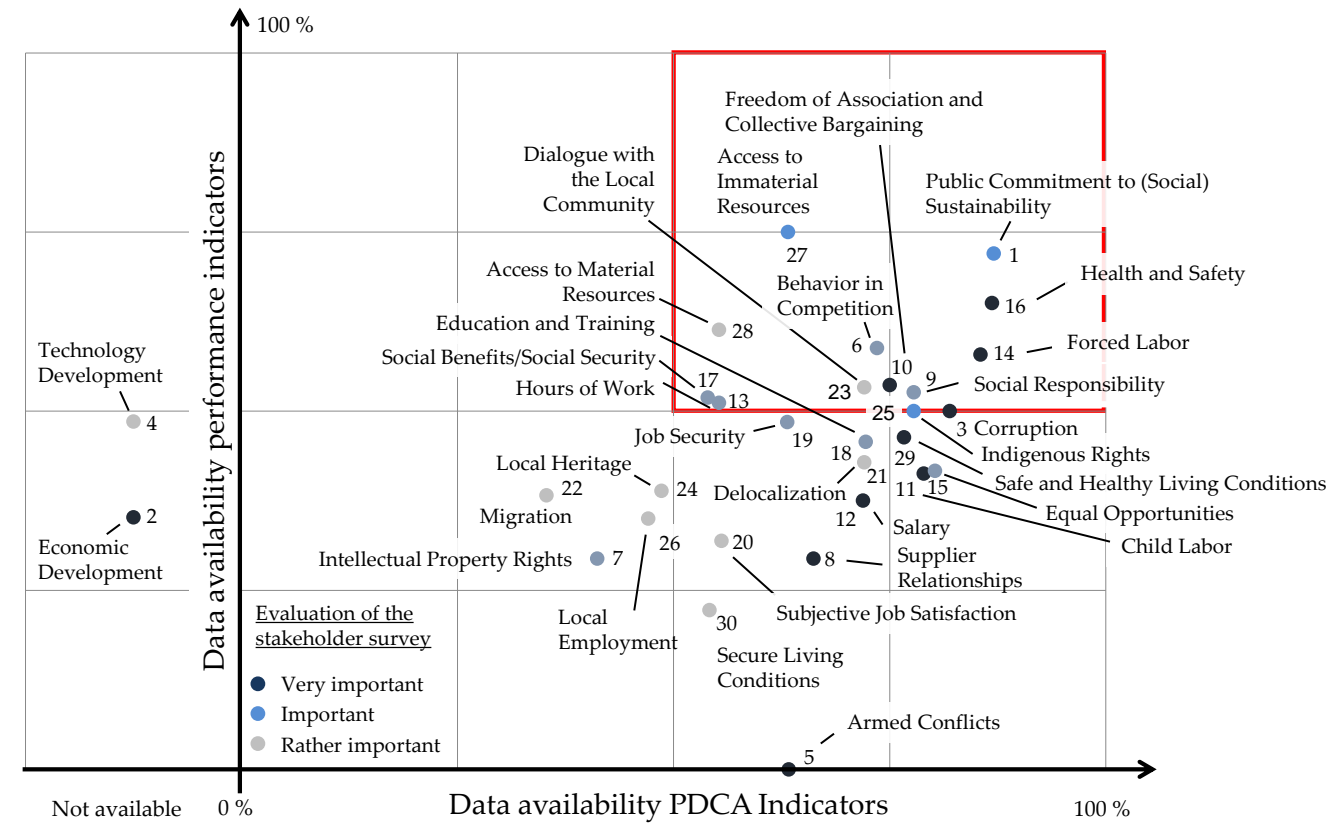

Figure 10. Linking the results of prioritizing the social aspects with the mean values from the survey and the data availability of the PDCA and performance indicators. The answers to the social PDCA and performance indicators were set in relation to the maximum possible answers. The values in this figure are given as percentages. The social aspects within the square marked in red had good data availability in the primary data collection (response rate over 50\%). The social aspects prioritized in Section 4 in reference [82] are shown in this figure in dark blue for very important, in light blue for important and in grey for rather important. No PDCA indicators were asked for the social aspects 2 and 4 . 
A fundamentally good data availability of the performance and PDCA indicators increases the probability that data can also be collected during primary data collection. However, it does not initially say anything about whether this data is also available for all life cycle phases of a product along its entire life cycle or whether it is reported back by the companies when data is collected.

Five performance indicators were continuously reported back by all companies involved in the life cycle of the component:

- $\quad$ Are you training your employees on your code of conduct or your attitude to social sustainability? (social aspect 1, Public Commitment to Social Sustainability),

- What is the proportion of employees covered by collective agreements? (social aspect 10, Freedom of Association and Collective Bargaining),

- How many injuries and non-fatal accidents at work were there in the last year in the company? How many fatal accidents at work were there in the last year in the company? (social aspect 16, Health and Safety) and

- What is the average number of training days per employee per year (social aspect 18, Education and Training)?

Hereinafter, the indicator Are you training your employees on your code of conduct or your attitude to social sustainability? was not considered because the answers were too diverse.

The answers to the PDCA indicators and the qualitative performance indicators were also not consistently available everywhere. In these cases, however, the calculations could still be carried out.

In the context of this work, some examples were selected based on data availability and importance to demonstrate the different possibilities for the calculations in an SLCA. These are

- Number of (workplace) accidents (social aspect 16, Health and Safety) for the calculation of the performance indicators,

- $\quad$ PLAN indicator of the social aspect Corruption (3) and CHECK indicator of the social aspect Child Labor (11) for the individual calculation of the PDCA indicators,

- Are you a member of an initiative for promoting social responsibility along the value chain? (social aspect 9, Social Responsibility) for the integration of qualitative performance indicators,

- PDCA indicators of the social aspect Health and Safety (16) for the joint calculation of PDCA indicators, and

- $\quad$ PDCA indicators and one quantitative performance indicator (number of accidents) of the social aspect Health and Safety (16) for the use of these indicator types in an SLCA.

\section{Step 6a: Calculation of the performance indicators}

\section{Top-down approach}

The result of the top-down approach from Equation (4) is shown in Figures 11 and 12 as examples of the social indicator number of (workplace) accidents, which was defined here as the number of accidents with at least one day lost. The number of accidents reported by companies was converted into this indicator as far as possible. Most accidents occurred both in aluminum and in steel during component production (steel: $3.75 \times 10^{-9}$, aluminum: $2.66 \times 10^{-6}$ ), followed by dismantling (steel: $1.19 \times 10^{-6}$, aluminum: $3.33 \times 10^{-6}$ ). This was due to the high number of working hours during component production and the relatively high accident rate during dismantling. There was a total of $5.6 \times 10^{-6}$ accidents per steel component and $6.5 \times 10^{-6}$ accidents per aluminum component. Further values for the number of accidents and the results of the other available social performance indicators fatal accidents, number of training hours and working hours with collective agreements are presented in Appendix B.2.

When comparing the two results in Figures 11 and 12, it can also be seen that more working hours or accidents were attributed to the steel component during component production and dismantling due to the higher mass, although this does not correspond to reality. These two processes are more likely to be assumed to be independent of mass, since the number of accidents depends less on the 
weight than on the number of units of the component (and possibly other factors). However, the processes available in LCA databases are mostly mass-based, which is why they could not be calculated independently of the mass using the top-down approach. For this reason, the social data used here were analyzed again using a bottom-up approach. The shredding process was also discussed regarding mass (in)dependence. No significant relationship to mass, volume or number of units could be established. Due to the clearer relationship in the processes of component production and dismantling, only these were considered in the bottom-up approach.

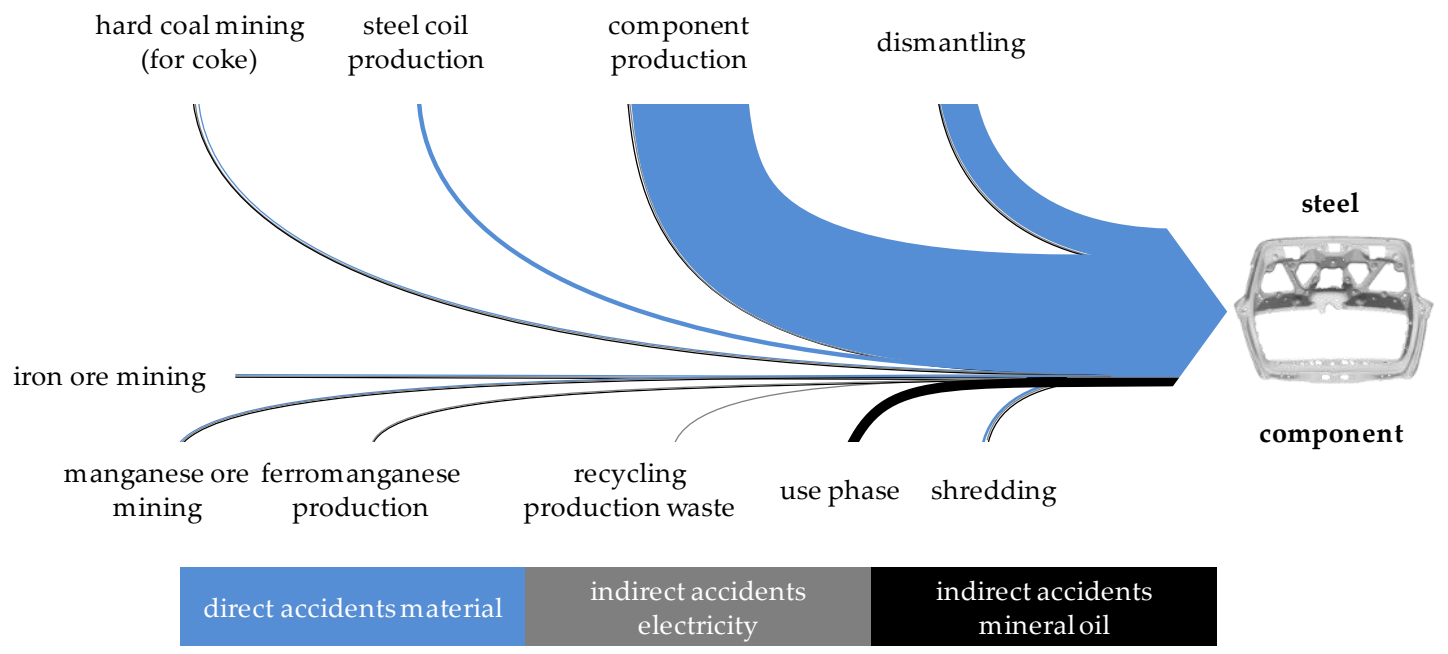

Figure 11. Sankey diagram of accidents for each process step of the steel component. Direct accidents occurred directly at the companies where the process was carried out. Indirect accidents occurred in power generation and were assigned to the respective process step. The line thicknesses are proportional to the number of accidents per process step.

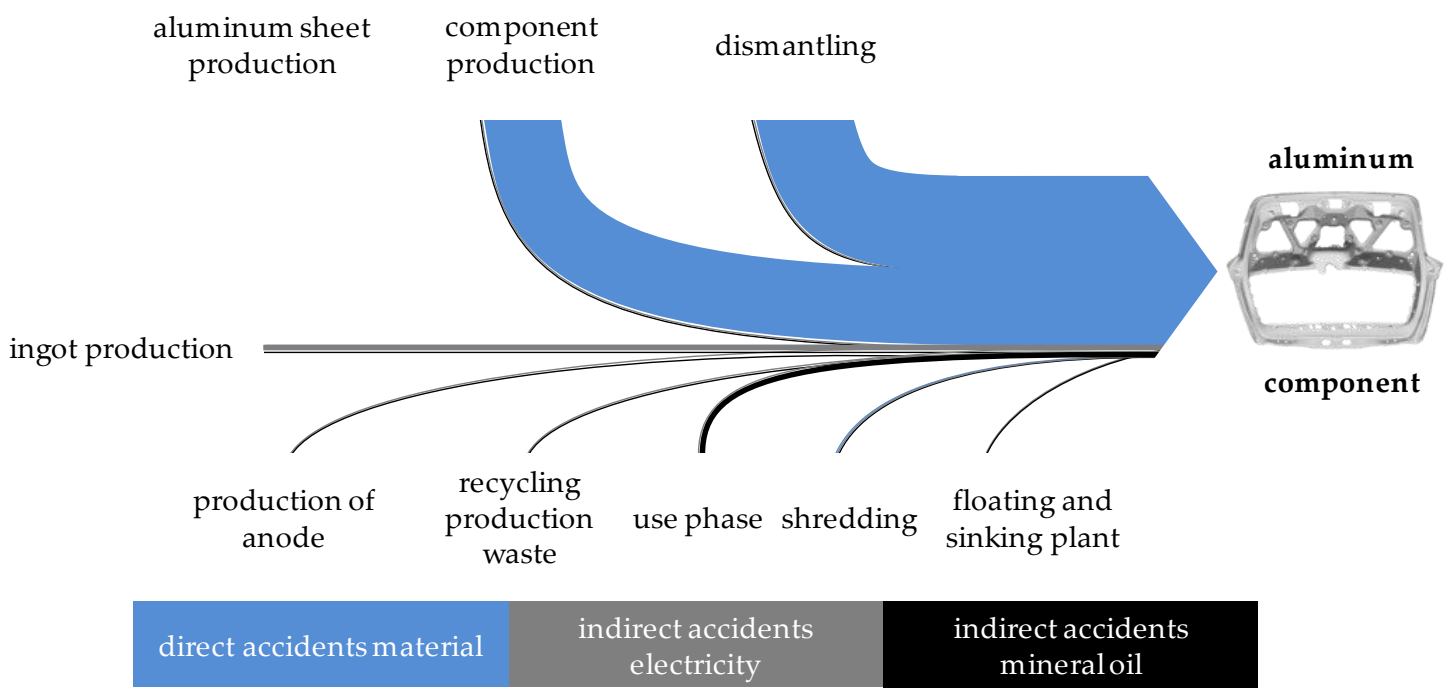

Figure 12. Sankey diagram of accidents for each process step of the aluminum component. Direct accidents occurred directly at the companies where the process was carried out. Indirect accidents occurred in power generation and were assigned to the respective process step. The line thicknesses are proportional to the number of accidents per process step.

It was also analyzed whether the choice of the reference value for the social data, such as turnover or mass instead of working hours, caused a difference in the results. Since the processes in the top-down approach could only be represented using mass and energy flows, it was mandatory to convert using these variables. However, the relationship between working hours, mass and turnover of a company 
always remained constant in the calculations, so that no differences in the absolute number of indicators per component resulted from the different reference values. The differences could only be calculated relatively (see Figure 13 for the steel component).

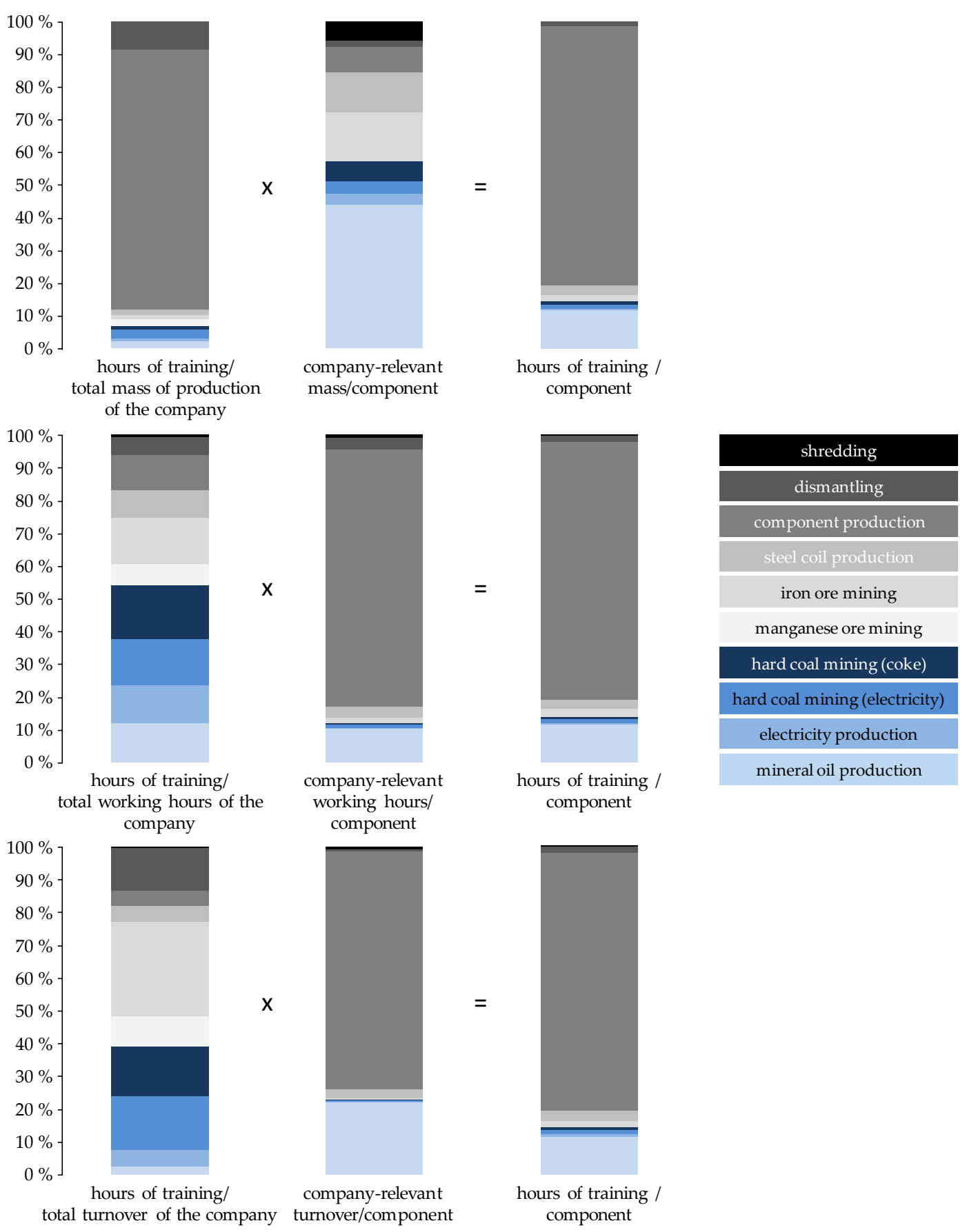

Figure 13. Relative differences in the derivation of the number of training hours in relation to the mass (top), working hours (middle) and turnover (bottom) of a company. The differences are shown exemplarily on the component made of steel.

\section{Bottom-up approach}

The bottom-up approach was analyzed exemplarily with the indicator number of accidents for the two processes component production and dismantling. At each stage of component production (development, press shop, body shop, painting and assembly) and dismantling, the aim was to obtain 
the indicator number of accidents per component. This was achieved by a specific consideration of different parameters (see Table 3). For example, the accidents in the paintwork were derived from the painted total area on a painted rear wall door. During dismantling, the company's accident data were related to the component with the dismantling time of the component. This made it possible to calculate the number of accidents during component production and dismantling independently of the mass.

Table 3. Bottom-up approach of the indicator number of accidents in component production and dismantling. RW means rear wall.

\begin{tabular}{|c|c|c|c|c|c|c|}
\hline & \multicolumn{5}{|c|}{ Component Production } & \multirow{2}{*}{ Dismantling } \\
\hline & Development & Press Shop & Body Shop & Painting & Assembly & \\
\hline $\begin{array}{c}\text { Considered } \\
\text { parameter }\end{array}$ & $\begin{array}{c}\text { Development } \\
\text { time/produced } \\
\text { RW door }\end{array}$ & RW door & $\begin{array}{l}\text { Number of } \\
\text { welding } \\
\text { spots of the } \\
\text { RW door }\end{array}$ & $\begin{array}{l}\text { Area of the } \\
\text { RW door }\end{array}$ & $\begin{array}{l}\text { Assembly } \\
\text { time/RW } \\
\text { door }\end{array}$ & $\begin{array}{l}\text { Dismantling } \\
\text { time/RW } \\
\text { door }\end{array}$ \\
\hline $\begin{array}{l}\text { Reference } \\
\text { value }\end{array}$ & $\begin{array}{c}\text { Total } \\
\text { working } \\
\text { hours of the } \\
\text { development } \\
\text { department }\end{array}$ & $\begin{array}{c}\text { Number of } \\
\text { pressed RW } \\
\text { doors }\end{array}$ & $\begin{array}{l}\text { Number of } \\
\text { welding } \\
\text { spots in the } \\
\text { body shop }\end{array}$ & $\begin{array}{c}\text { Painted total } \\
\text { area }\end{array}$ & $\begin{array}{c}\text { Total } \\
\text { working } \\
\text { hours of } \\
\text { assembly }\end{array}$ & $\begin{array}{c}\text { Total } \\
\text { working } \\
\text { hours of } \\
\text { dismantling }\end{array}$ \\
\hline Aim & \multicolumn{6}{|c|}{ Accidents/RW door } \\
\hline Results & $7.67 \times 10^{-8}$ & $9.76 \times 10^{-7}$ & $8.88 \times 10^{-7}$ & $1.35 \times 10^{-7}$ & $8.03 \times 10^{-7}$ & $7.07 \times 10^{-6}$ \\
\hline
\end{tabular}

To be able to compare the accident figures of the bottom-up approach with the accident figures of the top-down approach, an estimate for the accident figures of the administration was added. For this work, Equation (5) $\mathrm{T}_{\mathrm{V}}=0.542$ was used. This means that about half an hour of administration was required for one production hour of the component. For the social indicator number of accidents, this resulted in $4.20 \times 10^{-6}$ (without administration it would be $4.09 \times 10^{-6}$ ) accidents per component, regardless of the material used for production.

Figures 14 and 15 compare the results for the number of accidents using the top-down and bottom-up approaches. In total, there were $5.6 \times 0^{-6}$ accidents per component for steel in the top-down approach and $6.2 \times 10^{-6}$ accidents per component in the bottom-up approach. For aluminum, it resulted in $6.5 \times 10^{-6}$ (top-down approach) and $10.4 \times 10^{-6}$ (bottom-up approach) accidents per component. A comparison of the top-down and bottom-up approaches shows that the top-down approach assigned more accidents to the steel component than to the aluminum component due to the higher mass involved in component production. In the bottom-up approach, the same number of accidents were assigned to the components for this process step, since no difference between the two materials was assumed in the internal concept comparison. The higher proportion of aluminum components dismantled was even more noticeable in the bottom-up approach than in the top-down approach, where fewer accidents were attributed due to the lower weight of the aluminum component.

Although the number of accidents in component production was higher for both components in the bottom-up approach than in the top-down approach, it was of the same order of magnitude. One possible explanation for this is that the component under consideration in this work went through a relatively large number of process steps in the automotive company. As a result, the indicator number of accidents was averaged over the various process steps in a manner that was similar to the top-down approach. The reduction in the number of accidents in the top-down approach due to the lower weight of the aluminum component was eliminated in the bottom-up approach. Thus, significantly more accidents were assigned to the component. 


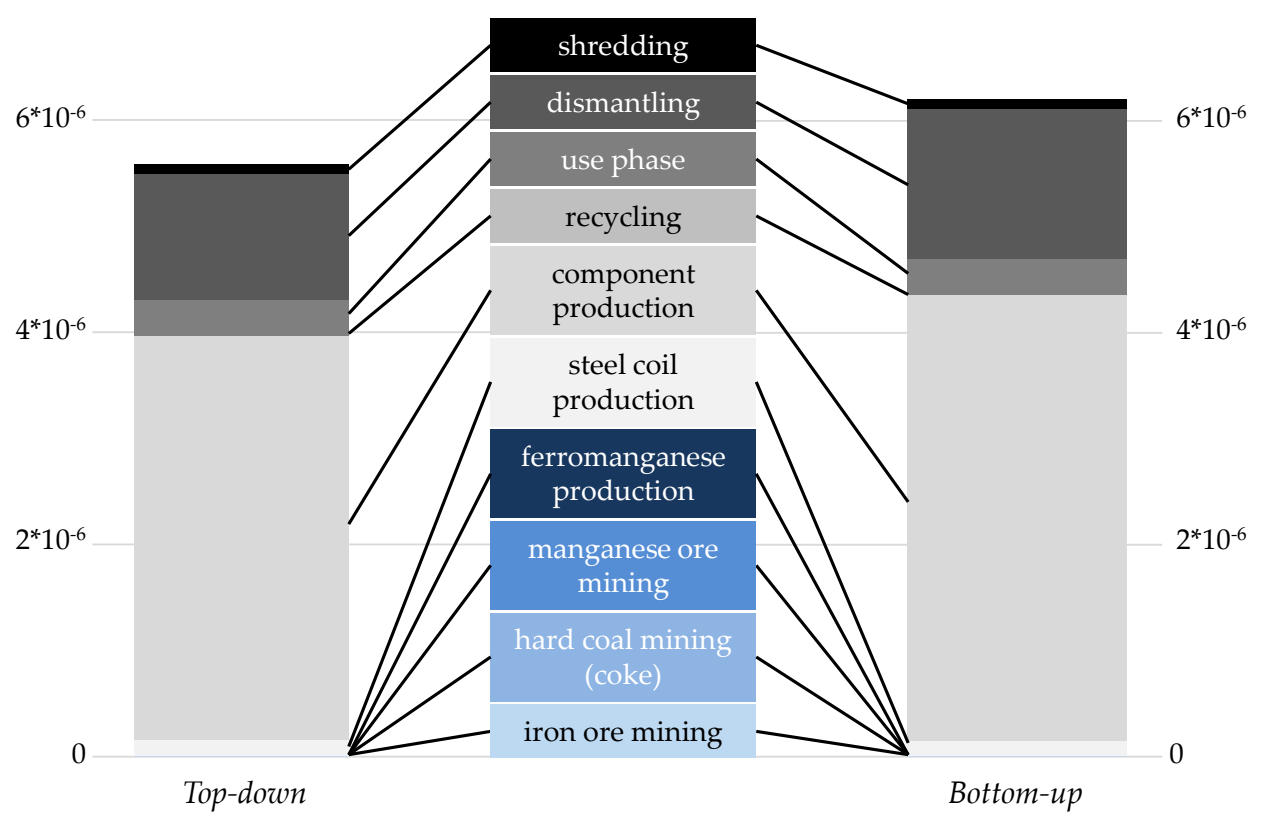

Figure 14. The social indicator number of accidents along the life cycle of the steel component in the top-down (left) and bottom-up approach (right).

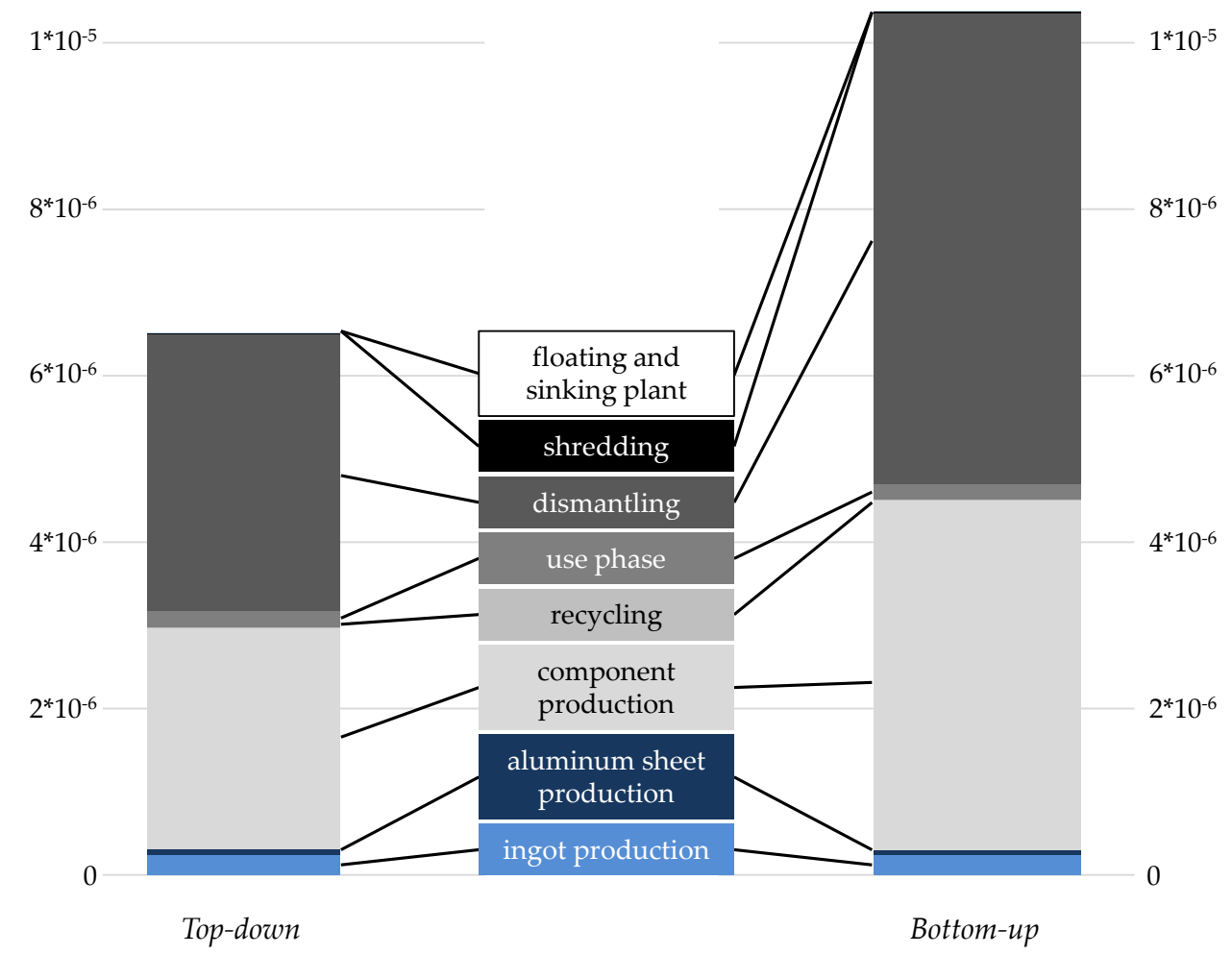

Figure 15. The social indicator number of accidents along the life cycle of the aluminum component in the top-down (left) and bottom-up approach (right).

\section{Step 6b: Calculation of the PDCA indicators}

\section{Individual evaluation of the PDCA indicators}

The answers to the PDCA indicators from the primary data collection were assigned to the working hours of the respective company and then aggregated over the entire life cycle. 
For the indicator written principles (PLAN) of the social aspect Corruption (see Figure 16), for example, it was found that $96.26 \%$ of the working hours for the steel component were covered by written principles, $0.49 \%$ were not covered and $3.25 \%$ of the working hours were not specified. For the aluminum component, $99.93 \%$ and $0.07 \%$ of the working hours were covered or not covered, respectively. The companies that had not provided any information for the steel component were those with which a set of indicators other than PDCA indicators (iron ore, manganese ore mining and steel coil manufacturing; see reference [82]) was determined in the primary data collection.

There were also some companies that did not report on the indicator control mechanisms (CHECK) of the social aspect Child Labor (see Figure 17). In addition to the companies with which a set without PDCA indicators was determined from the beginning, another company was added to this example (see Appendix B.2). As this company operates globally, it should be re-examined for a final evaluation, which was not possible within the scope of this work. Overall, $3.34 \%$ of the working hours for the steel component and 3.92\% of the working hours for the aluminum component were not reported. In addition to the Yes (steel: $95.91 \%$, aluminum: $80.79 \%$ ) and $N o$ answers (steel: $0.50 \%$, aluminum: $0.07 \%$ ), two companies also stated that this social aspect was not relevant to them. For one of the companies, this was considered to be realistic. The company operates in a country in Europe for which the risk of child labor in the SHDB is rated as being very low. However, the other company operates globally. Here it cannot be assumed that the risk of child labor is low in all countries this company operates in. Therefore, this would have to be analyzed in more detail in a final evaluation.

Qualitative performance indicators, such as Are you a member of an initiative for promoting social responsibility along the value chain? of the social aspect Social Responsibility (9), can also be evaluated in this way. For the steel component, no information was given for $5.10 \%$ of the working hours and for $4.27 \%$ the answer was No (90.63\% Yes). For the aluminum component, the answer was Yes for $89.57 \%$ and No for $10.43 \%$ of the working hours. In this case, too, it would be important to repeat the review of the companies that did not provide any information in order to make a final assessment.

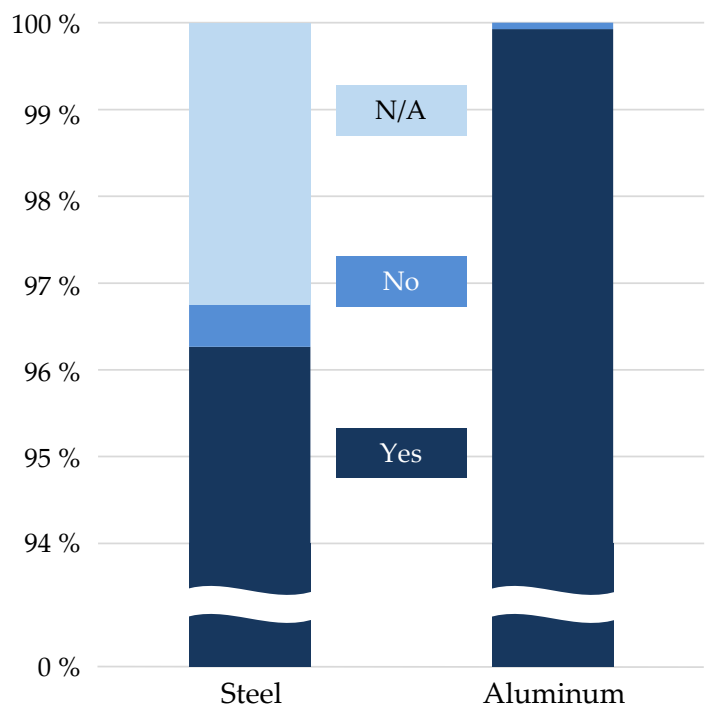

Figure 16. Comparison of responses to the PLAN indicator of the social aspect Corruption between the steel component (left) and the aluminum component (right). The various responses are divided into Yes, No and N/A (no answer) and are expressed as a percentage of working hours. 


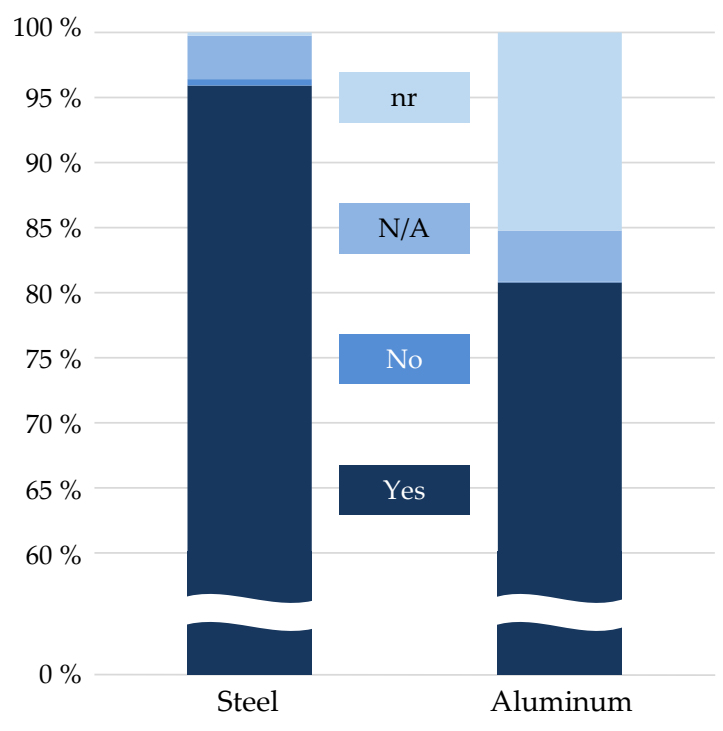

Figure 17. Comparison of responses to the CHECK indicator of the social aspect Child Labor between the steel component (left) and the aluminum component (right). The various responses are divided into Yes, No, N/A (no answer) and $n r$ (not relevant) and are expressed as a percentage of working hours.

\section{Joint evaluation of the PDCA indicators}

In addition to individual indicators, all PDCA indicators can also be evaluated together. This was done as an example for the PDCA indicators of the social aspect Health and Safety and can be seen in Figure 18 . For the steel component, $96.51 \%$ of the working hours were covered by the PDCA approach, for the aluminum component $99.96 \%$. Not covered made up $0.24 \%$ for the steel component and $0.04 \%$ for the aluminum component. There were no answers for $3.25 \%$ of the working hours of the steel component. However, no answers and the response No do not make it clear whether, for example, a company did not provide information on all PDCA indicators or only on one indicator. Here the respective process steps and indicators would have to be specifically analyzed.

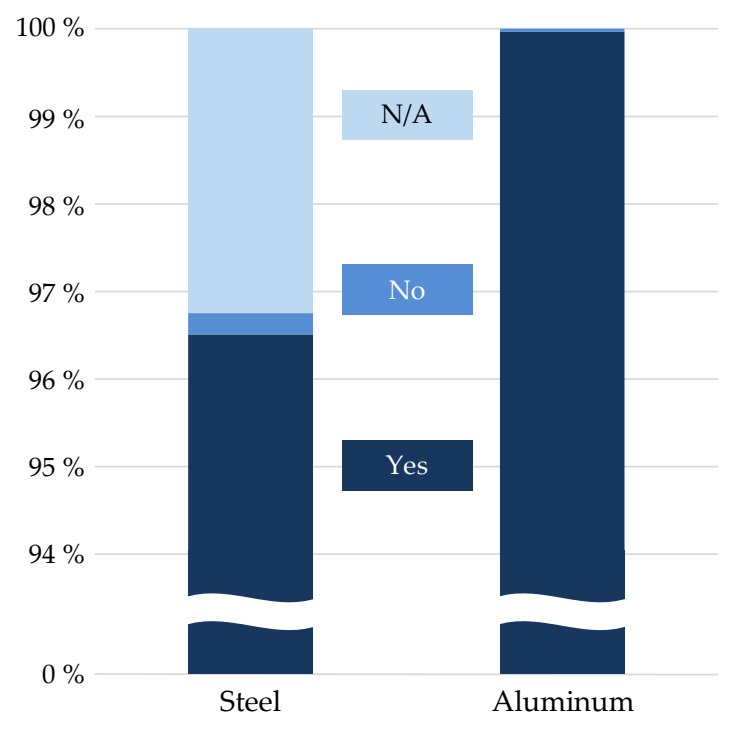

Figure 18. Comparison of responses to the PDCA indicators of the social aspect Health and Safety between the steel component (left) and the aluminum component (right). The different responses are divided into Yes, No and N/A (no answer) and are expressed as a percentage of working hours. 
As an alternative to working hours, the indicators can also be related to other variables such as turnover (for detailed values see Appendix B.2). This depends on which variable the indicator is related to. For example, the written principles of the social aspect Corruption can be expressed both in working hours and in turnover (see Figure 19). For the steel component, 97.54\% of turnover were covered by written principles on Corruption, for the aluminum component $99.93 \%$. The equivalent not covered percentages were $0.44 \%$ for steel and $0.07 \%$ for aluminum. For the steel component, $2.03 \%$ of turnover was not reported. The indicator related to working hours per process step is shown again on the left in Figure 19 for comparison (see also Figure 16). The differences are because the companies that did not provide any data had proportionately less turnover than working hours per process step (see Figure 20).

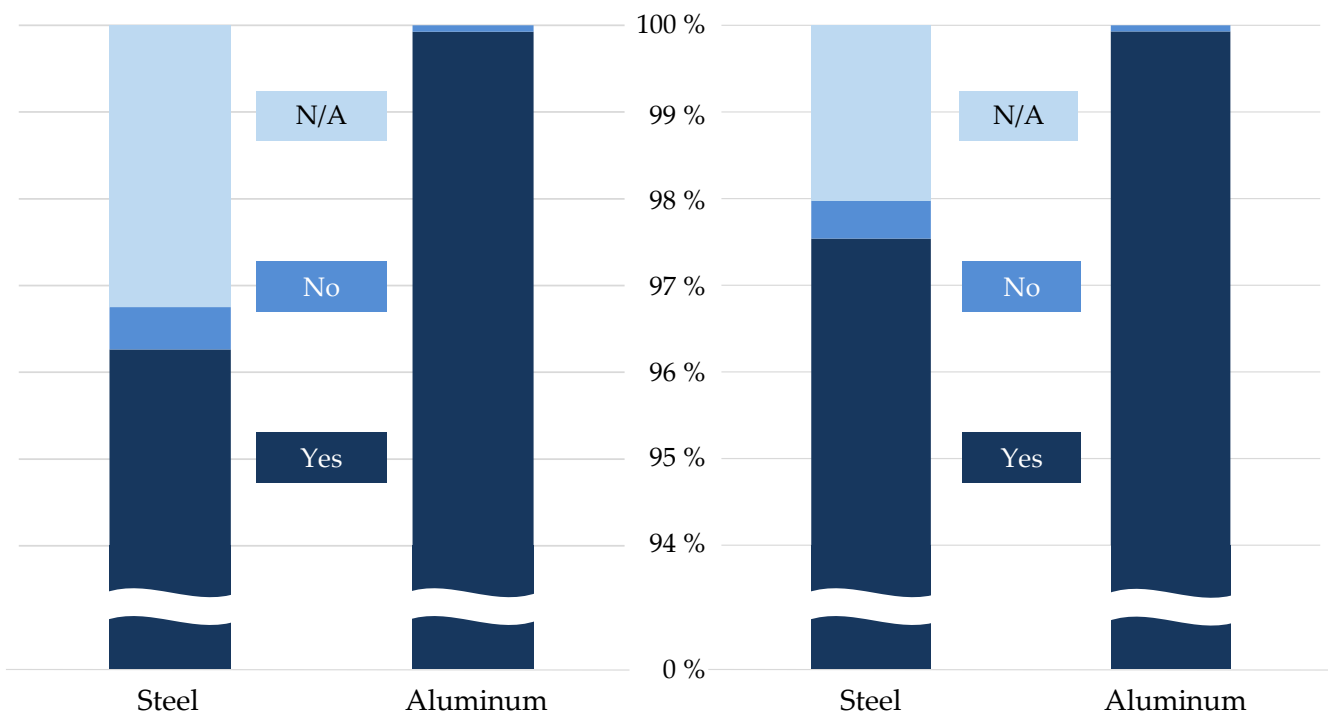

Figure 19. Comparison of responses to the PLAN indicator of the social aspect Corruption between the steel component and the aluminum component. The various responses are divided into Yes, No and N/A (no answer) and are expressed as a percentage of working hours (left) and percentage of turnover (right).

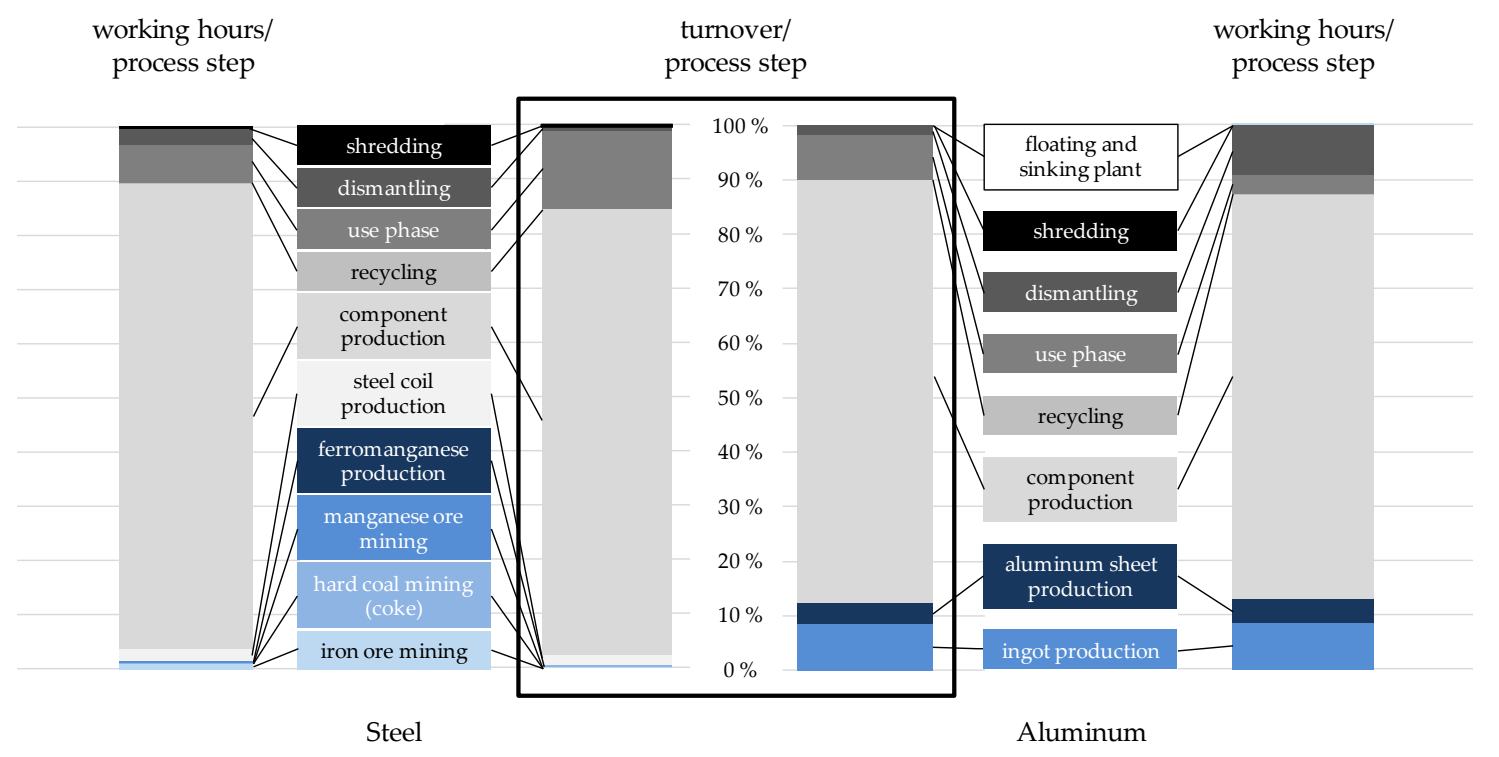

Figure 20. Comparison of turnover and working hours per process step for the steel component (left) and the aluminum component (right). In the diagrams, the values are given in percent. The value turnover per process step is bordered in black. 


\section{Step 7: Using performance and PDCA indicators in an SLCA}

Below are several ways to apply the performance and PDCA indicators in an SLCA. The individual use is no longer dealt with explicitly, as it has already been described in steps $6 \mathrm{a}$ and $6 \mathrm{~b}$ with application examples.

\section{Joint use of the indicator types}

\section{Definition of scores for the indicators}

The procedure is illustrated by the performance indicator number of accidents and the PDCA indicators Health and Safety. The following rating was set for the performance indicator: 0 accidents per working hour means a rating of $100 \%, 0.0001$ accidents per working hour means a rating of $0 \%$ (based on the highest accident rate in primary data collection). For the aluminum component, the rating was therefore $89.32 \%$ for accidents throughout the life cycle. In the case of the PDCA indicators, the percentage coverage of working hours was $99.96 \%$, which was used here as a rating. This allowed an average value of $94.64 \%$ to be calculated. This can now be compared with alternative scenarios (such as other suppliers, other materials). For example, for the steel component the rating for accidents was $95.01 \%$, and the coverage of PDCA indicators was $96.51 \%$. Thus, the mean value was $95.76 \%$. This means that the steel component would be preferable to the aluminum component.

Determination of PDCA indicators as a condition for performance indicators

Individual or all PDCA indicators can be considered as a condition for the evaluation of performance indicators. A possible realization would be the integration of these indicators into the actual functional unit, such as 160,000 km driven by a car.

In the case of the PDCA indicators for the social aspect Health and Safety, for example, one company in the aluminum component stated in the primary data collection that it had not implemented CHECK and ACT indicators. In the case of the steel component, three additional companies did not provide any information. Thus, the PDCA indicators Health and Safety could not be integrated into the functional unit if all companies were to be considered. Alternatively, the companies that did not provide any information would have to be specifically addressed again. The company that had not implemented CHECK and ACT indicators could be supported in the corresponding development or a replacement supplier would have to be sought. In addition, it would also be possible to define only one indicator of the PDCA indicators as a condition for the suppliers. If, for example, the PLAN indicator (written principles) were selected here, it could be integrated into the functional unit for the aluminum component. For the steel component, the companies that did not provide any information would still have to be contacted.

\subsection{Discussion of the Presented SLCA Approach}

For the first time in an industry with complex, international production and supplier structures, the practical suitability of life cycle-oriented social aspects and indicators, mostly developed theoretically in the SLCA research community, was comprehensively analyzed.

In the case of the steel and aluminum components, life cycle-oriented company-specific social data from resource extraction to end-of-life vehicle disposal could be collected throughout, which were used for further investigations regarding an approach for a practical SLCA of a car.

In addition, all challenges that arose during the company-specific data collection process were described and analyzed in detail in this work. These are taken up again further on in this section.

In developing the approach and subsequently applying it in case studies, an SLCA study was conducted for the first time with company-specific social data in an industry with complex, international manufacturing and supplier structures at Life Cycle Inventory level. Both mass and energy flows were mapped. Therefore, this work fills the research gaps (Section 1.3) regarding the application of SLCA in industries with complex, international manufacturing and supplier structures like the 
automotive industry with the priority use of company-specific data. For all energy processes in this work, a mineral oil producer and an electricity producer (including - if available- the companies in the upstream chain) were analyzed as examples.

Two different approaches have been developed for the performance indicators of life cycle-oriented social aspects. In the top-down approach, the social indicators were collected at company level and averaged across all processes of a company. In contrast, in the bottom-up approach the indicators were considered specifically for each process step. In the latter case, unlike the LCA, the administrative and developmental components must be considered accordingly. In both cases, the indicators can then be aggregated along the life cycle. Of the two methods the top-down approach requires less effort, while the bottom-up approach has a higher precision. For the PDCA indicators and the qualitative performance indicators, the LCAA method was integrated into the approach. In addition, this work has shown how these can be used together with the quantitative performance indicators at the Life Cycle Inventory level. On the one hand, this was achieved through scoring, and on the other hand, the PDCA indicators were defined as a condition for the performance indicators.

As a practical application of the approach for an SLCA method in the automotive industry, the first case studies were carried out on the inner part of the rear door, made of steel in the case of one component and aluminum in the other. The case studies showed for individual performance indicators that social data collected from companies can be related to the various processes in the life cycle in a top-down approach. However, the comparison of the top-down approach with the bottom-up approach carried out within this framework revealed that the bottom-up approach for mass-independent life cycle phases (here: component production and dismantling) was more precise than the top-down approach. The feasibility of the LCAA method was demonstrated for a selected set of PDCA indicators. Even if the results of the application of the proposed SLCA approach are not meaningful for the real components due to the assumptions during data collection (see Appendix B.1), the principle of feasibility was nevertheless demonstrated.

The approach would also be practicable for further indicators, but data availability and meaningfulness would have to be considered. Ideally, in an SLCA, at least those social aspects should be considered in a company that are rated as very important by the company's stakeholders.

In summary, the previous chapters showed that an SLCA with company-specific data can basically be carried out in an industry with complex, international manufacturing and supplier structures. However, there are several challenges, and the most important ones are presented below (Sections 3.3.1-3.3.4). Furthermore, in Section 3.3.5, the transfer of the results of individual components to the car level is addressed.

\subsubsection{Availability and Quality of Social Data}

The data with which the calculations are performed are fundamental to the accuracy and significance of the SLCA. If some of these data are missing or are influenced by other factors, this has a negative effect on the results of an SLCA.

\section{Standardization of indicators}

During the development and data collection of social performance indicators, it became apparent in this work that clear interpretability is only possible in a few cases. The indicators are often not standardized and therefore cannot be compared between different companies (see also reference [91]). This is also the case for indicators in sustainability reporting guidelines, such as the GRI guidelines. The indicator number of accidents used in many case studies is a good example. Some companies only relate this number to their own employees, others also do so to external workers. In some cases, the absolute number of accidents is given, but often only after a certain number of days of absence due to the accident. Some companies also include commuting accidents. The companies have therefore frequently already developed data collection systems that are often different from each other. In addition, many indicators fluctuate from year to year, also depending on the production volume, so averages should 
be made over several years. In the case of the indicator complaints, several companies noted that only justified complaints were meaningful across several social aspects. The interpretation in this respect, however, is specific to each company. The same applies to the indicator lawsuits. There were a wide variety of proposals from the companies, such as justified lawsuits, legal disputes or lawsuits that were successful in court, in order to make the aspect objective. At least the last two proposals would be conceivable in constitutional states, provided that the persons or companies concerned have the (financial) opportunity to bring their case before the courts.

For the PDCA indicators, it is equally important to set standards that companies must at least implement in order to obtain a positive assessment.

2. Dealing with the lack of company-specific social data in the life cycle

If, for example, social data collection is not possible for resource extraction because some companies only have an overview of their direct suppliers or buy raw materials on stock exchanges, generic data such as industry data or data from social risk databases could be used. However, it must be considered that different ways of collecting and evaluating data can prevent the comparability of results. A similar situation also exists for the use or the end-of-life phase of a car, since it is beyond the control of the car manufacturer where the end consumer refuels or disposes of his car.

Furthermore, many companies are very cautious about publishing social data. The OEM's influence on the companies of the entire life cycle is not sufficient to oblige everyone to publish. It is also questionable whether the results would be reliable in the event of such an obligation. Within the framework of corporate relations, it is only possible to collect social data through direct contact or the use of published documents. However, many companies do not consider data from the media or from investigations by NGOs to be independent.

\section{Positive self-presentation of the companies}

It is questionable whether companies will provide answers that would make them appear in a negative light or reveal social grievances. When a company is asked about the minimum wage or the maximum weekly working time, it will only indicate something other than the legally required regulations if it can provide more positive values. Data collection via sustainability reports does not solve the problem either. The reports often have a different depth of information, as the companies themselves determine how extensively they communicate externally [111]. It is usually not clear whether the absence of an indicator or a social aspect means that the company is doing poorly in this respect or whether the issue has not been addressed.

\subsubsection{Establishing a Process Reference for the Life Cycle-Oriented Social Aspects}

In order to carry out an SLCA analogously to the LCA or to integrate it into a LCSA together with the LCA and LCC, a process reference for the life cycle-oriented social aspects is indispensable. This is often difficult to establish for social data, since many of the social aspects and indicators refer to the behavior and not to the processes of the company. In practice, social data that theoretically relate to processes are usually communicated by companies at the corporate level anyway. For these reasons, a practical SLCA method must offer the possibility of integrating such social data through suitable calculations (such as allocation).

For quantitative indicators, the top-down approach can be used to assign them to processes using an activity variable that has the required process reference (such as working hours). However, these are often confidential. In the present work, the mass and energy flows of the LCA and company-specific data were used to obtain an activity variable with process reference through allocation. However, as with the LCA [106], allocation poses new challenges. Since company data is used to calculate the activity variables for each process step, the variable is automatically averaged over the different countries, activities and products of the company in question. This can lead to imprecise estimates in certain situations: 
- In a company, several products are manufactured during whose production large differences occur in the activity variable and in the SLCA only one of these products is considered.

- A company produces the same product in several countries with large differences in the activity variable and in SLCA only one of these countries is analyzed.

- In a company, some parts of a product are manufactured in-house, while others are purchased. Since in this approach the activity variable refers to the mass, too much is allocated to the purchased parts and too little to the self-manufactured parts.

- The total mass output of a company is an important parameter in this approach (see Section 3.1.2). However, in the data provided by different companies, it can refer to different quantities, such as output or sales, and is difficult to compare in such cases.

In certain circumstances, inaccuracies may also occur in the reference of social data to the activity variable:

- The social data are not proportional to the selected activity variable or have no relation at all to an activity variable.

- Although the social data are proportional to the chosen activity variable, they show large deviations in different processes.

With the bottom-up approach, the challenges described for the top-down approach do not arise, since the social data are directly incorporated into the respective process steps and a reference value can be determined specifically. However, this procedure is very time-consuming, since each process step must be considered individually, and a suitable reference value must be determined. In addition, the administrative and development components should be adequately considered. These are already included in the top-down approach.

For qualitative indicators or PDCA indicators, the process reference can be established using the LCAA method. The only limitation here is the inaccuracies for the activity variable mentioned above.

\subsubsection{Use of the Calculated Indicators in an SLCA}

Several possibilities for the use of the calculated indicators were shown in this work. The challenges are different in each case.

The most direct way is not offsetting indicators. Thus, the major challenge is to analyze a large number of different indicators.

In the calculation of PDCA and performance indicators for a social aspect, evaluations are implemented and then averaged. The following issues must be considered: On the one hand, detailed information is lost with the evaluations and the averaging, on the other hand there is always the risk that the subjectivity of the person carrying out the evaluation can have an effect on the results. In addition, negative results in performance indicators can be offset by positive results in PDCA indicators. However, this should not happen if the PDCA approach is correctly implemented, as the actual goal is to improve performance indicators.

Furthermore, the PDCA indicators can be integrated into the functional unit as a condition for the performance indicators in order to ensure a systematic approach. The difficulty here is that companies or processes which do not implement the PDCA indicators cannot be included in the SLCA. This procedure is only possible in situations in which the PDCA indicators have already been implemented at the participating companies or in which there are corresponding possibilities of influencing them.

The integration of the PDCA indicators into the functional unit would also offer the possibility of integrating social aspects, which relate very strongly to the behavior of a company and can only be analyzed to a limited extent using performance indicators, such as Forced Labor, into an SLCA. However, they would not be included in the balance sheet-which is one of the essential functions of SLCA. Whether and how such social aspects can be integrated into an SLCA remains to be seen. 


\subsubsection{Assessment of the Social Aspects}

This work does not include an assessment of the SLCA results but presents an approach for a practical SLCA in the automotive industry at the Life Cycle Inventory level. However, in the development of social aspects and indicators and in primary data collection, issues arose that could create difficulties for the assessment part of an SLCA.

1. Unambiguous interpretation of the social aspects

For many social aspects, an unambiguous interpretation and thus a clear evaluation are (still) difficult. An example of this is Economic Development: How can a company be evaluated that has a high turnover and does not attach importance to diversity in comparison to a company with little turnover but a high proportion of disabled persons? The difficult or unclear assessment was also recognized in the research on Child Labor, Hours of Work and Intellectual Property [56,112]. The Guidelines and the other sources do not provide any indications for the assessment either.

\section{Additional information for the evaluation of social aspects}

Due to the strong link between the social aspects and the companies, some factors, such as the size or sector of the companies, are decisive for an evaluation. For example, Public Commitment to (Social) Sustainability, Corruption, Job Security or Social Responsibility had only been addressed by large companies in the primary data collection, but this does not necessarily mean that the smaller companies are poorly rated. In most cases, companies with office activities have a lower social impact than a mining company and should therefore be evaluated differently.

Moreover, social issues are more influenced by cultural and country-specific circumstances than environmental issues (except for a few cases such as water scarcity). In some countries, for example, trade unions are seen more positively (such as in Germany), while in others (such as the US) most workers would reject a union membership. The dependence of assessment on cultural and country-specific circumstances was also noted in reference [43].

Many of the social aspects, such as Salary, require information about the local situation for the assessment. In the published data, the reference to the place of production is usually not published or the companies only provide social data as an average at the organizational level, even if they operate in several locations in different countries.

\section{Subjectivity of social aspects}

Some of the social aspects can only be assessed through qualitative indicators, which often require subjective assessments. In this work, the data on PDCA indicators were easier to obtain, but the responses are often very diverse and more difficult to compare or evaluate between different companies. This makes it difficult to compare SLCA results.

\subsubsection{Transfer of the Approach from the Component to the Car Level}

Due to the complexity of a car and of the supply chains in the automotive industry, five exemplary materials were selected in the primary data collection based on the material composition of a Mercedes-Benz car (Section 2.1.1). In order to carry out an SLCA of a car, thus to relate the results of the calculations from the component level to a car, different procedures must be selected depending on the life cycle phase (see Table 4). These are described below. It is assumed that the necessary calculations have already been carried out for all components of the car. 
Table 4. Transfer of the results from the component level to the car level.

\begin{tabular}{|c|c|c|}
\hline Life Cycle Phase & $\begin{array}{l}\text { Reference Value for the } \\
\text { Consideration of a Component }\end{array}$ & $\begin{array}{c}\text { Necessary Steps for the Consideration } \\
\text { of the Complete Car }\end{array}$ \\
\hline Upstream chain & Mass (top-down) & $\begin{array}{l}\text { Adding the results of the different } \\
\text { components }\end{array}$ \\
\hline Manufacturing & Component (bottom-up) & Top-down in relation to the vehicle \\
\hline Use phase (fuel path) & Mass (top-down), fuel reduction factor & $\begin{array}{l}\text { Top-down in relation to the fuel } \\
\text { consumption of the vehicle }\end{array}$ \\
\hline Dismantling & Component (bottom-up) & $\begin{array}{l}\text { Top-down in relation to the vehicle, } \\
\text { dismantling rate is to be considered }\end{array}$ \\
\hline Shredding & Mass (top-down) & $\begin{array}{l}\text { Top-down in relation to the vehicle, } \\
\text { shredding rate is to be considered }\end{array}$ \\
\hline
\end{tabular}

\section{Upstream chain}

For the upstream chain of a car, the social indicators of the upstream chains of the individual components are calculated using the top-down approach and then added together. The top-down approach is suitable for this, as the upstream chains are mainly materials such as steel, which are expressed in mass.

\section{Manufacturing}

When looking at manufacturing at component level, it is useful to analyze the social aspects using the bottom-up approach, as these more often depend on the number of pieces than on the weight of the component. This should be checked on a case-by-case basis.

If the entire vehicle is to be considered for the manufacturing phase, it makes sense to apply the top-down approach directly to the entire automotive company and not to examine and add the components individually using the bottom-up approach. Since different models from one manufacturer are more similar than different components within the same vehicle (e.g., rear door and engine), the meaningfulness is comparable, and the effort is significantly lower.

\section{Use phase}

In the use phase, the fuel path is considered. This can be mapped both at component and vehicle level together with the expected mileage using a top-down approach. The accuracy is increased at car level, since the calculation of the reduced consumption for individual components is not required.

\section{Dismantling}

For dismantling, due to the mass independence of the process (see Section 3.2.2, step 6a), it makes sense to analyze the social impacts with the bottom-up approach for the components. At the vehicle level, however, social indicators can be more efficiently (like the manufacturing phase) represented by a top-down approach in relation to a vehicle. The dismantling rate must be included.

\section{Shredding}

In this work, the shredding process is regarded as mass-dependent (see Section 3.2.2, step 6a). Therefore, the social indicators are analyzed using a top-down approach. For the vehicle level, these are converted to the shredding rate of the car.

In summary, at the component level, the bottom-up approach appears to be more precise than the top-down approach for certain life cycle phases. On car level even the less complex top-down approach could be chosen, since the differences between individual components would presumably be averaged. However, in the context of this work, an investigation was carried out only for one component. 


\section{Conclusions and Outlook}

\subsection{Applicability of the SLCA Method}

The results of this work show that SLCA with company-specific data is also feasible in an industry with complex, international manufacturing and supplier structures such as the automotive industry-at present, however, the method still has some limitations.

An SLCA analogous to an LCA can be realized above all for those life cycle-oriented social aspects that have indicators with process reference or those that can be meaningfully related to processes with an activity variable. These include almost all social aspects that affect the stakeholder employee. When implementing the SLCA, however, issues such as the standardization of indicators, a good knowledge of processes and the area of impact assessment must be considered that have not yet been conclusively established at the current stage of development (see Section 4.3).

Since many social aspects relate to the behavior of companies, these can be mapped well with semi-quantitative or qualitative indicators such as PDCA indicators. Data availability is also significantly higher here than for quantitative indicators, as companies communicate processes rather than performance data. However, the joint use of PDCA and performance indicators in an SLCA remains a challenge for future studies. Both the integration of the PDCA indicators into the functional unit and the joint calculation of the PDCA and performance indicators still have limitations regarding the cases in which they can be applied and the interpretation of the results (see Section 3.3.3). The correct choice depends on the question to be dealt with by SLCA.

For all life cycle-oriented social aspects that have no relation to processes and for which it is not expedient and meaningful to refer these to process level through activity variables, consideration in an SLCA is not foreseeable in the short and medium term. The same applies to social aspects that are not communicated on the process level due to confidentiality reasons. Accordingly, since only data at the organizational level are available for these social aspects, an assessment at this level would be a promising approach that could also facilitate their interpretation. For this challenge (see also Section 3.1.1, Obtaining data at the process level), SOLCA provides a solution. It might also offer improvements for the mentioned challenges Comparability of social data between different companies (Section 3.1.1) and Standardization of indicators (Section 3.3.1), as at least approaches do currently exist for standardizing indicators at the organizational level (e.g., GRI guidelines).

In addition to consideration in SOLCAs, social aspects that are addressed at the organizational level and for which no meaningful reference can be made to processes can also be examined through audits or certifications as part of supplier management. This approach should also be considered for social aspects that are difficult to assess through performance indicators and for which it is questionable whether aggregation along the life cycle makes sense, such as Child Labor or Forced Labor.

In this work, the social data were collected on a company-specific basis to determine on the one hand whether and how an SLCA based on such data is possible in industries with complex, international manufacturing and supplier structures. On the other hand, generic data never reflect the actual social impact of the companies involved in the life cycle. However, the collection of company-specific data is very time-consuming and poses specific challenges (see Section 3.3.1). Therefore, it may be useful in general to use additional industry or country data when such data is available. One advantage of this is the possibility of carrying out social analyzes of processes for which no company-specific data is available. This can be the case, for example, with raw materials that are purchased on the stock exchange or with processes such as end-of-life vehicle disposal with often unclear global export and trade flows.

It is also possible to use social risk databases such as the SHDB to map risks along the life cycle of a product or along the supply chain. This could be desirable, for example, for companies that primarily wish to avoid damage to their image due to social grievances in the supply chain. Although there are still data gaps in the SHDB for some industries, it already shows how likely a negative social impact is in a country. However, it is not certain whether social grievances will actually occur in 
a specific company in a high-risk country. Additionally, positive activities of such companies cannot be appreciated.

Ultimately, the question is always what the purpose of an SLCA is and what the company's goals are. Depending on this, social evaluations are already possible today. This also applies to industries with complex, international manufacturing and supplier structures such as the automotive industry.

\subsection{Recommendations for the Automotive Industry}

Automotive companies should continue to focus on social issues in the life cycle of a car, as the importance for their stakeholders is already high according to the survey in reference [82] and will become even higher. Irrespective of whether the greatest social responsibilities and influence lie with the countries, the companies in the life cycle or the automobile manufacturers, an automobile company can contribute to the improvement of social issues within the scope of its current possibilities.

If an automotive company is interested in identifying and addressing social risks along the life cycle of its products or along its supply chain, it can already draw on existing databases, as mentioned in the previous chapter. This enables it to identify high-risk countries and industries and then analyze the corresponding suppliers in more detail. This possibility can be used within the framework of supplier management but is not sufficient for a holistic product assessment due to the exclusive risk reference. For individual social aspects, this work has shown that it is already possible today to collect company-specific data and use it for an SLCA calculation if the necessary standardizations are considered.

In principle, an automotive company could go one step further and integrate both life cycle and end consumer-oriented social aspects into the development process of its vehicles. Thus, social aspects could be considered when making decisions about materials, concepts and materials as well as for improving the overall vehicle compared with its predecessor. An implementation would already be feasible today for certain social aspects in some areas of development, such as material decisions, using industry data.

However, there is still a long way to go before social issues can be fully considered in the development process, and an SLCA can be devised for a complete vehicle. In the future, a system similar to the International Material Data System (IMDS) [113] could be set up in which suppliers would provide standardized social aspects and indicators. Energy data could be collected on a sector-specific basis. In addition, the prioritization of the social aspects could be carried out across the industry analogous to the survey in reference [82] among the stakeholders of Daimler in order to define a generally accepted set of social aspects. A similar approach was implemented in the aluminum industry by the Aluminium Stewardship Initiative.

\subsection{Further Research Needs}

The analysis of the present work provides starting points for future investigations.

For those social aspects for which an SLCA is theoretically feasible analogous to an LCA due to its characteristics, the following topics are important for the practical implementation:

- In the future, a strong focus should continue to be placed on the concretization and standardization of the indicators, including the constant reporting of companies. This could be used to set up a database with uniform indicators for different sectors and countries. With the help of such a database, missing company-specific social data could be balanced out and the data received could be evaluated.

- The mining, production and disposal processes and their interrelations with activity variables should be analyzed in more detail and the results of the investigations should be made available. Thus, the detour via the mass output of the companies, which had to be used in this work, would not be necessary and a more exact mapping of the processes would be possible. For example, an SLCA database (analogous to an LCA database) would be desirable in which different 
activity variables are listed for each process step. Since companies often treat this information confidentially, they could be listed in such a database on an industry-specific basis and thus maintain confidentiality.

- For the impact assessment in an SLCA within the framework of an LCSA, it is necessary to further analyze the evaluation of the social aspects. The aim of these studies should be to develop a system for evaluating the social aspects that will be included in future versions of the Guidelines or comparable documents.

Since semi-quantitative and qualitative indicators are important components of the description of the social aspects and quantitative indicators are required for an SLCA, further research activities are necessary regarding offsetting. The LCAA approach shows an initial solution here, but additional application examples and further options for integration into an SLCA would be important for future developments.

The SOLCA approach [73] also appears to be a promising method as it addresses the social aspects on the level of their main characteristics. Therefore, social aspects without process reference or data availability at process level can also be considered. Further research on SOLCA - both practical and theoretical—will be crucial in the future.

Author Contributions: H.K. is the first and main author of the article. The research including literature survey, social data collection and development of the SLCA approach including the case studies was carried out by her. H.K., A.L., K.R. and M.F. contributed to the overall research idea, to the research design of the study, to writing, revising, proofreading and approving the final manuscript.

Funding: This paper is based on parts of a PhD thesis which was conducted at Daimler.

Acknowledgments: We thank Walter Klöpffer for his valuable input and the encouraging discussions. Many thanks also go to all companies that participated in the primary data collection.

Conflicts of Interest: The authors declare no conflict of interest.

\section{Appendix A Detailed Overview of the PDCA and Performance Indicators}

Table A1. Detailed overview of the indicators and questions of the social aspects (which are highlighted in grey) used in the data collection form. The PDCA indicators are only listed in detail if they have a slightly different wording than the standard one: The PDCA indicators describe management processes, they are used to analyze whether a company has defined (written) principles for the respective social aspect (PLAN), has developed measures/systems to implement the principles (DO), has introduced control measures to monitor the implementation (CHECK) and has established processes to react to violations (ACT). The performance indicators (Perf) represent measurable parameters of the social aspects. The social aspects of Economic Development (2) and Technological Development (4) do not include PDCA indicators. Sources from the indicators and more details see reference [82].

\begin{tabular}{l|l}
\hline Category & \multicolumn{1}{c}{ Indicators/Questions } \\
\hline 1. Public Commitment to (Social) Sustainability \\
\hline \multirow{5}{*}{ PLAN } & Have you introduced (in writing) and signed social sustainability principles? \\
& If yes, which one: \\
& Universal Declaration of Human Rights \\
& ILO standards \\
& UN Global Compact \\
& OECD Guidelines for Multinational Enterprises \\
& Company's own code of conduct \\
\hline
\end{tabular}


Table A1. Cont.

\begin{tabular}{|c|c|}
\hline Category & Indicators/Questions \\
\hline $\mathrm{DO} / \mathrm{CHECK}$ & $\begin{array}{l}\text { Have you developed procedures and measures for applying and monitoring these social } \\
\text { sustainability principles? } \\
\text { If yes, which one: } \\
\text { Sustainability management } \\
\text { Scorecard } \\
\text { Membership in associations/programs for promoting socially sustainable business practices } \\
\text { Other: }\end{array}$ \\
\hline $\mathrm{ACT}$ & $\begin{array}{l}\text { Have you established procedures for responding to violations regarding these social } \\
\text { sustainability principles respectively regarding complaints? If yes, please specify. }\end{array}$ \\
\hline Perf & $\begin{array}{l}\text { Do you publish documents containing promises and agreements regarding (social) } \\
\text { sustainability? If yes, please specify. }\end{array}$ \\
\hline Perf & $\begin{array}{l}\text { Have you received awards for your commitment to social sustainability? If yes: How many? } \\
\text { Which ones? }\end{array}$ \\
\hline Perf & $\begin{array}{l}\text { Do you train employees in your code of conduct/position on social sustainability? If yes: How } \\
\text { many have you trained last year (in percent)? }\end{array}$ \\
\hline Perf & $\begin{array}{l}\text { Have you received complaints concerning non-compliance against the principles in the last } \\
\text { five years? If yes: How many? What was their nature? }\end{array}$ \\
\hline \multicolumn{2}{|c|}{ 2. Economic Development } \\
\hline Perf & $\begin{array}{l}\text { How much does your product contribute to your country's economic growth? } \\
\text { Gross value added (in } € \text { ) } \\
\text { Revenues (in } € \text { ) } \\
\text { Profit (in } € \text { ) } \\
\text { Salaries paid (in } € \text { ) } \\
\text { Contribution to government budget (taxes paid, subsidies received) (in } € \text { ) } \\
\text { Other: }\end{array}$ \\
\hline Perf & $\begin{array}{l}\text { How much does your product contribute to the economic growth of developing countries (in } \\
€) \text { ? } \\
\text { Imports from developing countries } \\
\text { Investment in developing countries }\end{array}$ \\
\hline Perf & $\begin{array}{l}\text { How many key investment agreements containing human rights provisions or that were } \\
\text { vetted under human rights aspects do you have (in number and in percentage of all } \\
\text { investment agreements)? }\end{array}$ \\
\hline \multicolumn{2}{|c|}{ 3. Corruption } \\
\hline PDCA & See table heading \\
\hline Perf & $\begin{array}{l}\text { Are you suffering/have you ever suffered financial losses (in } € \text { ) from corruption? If yes: What } \\
\text { amount? What type? }\end{array}$ \\
\hline Perf & $\begin{array}{l}\text { Do you train your employees in anti-corruption policy and procedures? If yes: How many } \\
\text { have you been trained last year (in percent)? }\end{array}$ \\
\hline \multicolumn{2}{|c|}{ 4. Technology Development } \\
\hline Perf & $\begin{array}{l}\text { Are you involved in external research projects including technology, expertise, know-how or } \\
\text { facilities? If yes: in how many? In which ones? }\end{array}$ \\
\hline Perf & Do you have research and development partnerships? If yes: How many? Which ones? \\
\hline Perf & How much (in $€$ ) did you invest in technological development last year? \\
\hline Perf & On average, how many patents do you file per year? \\
\hline \multicolumn{2}{|c|}{ 5. Armed Conflicts } \\
\hline In advance & $\begin{array}{l}\text { Do you have business activities in regions with ongoing conflicts? If no, please continue with } \\
\text { Behavior in competition; if yes please answer the following questions: }\end{array}$ \\
\hline PDCA & See table heading \\
\hline Perf & $\begin{array}{l}\text { Have you been involved in conflicts/have there been problems with the local community etc.? } \\
\text { If yes: How often? Why? }\end{array}$ \\
\hline
\end{tabular}


Table A1. Cont.

\begin{tabular}{|c|c|}
\hline Category & Indicators/Questions \\
\hline \multicolumn{2}{|c|}{ 6. Behavior in Competition } \\
\hline PDCA & See table heading \\
\hline Perf & $\begin{array}{l}\text { Have lawsuits been filed against you for anti-competitive behavior, forming trusts or } \\
\text { establishing a monopoly in the past? If yes: How many? What were the results? }\end{array}$ \\
\hline \multicolumn{2}{|c|}{ 7. Intellectual Property Rights } \\
\hline PDCA & See table heading \\
\hline Perf & $\begin{array}{l}\text { Have there been claim against you regarding violations of intellectual property rights in the } \\
\text { last five years (including court decisions)? If yes: How many? What kinds? }\end{array}$ \\
\hline \multicolumn{2}{|c|}{ 8. Supplier Relationships } \\
\hline PDCA & See table heading \\
\hline Perf & $\begin{array}{l}\text { How long are the relationships with your suppliers lasting on average in the main } \\
\text { components? (new suggestion from one company) }\end{array}$ \\
\hline Perf & $\begin{array}{l}\text { Have there been complaints from suppliers in the last five years? If yes: How many? What } \\
\text { was their nature? }\end{array}$ \\
\hline \multicolumn{2}{|c|}{ 9. Social Responsibility } \\
\hline PDCA & See table heading \\
\hline Perf & What percentage of your suppliers did you audit last year? \\
\hline Perf & $\begin{array}{l}\text { Are you a member of an initiative for promoting social responsibility along the value chain? If } \\
\text { yes: What initiative? }\end{array}$ \\
\hline Perf & Do you have fair trade labels or the like? If yes: How many? Which ones? \\
\hline \multicolumn{2}{|c|}{ 10. Freedom of Association and Collective Bargaining } \\
\hline PLAN & $\begin{array}{l}\text { Have you established (in writing) principles concerning freedom of association and the right to } \\
\text { collective bargaining? If yes, which ones? }\end{array}$ \\
\hline $\mathrm{DO}$ & $\begin{array}{l}\text { Have you implemented procedures or measures regarding freedom of association and the } \\
\text { right to collective bargaining? } \\
\text { If yes, which ones? } \\
\text { Are unions adequately supported within the company (availability of infrastructure, time, } \\
\text { ability to exercise corresponding functions with pay)? } \\
\text { Are employee/union representatives invited to participate in planning major changes at the } \\
\text { company that will have an effect on working conditions? } \\
\text { Are written records and decisions resulting from collective bargaining kept on file? } \\
\text { Are minimum periods for giving notice of significant operational changes specified? } \\
\text { Do employees have access to a neutral, binding and independent dispute resolution process or } \\
\text { an independent counseling office? } \\
\text { Other: }\end{array}$ \\
\hline CHECK & $\begin{array}{l}\text { Have you introduced control mechanisms for verifying whether all employees are ensured } \\
\text { freedom of association and the right to collective bargaining? If yes, which ones? }\end{array}$ \\
\hline ACT & $\begin{array}{l}\text { Have you established procedures for responding to violations of freedom of association and } \\
\text { the right to collective bargaining in your company? If yes, which ones? }\end{array}$ \\
\hline Perf & What percentage of your employees are covered by collective bargaining agreements? \\
\hline Perf & $\begin{array}{l}\text { Have there been complaints from employees concerning freedom of association or the right to } \\
\text { collective bargaining in the last five years? If yes: How many? What kind? }\end{array}$ \\
\hline \multicolumn{2}{|c|}{ 11. Child Labor } \\
\hline PLAN & Have you established (in writing) principles for preventing child labor? If yes, which ones? \\
\hline $\mathrm{DO}$ & $\begin{array}{l}\text { Have you developed procedures or measures to prevent child labor or improve the situation } \\
\text { for working children? If yes, which ones? Do you verify the actual age of new employees by } \\
\text { means of official documentation? If yes, what percentage? (new suggestion from one } \\
\text { company)Are records of employees' name and age or date of birth kept on file? Are working } \\
\text { school-age children allowed to attend school (with their parents being compensated for the } \\
\text { lost income)? Other: }\end{array}$ \\
\hline
\end{tabular}


Table A1. Cont.

\begin{tabular}{|c|c|}
\hline Category & Indicators/Questions \\
\hline CHECK & $\begin{array}{l}\text { Have you introduced control mechanisms for identifying child labor (including external } \\
\text { control offices etc.)? If yes, which ones? }\end{array}$ \\
\hline $\mathrm{ACT}$ & Have you established procedures for responding to child labor? If yes, which ones? \\
\hline Perf & How old do employees have to be in order to perform dangerous tasks? \\
\hline Perf & How old is your youngest employee? \\
\hline Perf & $\begin{array}{l}\text { Have there been complaints concerning child labor in the last five years? If yes: How many? } \\
\text { What was their nature? }\end{array}$ \\
\hline \multicolumn{2}{|r|}{ I } \\
\hline PLAN & Have you established (in writing) fair wage principles for your employees? If yes, which ones? \\
\hline $\mathrm{DO}$ & $\begin{array}{l}\text { Have you developed procedures or measures for implementing fair wages for your } \\
\text { employees? If yes, which ones? }\end{array}$ \\
\hline CHECK/ACT & $\begin{array}{l}\text { Have you established procedures to regularly review and adjust the fair wages? If yes, which } \\
\text { ones? }\end{array}$ \\
\hline Perf & How much (in $€$ ) does your lowest paid full-time employee earn? \\
\hline Perf & How much (in $€$ ) does an employee with an average wage earn at your company? \\
\hline Perf & At what intervals are your employees paid? \\
\hline Perf & How many days of paid vacation do your employees receive per year? \\
\hline Perf & Is overtime of employees paid? If no, is there another compensation? \\
\hline Perf & How do you influence the wages of your temporary workers? \\
\hline Perf & $\begin{array}{l}\text { Have there been complaints about wages in the last five years? If yes: How many? What was } \\
\text { their nature? }\end{array}$ \\
\hline \multicolumn{2}{|c|}{ 13. Hours of Work } \\
\hline PDCA & See table heading \\
\hline Perf & Do your workers have individual flexibility in their hours? If yes, which ones? \\
\hline Perf & On average, how many hours do employees work each week? \\
\hline Perf & What is the maximum number of hours employees work per week (full time)? \\
\hline Perf & After how many consecutive days are employees given at least one day off? \\
\hline Perf & How many part-time employees work for you (in percent)? \\
\hline \multicolumn{2}{|c|}{ 14. Forced Labor } \\
\hline PLAN & Have you established (in writing) principles for preventing forced labor? If yes, which ones? \\
\hline $\mathrm{DO}$ & $\begin{array}{l}\text { Have you developed procedures or measures for preventing forced labor? } \\
\text { If yes, which ones? } \\
\text { Do your employment contracts establish pay, hours, vacation and conditions for termination? } \\
\text { Do you deliver original documents belonging to the employee to the employees again? } \\
\text { Employees voluntarily agree to the terms of employment. } \\
\text { Other: }\end{array}$ \\
\hline CHECK & $\begin{array}{l}\text { Have you introduced control mechanisms for identifying forced labor (including external } \\
\text { control offices)? If yes, which ones? }\end{array}$ \\
\hline ACT & Have you established procedures for responding to forced labor? If yes, which ones? \\
\hline Perf & $\begin{array}{l}\text { Have there been complaints about forced labor in the last five years? If yes: How many? What } \\
\text { was their nature? }\end{array}$ \\
\hline \multicolumn{2}{|c|}{ 15. Equal Opportunities } \\
\hline PDCA & See table heading \\
\hline Perf & $\begin{array}{l}\text { What is the composition of your governing bodies and break-down of your employees (in } \\
\text { percent) by gender, age group and minority group membership (elderly, disabled, religion)? }\end{array}$ \\
\hline Perf & What is the base pay for women (in $€$ )? \\
\hline Perf & What is the base pay for men (in $€$ )? \\
\hline
\end{tabular}


Table A1. Cont.

\begin{tabular}{|c|c|}
\hline Category & Indicators/Questions \\
\hline Perf & How many women are in the management level? (new suggestion from one company) \\
\hline Perf & How many (severely) disabled persons work for you? \\
\hline Perf & $\begin{array}{l}\text { Have there been incidents of discrimination in the last five years? If yes: How many? Which } \\
\text { ones? }\end{array}$ \\
\hline \multicolumn{2}{|c|}{ 16. Health and Safety } \\
\hline PLAN & $\begin{array}{l}\text { Have you established (in writing) principles for ensuring and promoting employee health and } \\
\text { safety? If yes, which ones? }\end{array}$ \\
\hline $\mathrm{DO}$ & $\begin{array}{l}\text { Have you developed measures or procedures for ensuring/promoting employee health and } \\
\text { safety? } \\
\text { If yes, which ones? } \\
\text { Are you certified according to OHSAS } 18001 \text { ? } \\
\text { Are there measures in place (training, protective clothing, etc.) to prevent accidents and } \\
\text { illnesses? } \\
\text { Are there measures in place for accidents or hazardous situation (e.g., emergency plans)? } \\
\text { Do employees have a way to report risks, make suggestions for improvement, etc. to } \\
\text { a responsible authority? } \\
\text { Do you have an employee counseling program? } \\
\text { Do you have programs to combat locally significant health issues? } \\
\text { Other: }\end{array}$ \\
\hline CHECK & Have you introduced control mechanisms for monitoring compliance? If yes, which ones? \\
\hline $\mathrm{ACT}$ & $\begin{array}{l}\text { Have you established procedures for responding to problems with the above-mentioned } \\
\text { measures or procedures? If yes, which ones? }\end{array}$ \\
\hline Perf & Last year, how many injuries and non-fatal workplace accidents occurred? \\
\hline Perf & Last year, how many fatal workplace accidents occurred? \\
\hline Perf & $\begin{array}{l}\text { Have there occurred occupational illnesses in the last five years? If yes: How many? What } \\
\text { kinds? }\end{array}$ \\
\hline \multicolumn{2}{|c|}{ 17. Social Benefits/Social Security } \\
\hline PDCA & See table heading \\
\hline Perf & What social benefits/social security do you offer? \\
\hline Perf & How much (in $€$ ) do you spend on social benefits/social security? \\
\hline Perf & Are any benefits provided to full-time employees only? If yes, which ones? \\
\hline Perf & How long (in days) do you continue paying wages in cases of maternity leave? \\
\hline Perf & How long (in days) do you continue paying wages in cases of employee sickness? \\
\hline \multicolumn{2}{|c|}{ 18. Education and Training } \\
\hline PDCA & See table heading \\
\hline Perf & How much (in $€$ ) do you spend on education and training of your employees? \\
\hline Perf & What percentages of skilled and unskilled workers do you employ? \\
\hline Perf & What percentage of trainees/apprentices do you employ? \\
\hline Perf & What percentage of your employees attend education and training courses? \\
\hline Perf & What is the average number of days spent on education/training per employee per year? \\
\hline \multicolumn{2}{|c|}{ 19. Job Security } \\
\hline PLAN & See table heading \\
\hline Perf & $\begin{array}{l}\text { What percentages of permanent employees, fixed-term employees, workers from temporary } \\
\text { staffing agencies and from contractors do you have? }\end{array}$ \\
\hline Perf & How many employees (in percent) are dismissed each year as a share of your total workforce? \\
\hline Perf & $\begin{array}{l}\text { How much has your headcount risen or fallen in the last five years (divided by age, gender } \\
\text { and religion)? }\end{array}$ \\
\hline
\end{tabular}


Table A1. Cont.

\begin{tabular}{|c|c|}
\hline Category & Indicators/Questions \\
\hline \multicolumn{2}{|c|}{ 20. Subjective Job Satisfaction } \\
\hline PDCA & See table heading \\
\hline Perf & $\begin{array}{l}\text { What were the results of your last survey meaning for example what percentage of the } \\
\text { employees are satisfied? }\end{array}$ \\
\hline Perf & Were all the responses confidential? \\
\hline Perf & Do you communicate your results with your employees? \\
\hline \multicolumn{2}{|c|}{ 21. Delocalization } \\
\hline PDCA & See table heading \\
\hline Perf & How many people had to be displaced because of the company? \\
\hline Perf & $\begin{array}{l}\text { In recent years, have there been any complaints regarding delocalization? If yes: How many? } \\
\text { What kind? }\end{array}$ \\
\hline \multicolumn{2}{|c|}{ 22. Migration } \\
\hline PDCA & See table heading \\
\hline Perf & Do you offer annual language and integration courses for foreign/migrant workers? \\
\hline Perf & $\begin{array}{l}\text { In recent years, have there been any complaints regarding this issue? If yes: How many? What } \\
\text { kind? }\end{array}$ \\
\hline \multicolumn{2}{|c|}{ 23. Dialogue with the Local Community } \\
\hline PDCA & See table heading \\
\hline Perf & $\begin{array}{l}\text { Do you meet with stakeholder groups (independent from current events)? If yes: With how } \\
\text { many? How often? In what form? }\end{array}$ \\
\hline Perf & How do you support community initiatives (through volunteer work or finances)? \\
\hline Perf & $\begin{array}{l}\text { Have you violated any rules of local political or social governing bodies? If yes: In what } \\
\text { manner? How often? }\end{array}$ \\
\hline \multicolumn{2}{|c|}{ 24. Local Heritage } \\
\hline PDCA & See table heading \\
\hline Perf & $\begin{array}{l}\text { Have there been complaints concerning disregard for the local cultural heritage in the past } 5 \\
\text { years? If yes: How often? What kind? }\end{array}$ \\
\hline \multicolumn{2}{|c|}{ 25. Indigenous Rights } \\
\hline In advance & $\begin{array}{l}\text { Are you active in a region where there are indigenous populations? If no, please continue with } \\
\text { Access to immaterial resources; if yes please answer the following questions: }\end{array}$ \\
\hline PDCA & See table heading \\
\hline Perf & Do you meet with indigenous populations? If yes: How often? In what form? \\
\hline Perf & $\begin{array}{l}\text { Have there been complaints concerning disregard for the rights of the Indigenous populations } \\
\text { in the past } 5 \text { years? If yes: How often? Which ones? }\end{array}$ \\
\hline \multicolumn{2}{|c|}{ 26. Local Employment } \\
\hline PDCA & See table heading \\
\hline Perf & What percentage of your employees are hired locally (radius $100 \mathrm{~km}$ )? \\
\hline Perf & What percentage of your suppliers do business locally (radius $100 \mathrm{~km}$ )? \\
\hline \multicolumn{2}{|c|}{ 27. Access to Immaterial Resources } \\
\hline PDCA & See table heading \\
\hline Perf & Do you have education initiatives for the local community? If yes: How many? What kind? \\
\hline \multicolumn{2}{|c|}{ 28. Access to Material Resources } \\
\hline PDCA & See table heading \\
\hline Perf & Do you provide infrastructure facilities for the community? If yes, which ones? \\
\hline Perf & Does the company have a certified environmental management system? \\
\hline
\end{tabular}


Table A1. Cont.

\begin{tabular}{|c|c|}
\hline Category & Indicators/Questions \\
\hline \multicolumn{2}{|c|}{ 29. Safe and Healthy Living Conditions } \\
\hline In advance & $\begin{array}{l}\text { What health risks and opportunities does the population have in the area surrounding the } \\
\text { company? } \\
\text { Does the company handle radioactive materials and/or promote activities in the field of } \\
\text { nuclear weapons/nuclear energy or genetic engineering? } \\
\text { Have you established (in writing) principles concerning health issues in the local sur-rounding } \\
\text { area? If yes, which ones? }\end{array}$ \\
\hline PDCA & See table heading \\
\hline Perf & $\begin{array}{l}\text { How many fatal/non-fatal accidents have there been in the local surrounding area in the last } 5 \\
\text { years related to the company's activities? }\end{array}$ \\
\hline Perf & $\begin{array}{l}\text { Have there been complaints in the last } 5 \text { years concerning health issues in the local } \\
\text { surrounding area related to the company's activities? If yes: How many? What kind? }\end{array}$ \\
\hline \multicolumn{2}{|c|}{ 30. Secure Living Conditions } \\
\hline PDCA & See table heading \\
\hline Perf & $\begin{array}{l}\text { Have there been lawsuits/complaints about secure living conditions in the last } 5 \text { years? If yes: } \\
\text { How often? What kind? }\end{array}$ \\
\hline
\end{tabular}

\section{Appendix B Detailed Information on the Case Studies of the Life Cycle Approach}

\section{Appendix B.1 Data on the Mass and Energy Flows}

Further details, assumptions and the sources of the individual processes of the mass and energy flows of the inner part of the rear door for aluminum and for steel are described below. Figures A1 and $A 2$ show the different processes with numbers, for which numerical values and the literature sources are shown in Tables A2 and A3. The mass and energy flows are based on GaBi [102] (22nd Servicepack) and ecoinvent data sets [103] (Version 2.2). Additional sources were the references [104,105].

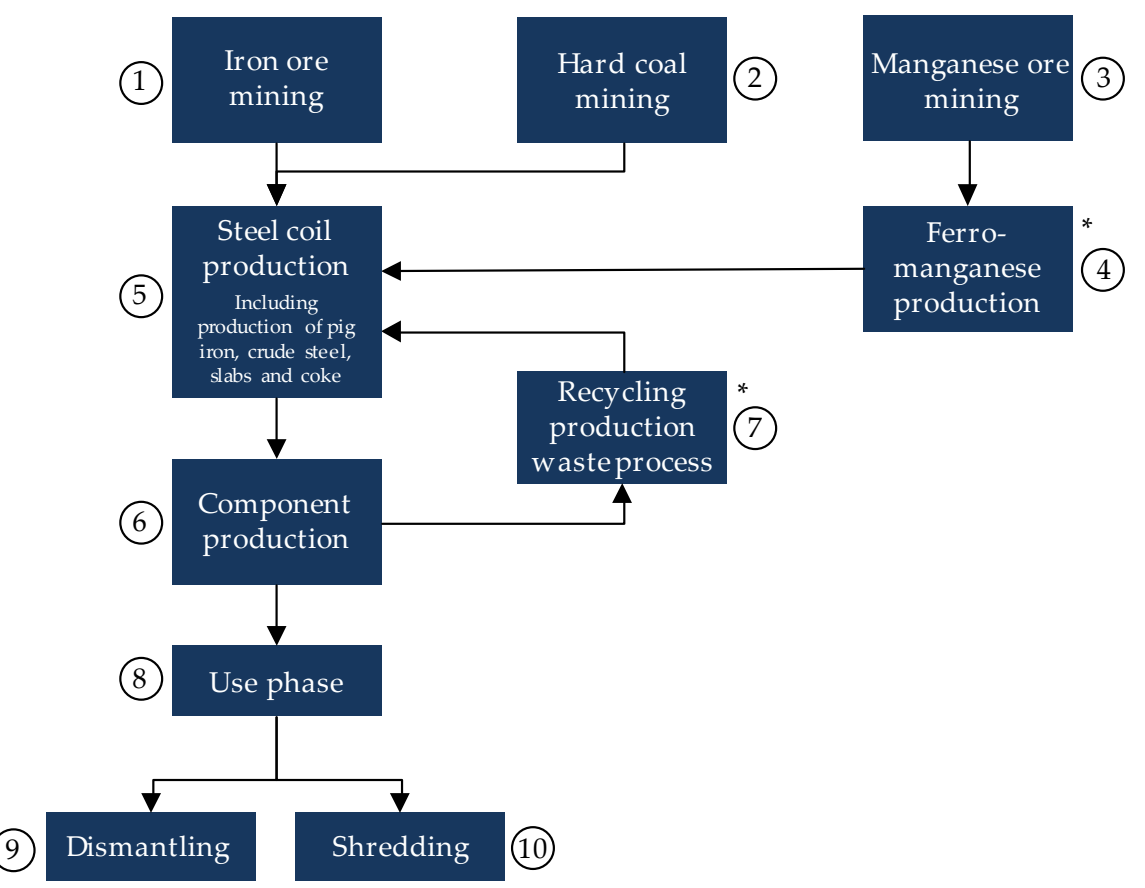

Figure A1. The processes of the steel component considered in the calculations. The asterisk indicates the processes in which only social data of the energy processes could be collected. The numbers are described in Table A2. Detailed explanations of the processes are given in reference [82] (Section 6.1.2). The figure was modified according to the references [114,115]. 
No social data could be analyzed for some individual processes, therefore only the social data of the energy flows were considered here. These processes were: Ferromanganese production (steel), anode production and the swimming and sinking facility (aluminum). No information on energy and mass flows was available for the other resource extraction processes in aluminum, so these were neglected (see Figure A2). Transport processes and car maintenance were also neglected. The aim was to show the main processes of the steel and aluminum component.

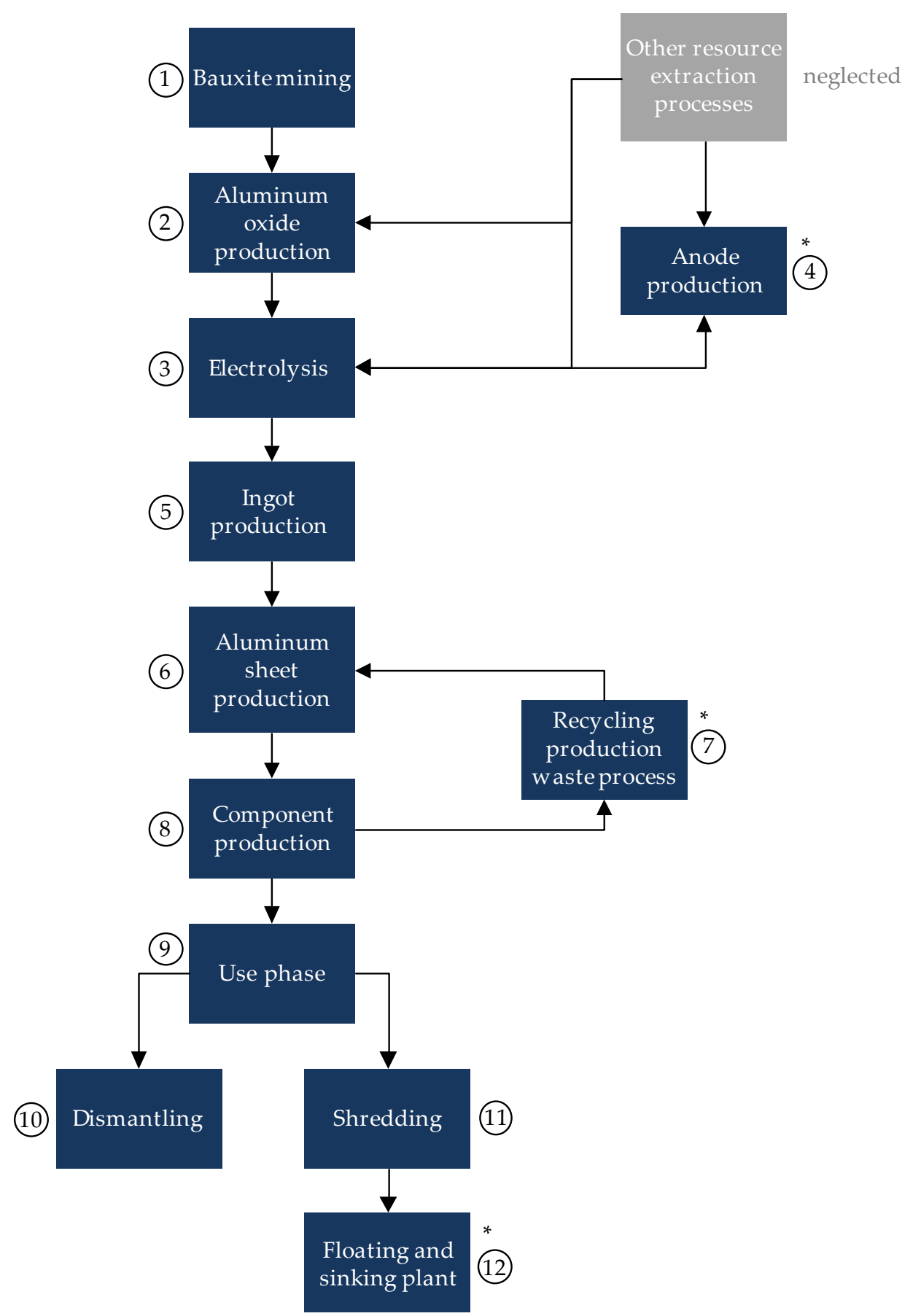

Figure A2. The processes of the aluminum component considered in the calculations. The asterisk indicates the processes in which only social data of the energy processes could be collected. The grey process has been neglected. The numbers are described in Table A3. Detailed explanations of the processes are given in reference [82] (Section 6.1.2). The figure was modified according to reference [104]. 
There are two main recycling processes in the two processes. On the one hand, scrap is recycled during the production of semi-finished products (steel coil and aluminum sheet). In the case of the steel component, this is already contained in the back-linked data record in $\mathrm{GaBi}$; in the case of the aluminum component, this is integrated in number 6 . On the other hand, this is the recycling of the waste during component production. From the latter, only the social data of the energy flows were considered. Overall, however, fewer primary raw materials were used.

Due to the higher material value, a higher dismantling rate was assumed for aluminum. For the energy flows in the individual processes in Tables A2 and A3 one mineral oil producer and one electricity producer were interviewed as examples. The social data of the oil company covered both process energy, such as thermal energy, useful heat or natural gas, and diesel as a fuel. This was possible due to the production spectrum of the oil company. The useful heat, however, was covered by the electricity consumption and the hard coal consumption in the production of useful heat. The data and literature sources for both materials are shown in Table A4. The (lower) calorific values were taken from the technical values in GaBi. These are only listed if assumptions have been made for them (e.g., countries of origin for coal).

Table A2. More detailed information about the processes of the component inner part of the steel rear door. f.: the following page; ff.: the following pages.

\begin{tabular}{|c|c|c|c|c|}
\hline Process & Material Input & Material Output & Energy Consumption & Source \\
\hline (1) & - & $11.3 \mathrm{~kg}$ Iron ore & $\begin{array}{l}0.0423 \text { MJ Diesel } \\
0.0211 \text { kWh Electricity }\end{array}$ & [116] (Part II, pp. 10, 13) \\
\hline (2) & - & $4.63 \mathrm{~kg}$ Coal & $\begin{array}{l}\text { 0.303 MJ Diesel } \\
0.0352 \mathrm{MJ} \text { Useful heat } \\
0.0837 \mathrm{kWh} \text { Electricity }\end{array}$ & $\begin{array}{l}\text { [117] (p. } 54) \\
\text { Country of origin is } \\
\text { mainly Australia: Lower } \\
\text { calorific value (hard } \\
\text { coal): } 27.5 \mathrm{MJ} / \mathrm{kg}(\mathrm{GaBi})\end{array}$ \\
\hline (3) & - & $\begin{array}{l}0.0228 \mathrm{~kg} \\
\text { Manganese ore }\end{array}$ & $\begin{array}{l}0.00182 \mathrm{MJ} \text { Diesel } \\
0.000172 \mathrm{kWh} \\
\text { Electricity }\end{array}$ & [116] (Part VII, pp. 18 f.) \\
\hline (4) & $0.0228 \mathrm{~kg}$ Manganese ore & $\begin{array}{l}0.00979 \mathrm{~kg} \\
\text { Ferromanganese }\end{array}$ & $0.0252 \mathrm{kWh}$ Electricity & [116] (Part VII, pp. 26 f.) \\
\hline (5) & $\begin{array}{l}11.3 \mathrm{~kg} \text { Iron ore } \\
3.36 \mathrm{~kg} \text { Steel from } \\
\text { recycling } \\
4.63 \mathrm{~kg} \text { Coal } \\
0.00979 \mathrm{~kg} \\
\text { Ferromanganese }\end{array}$ & $9.44 \mathrm{~kg}$ Steel coil & $\begin{array}{l}\text { The production of steel } \\
\text { coils was considered } \\
\text { self-sufficient due to } \\
\text { coke production. }\end{array}$ & $\begin{array}{l}\text { GaBi, Steel coil, } \\
\text { cold-rolled }\end{array}$ \\
\hline (6) & $9.44 \mathrm{~kg}$ Steel coil & $5.90 \mathrm{~kg}$ Component & $\begin{array}{l}\text { 1.65 MJ Useful heat } \\
1.80 \mathrm{kWh} \text { Electricity }\end{array}$ & $\begin{array}{l}\text { GaBi, DE steel sheet } \\
\text { metal deep drawing } \\
\text { (multistage) }\end{array}$ \\
\hline (7) & $3.54 \mathrm{~kg}$ Offcuts & 3.36 kg Steel & $1.42 \mathrm{kWh}$ Electricity & [116] (Part II, pp. 57 ff.) \\
\hline (8) & $5.90 \mathrm{~kg}$ Component & $5.90 \mathrm{~kg}$ Component & 1212 MJ Diesel & - \\
\hline (9) & $1.18 \mathrm{~kg}$ Component & $1.18 \mathrm{~kg}$ Component & 0.00488 kWh Electricity & [105] (p. 139) \\
\hline (10) & $4.72 \mathrm{~kg}$ Component & $4.72 \mathrm{~kg}$ Component & $0.478 \mathrm{kWh}$ Electricity & [105] (p. 139) \\
\hline
\end{tabular}


Table A3. More detailed information about the processes of the component inner part of the aluminum rear door. Thermal energy is generated by burning natural gas and petroleum products [104].

\begin{tabular}{|c|c|c|c|c|}
\hline Process & Material Input & Material Output & EnergyConsumption & Source \\
\hline (1) & - & $18.2 \mathrm{~kg}$ Bauxite & $\begin{array}{l}0.237 \mathrm{MJ} \text { Thermal energy } \\
0.00810 \mathrm{kWh} \text { Electricity }\end{array}$ & [104] (p. 23) \\
\hline (2) & $18.2 \mathrm{~kg}$ Bauxite & $\begin{array}{l}8.29 \mathrm{~kg} \text { Aluminum } \\
\text { oxide }\end{array}$ & $\begin{array}{l}\text { 78.9 MJ Thermal energy } \\
2.00 \mathrm{kWh} \text { Electricity }\end{array}$ & [104] (p. 24) \\
\hline (3) & $8.29 \mathrm{~kg}$ Aluminum oxide & $\begin{array}{l}4.31 \mathrm{~kg} \text { Liquid } \\
\text { aluminum }\end{array}$ & $63.9 \mathrm{kWh}$ Electricity & [104] (p. 27) \\
\hline (4) & $2.26 \mathrm{~kg}$ Anode & $\begin{array}{l}0.461 \mathrm{~kg} \text { Anode } \\
\text { residues }\end{array}$ & $\begin{array}{l}\text { 6.14 MJ Thermal energy } \\
0.333 \mathrm{kWh} \text { Electricity }\end{array}$ & [104] (p. 25) \\
\hline (5) & $\begin{array}{l}4.31 \mathrm{~kg} \text { Liquid } \\
\text { Aluminum }\end{array}$ & $4.28 \mathrm{~kg}$ Ingots & $\begin{array}{l}\text { 5.49 MJ Thermal energy } \\
0.542 \mathrm{kWh} \text { Electricity }\end{array}$ & [104] (p. 29) \\
\hline (6) & $\begin{array}{l}4.28 \mathrm{~kg} \text { Ingots } \\
2.35 \mathrm{~kg} \text { Aluminum from } \\
\text { recycling }\end{array}$ & $\begin{array}{l}6.61 \mathrm{~kg} \text { Aluminum } \\
\text { sheets }\end{array}$ & $\begin{array}{l}\text { 5.49 MJ Thermal energy } \\
0.542 \mathrm{kWh} \text { Strom }\end{array}$ & [104] (p. 41) \\
\hline (7) & $2.48 \mathrm{~kg}$ Offcuts & $2.35 \mathrm{~kg}$ Aluminum & $\begin{array}{l}\text { 7.93 MJ Thermal energy } \\
0.313 \mathrm{kWh} \text { Electricity }\end{array}$ & [104] (p. 41) \\
\hline (8) & $6.61 \mathrm{~kg}$ Aluminum sheets & 4.13 kg Component & $\begin{array}{l}\text { 13.8 MJ Thermal energy } \\
\text { 4.37 kWh Electricity }\end{array}$ & $\begin{array}{c}\text { GaBi, DE } \\
\text { Aluminium sheet } \\
\text { deep drawing }\end{array}$ \\
\hline (9) & $4.13 \mathrm{~kg}$ Component & $4.13 \mathrm{~kg}$ Component & 708 MJ Diesel & - \\
\hline (10) & $3.30 \mathrm{~kg}$ Component & 3.30 kg Component & $0.0137 \mathrm{kWh}$ Electricity & [105] (p. 139) \\
\hline (11) & 0.826 kg Component & $0.826 \mathrm{~kg}$ Component & $0.0836 \mathrm{kWh}$ Electricity & [105] (p. 139) \\
\hline (12) & $0.826 \mathrm{~kg}$ Scrap & $0.826 \mathrm{~kg}$ Scrap & $0.00258 \mathrm{kWh}$ Electricity & [105] (p. 139) \\
\hline
\end{tabular}

Table A4. More detailed information about the energy processes of the components inner part of the steel and the aluminum rear door. The different energy processes are highlighted in grey.

\begin{tabular}{|c|c|c|c|c|}
\hline Process & $\begin{array}{l}\text { Material } \\
\text { Input }\end{array}$ & $\begin{array}{c}\text { Material } \\
\text { Output }\end{array}$ & Energy Consumption & Source \\
\hline \multicolumn{5}{|l|}{ Electricity } \\
\hline $\begin{array}{l}\text { Hard coal from } \\
\text { mine }\end{array}$ & - & $\begin{array}{l}0.417 \mathrm{~kg} \\
\text { Hard coal }\end{array}$ & $\begin{array}{l}0.03 \mathrm{MJ} \\
0.0147 \mathrm{MJ} \text { Useful heat } \\
\text { (see below) } \\
0.00746 \mathrm{kWh} \text { Electricity }\end{array}$ & $\begin{array}{l}\text { [117] (p. 54) } \\
\text { The hard coal of the } \\
\text { company surveyed } \\
\text { comes mainly from } \\
\text { Chile, Colombia, South } \\
\text { Africa and Australia. An } \\
\text { average lower calorific } \\
\text { value of } 26.3 \mathrm{MJ} / \mathrm{kg} \text { was } \\
\text { assumed. }\end{array}$ \\
\hline $\begin{array}{l}\text { Hard coal in the } \\
\text { power plant DE }\end{array}$ & $\begin{array}{l}0.417 \mathrm{~kg} \\
\text { Hard coal }\end{array}$ & $\begin{array}{l}10.0 \mathrm{MJ} \\
\text { Hard coal }\end{array}$ & 0.00724 MJ Fuel oil & [117] (p. 91) \\
\hline $\begin{array}{l}\text { Electricity from } \\
\text { power plant DE }\end{array}$ & $\begin{array}{l}10.0 \mathrm{MJ} \\
\text { Hard coal }\end{array}$ & $\begin{array}{l}1.00 \mathrm{kWh} \\
\text { Electricity }\end{array}$ & - & [117] (p. 186) \\
\hline \multicolumn{5}{|l|}{ Diesel } \\
\hline $\begin{array}{c}\text { Crude oil from } \\
\text { onshore production } \\
\text { RAF }\end{array}$ & - & $\begin{array}{l}0.970 \mathrm{~kg} \\
\text { Crude oil }\end{array}$ & $\begin{array}{l}\text { 0.343 MJ Diesel } \\
\text { 128 MJ Natural gas } \\
\text { 1.94 MJ Natural } \\
\text { gas/sweet gas } \\
0.175 \text { MJ Sweet gas } \\
0.233 \text { MJ Fuel oil S } \\
0.0179 \text { kWh Electricity }\end{array}$ & [110] (p. 96) \\
\hline
\end{tabular}


Table A4. Cont.

\begin{tabular}{|c|c|c|c|c|}
\hline Process & $\begin{array}{c}\text { Material } \\
\text { Input }\end{array}$ & $\begin{array}{c}\text { Material } \\
\text { Output }\end{array}$ & Energy Consumption & Source \\
\hline $\begin{array}{l}\text { Diesel, from } \\
\text { refinery RER }\end{array}$ & $\begin{array}{l}0.970 \mathrm{~kg} \\
\text { Crude oil }\end{array}$ & $1.00 \mathrm{~kg}$ Diesel & $\begin{array}{l}\text { 1.69 MJ Naphtha } \\
\text { 0.680 MJ Fuel oil S } \\
\text { 0.0245 kWh Electricity } \\
\text { 2.06 MJ Refinery gas }\end{array}$ & [110] (p. 165) \\
\hline $\begin{array}{l}\text { Diesel, low in } \\
\text { sulfur, from } \\
\text { refinery RER }\end{array}$ & $1.00 \mathrm{~kg}$ Diesel & $\begin{array}{l}1.00 \mathrm{~kg} \text { Diesel, } \\
\text { low in sulfur }\end{array}$ & $\begin{array}{l}0.0427 \text { MJ Fuel oil S0.124 } \\
\text { MJ Refinery gas } \\
0.00147 \text { kWh Electricity }\end{array}$ & [110] (p. 171) \\
\hline \multicolumn{5}{|l|}{ Useful heat } \\
\hline $\begin{array}{c}\text { Hard coal, in } \\
\text { industrial furnaces } \\
\text { 1-10 MW RER } \\
\end{array}$ & $\begin{array}{l}0.0433 \mathrm{~kg} \\
\text { Hard coal mix }\end{array}$ & $\begin{array}{l}1.25 \mathrm{MJ} \\
\text { Hard coal }\end{array}$ & $0.00521 \mathrm{kWh}$ Electricity & [117] (p. 217) \\
\hline $\begin{array}{l}\text { Useful heat, hard } \\
\text { coal, from } \\
\text { industrial furnaces } \\
\text { 1-10 MW RER }\end{array}$ & $\begin{array}{l}1.25 \mathrm{MJ} \\
\text { Hard coal }\end{array}$ & $\begin{array}{l}1 \mathrm{MJ} \\
\text { Useful heat }\end{array}$ & - & [117] (p. 224) \\
\hline
\end{tabular}

\section{Appendix B.2 Social Data of Companies}

Table A5. Presentation of working hours, turnover and available social indicators (highlighted in grey) for each process step of the steel component.

\begin{tabular}{|c|c|c|c|c|}
\hline Process Step & Material & Electricity & Mineral Oil & $\begin{array}{c}\text { Sum Per } \\
\text { Process Step }\end{array}$ \\
\hline \multicolumn{5}{|l|}{ Working hours (in h) } \\
\hline Iron ore mining & $1.07 \times 10^{-2}$ & $2.92 \times 10^{-5}$ & $2.33 \times 10^{-6}$ & $1.07 \times 10^{-2}$ \\
\hline Hard coal mining & $3.34 \times 10^{-3}$ & $1.16 \times 10^{-4}$ & $1.66 \times 10^{-5}$ & $3.48 \times 10^{-3}$ \\
\hline Manganese ore mining & $8.05 \times 10^{-5}$ & $2.43 \times 10^{-7}$ & $9.89 \times 10^{-8}$ & $8.09 \times 10^{-5}$ \\
\hline Ferromanganese production & - & $3.47 \times 10^{-5}$ & $4.01 \times 10^{-8}$ & $3.47 \times 10^{-5}$ \\
\hline Steel coil production & $2.18 \times 10^{-2}$ & - & - & $2.18 \times 10^{-2}$ \\
\hline Component production & $5.01 \times 10^{-1}$ & $2.49 \times 10^{-3}$ & $9.23 \times 10^{-5}$ & $5.04 \times 10^{-1}$ \\
\hline Recycling & - & $1.97 \times 10^{-3}$ & - & $1.97 \times 10^{-3}$ \\
\hline Use phase & - & $3.80 \times 10^{-3}$ & $6.56 \times 10^{-2}$ & $6.94 \times 10^{-2}$ \\
\hline Dismantling & $2.24 \times 10^{-2}$ & $6.73 \times 10^{-6}$ & $7.78 \times 10^{-9}$ & $2.24 \times 10^{-2}$ \\
\hline Shredding & $4.89 \times 10^{-3}$ & $6.59 \times 10^{-4}$ & $7.62 \times 10^{-7}$ & $5.55 \times 10^{-3}$ \\
\hline \multicolumn{5}{|l|}{ Turnover (in $€$ ) } \\
\hline Iron ore mining & 1.10 & $1.98 \times 10^{-2}$ & $2.47 \times 10^{-3}$ & 1.13 \\
\hline Hard coal mining & $7.98 \times 10^{-1}$ & $7.90 \times 10^{-2}$ & $1.76 \times 10^{-2}$ & $8.94 \times 10^{-1}$ \\
\hline Manganese ore mining & $1.22 \times 10^{-2}$ & $1.65 \times 10^{-4}$ & $1.05 \times 10^{-4}$ & $1.24 \times 10^{-2}$ \\
\hline Ferromanganese production & - & $2.36 \times 10^{-2}$ & $4.26 \times 10^{-5}$ & $2.36 \times 10^{-2}$ \\
\hline Steel coil production & 8.72 & - & - & 8.72 \\
\hline Component production & $3.98 \times 10^{+2}$ & 1.69 & $9.81 \times 10^{-2}$ & $4.00 \times 10^{+2}$ \\
\hline Recycling & - & 1.33 & - & 1.33 \\
\hline Use phase & - & 2.58 & $6.98 \times 10^{+1}$ & $7.23 \times 10^{+1}$ \\
\hline Dismantling & 2.31 & $4.57 \times 10^{-3}$ & $8.27 \times 10^{-6}$ & 2.32 \\
\hline Shredding & 2.11 & $4.47 \times 10^{-1}$ & $8.10 \times 10^{-4}$ & 2.56 \\
\hline
\end{tabular}


Table A5. Cont.

\begin{tabular}{|c|c|c|c|c|}
\hline Process Step & Material & Electricity & Mineral Oil & $\begin{array}{c}\text { Sum Per } \\
\text { Process Step }\end{array}$ \\
\hline \multicolumn{5}{|l|}{ Number of accidents } \\
\hline Iron ore mining & $7.49 \times 10^{-9}$ & $6.53 \times 10^{-11}$ & $1.16 \times 10^{-11}$ & $7.56 \times 10^{-9}$ \\
\hline Hard coal mining & $1.92 \times 10^{-9}$ & $2.60 \times 10^{-10}$ & $8.28 \times 10^{-11}$ & $2.27 \times 10^{-9}$ \\
\hline Manganese ore mining & $1.18 \times 10^{-10}$ & $5.44 \times 10^{-13}$ & $4.95 \times 10^{-13}$ & $1.19 \times 10^{-10}$ \\
\hline Ferromanganese production & - & $7.76 \times 10^{-11}$ & $2.01 \times 10^{-13}$ & $7.78 \times 10^{-11}$ \\
\hline Steel coil production & $1.45 \times 10^{-7}$ & - & - & $1.45 \times 10^{-7}$ \\
\hline Component production & $3.81 \times 10^{-6}$ & $5.57 \times 10^{-9}$ & $4.62 \times 10^{-10}$ & $3.81 \times 10^{-6}$ \\
\hline Recycling & - & $4.39 \times 10^{-9}$ & - & $1.46 \times 10^{-9}$ \\
\hline Use phase & - & $8.49 \times 10^{-9}$ & $3.28 \times 10^{-7}$ & $3.37 \times 10^{-7}$ \\
\hline Dismantling & $1.19 \times 10^{-6}$ & $1.50 \times 10^{-11}$ & $3.89 \times 10^{-14}$ & $1.19 \times 10^{-6}$ \\
\hline Shredding & $8.99 \times 10^{-8}$ & $1.47 \times 10^{-9}$ & $3.81 \times 10^{-12}$ & $9.14 \times 10^{-8}$ \\
\hline \multicolumn{5}{|l|}{ Number of fatal accidents } \\
\hline Iron ore mining & $4.65 \times 10^{-10}$ & $2.03 \times 10^{-12}$ & $1.90 \times 10^{-13}$ & $4.67 \times 10^{-10}$ \\
\hline Hard coal mining & $4.54 \times 10^{-11}$ & $8.09 \times 10^{-12}$ & $1.35 \times 10^{-12}$ & $5.48 \times 10^{-11}$ \\
\hline Manganese ore mining & 0 & $1.69 \times 10^{-14}$ & $8.08 \times 10^{-15}$ & $2.50 \times 10^{-14}$ \\
\hline Ferromanganese production & - & $2.41 \times 10^{-12}$ & $3.28 \times 10^{-15}$ & $2.42 \times 10^{-12}$ \\
\hline Steel coil production & 0 & - & - & 0 \\
\hline Component production & $3.75 \times 10^{-9}$ & $1.73 \times 10^{-10}$ & $7.54 \times 10^{-12}$ & $3.93 \times 10^{-9}$ \\
\hline Recycling & - & $1.37 \times 10^{-10}$ & - & $1.37 \times 10^{-10}$ \\
\hline Use phase & - & $2.64 \times 10^{-10}$ & $5.36 \times 10^{-9}$ & $5.62 \times 10^{-9}$ \\
\hline Dismantling & 0 & $4.68 \times 10^{-13}$ & $6.35 \times 10^{-16}$ & $4.68 \times 10^{-13}$ \\
\hline Shredding & 0 & $4.58 \times 10^{-11}$ & $6.22 \times 10^{-14}$ & $4.59 \times 10^{-11}$ \\
\hline \multicolumn{5}{|c|}{ Number of training hours (in h) } \\
\hline Iron ore mining & $3.09 \times 10^{-4}$ & $8.09 \times 10^{-7}$ & $5.80 \times 10^{-8}$ & $3.10 \times 10^{-4}$ \\
\hline Hard coal mining & $1.16 \times 10^{-4}$ & $3.22 \times 10^{-6}$ & $4.13 \times 10^{-7}$ & $1.19 \times 10^{-4}$ \\
\hline Manganese ore mining & $1.09 \times 10^{-6}$ & $6.73 \times 10^{-9}$ & $2.47 \times 10^{-9}$ & $1.10 \times 10^{-6}$ \\
\hline Ferromanganese production & - & $9.61 \times 10^{-7}$ & $1.00 \times 10^{-9}$ & $9.62 \times 10^{-7}$ \\
\hline Steel coil production & $3.98 \times 10^{-4}$ & - & - & $3.98 \times 10^{-4}$ \\
\hline Component production & $1.11 \times 10^{-2}$ & $6.90 \times 10^{-5}$ & $2.30 \times 10^{-6}$ & $1.11 \times 10^{-2}$ \\
\hline Recycling & - & $5.44 \times 10^{-5}$ & - & $5.44 \times 10^{-5}$ \\
\hline Use phase & - & $1.05 \times 10^{-4}$ & $1.64 \times 10^{-3}$ & $1.74 \times 10^{-3}$ \\
\hline Dismantling & $2.48 \times 10^{-4}$ & $1.86 \times 10^{-7}$ & $1.94 \times 10^{-10}$ & $2.48 \times 10^{-4}$ \\
\hline Shredding & $6.74 \times 10^{-6}$ & $1.82 \times 10^{-5}$ & $1.90 \times 10^{-8}$ & $2.50 \times 10^{-5}$ \\
\hline \multicolumn{5}{|c|}{ Working hours with collective agreements } \\
\hline Iron ore mining & $96 \%$ & $87 \%$ & $68 \%$ & $96 \%$ \\
\hline Hard coal mining & $50 \%$ & $87 \%$ & $68 \%$ & $51 \%$ \\
\hline Manganese ore mining & $100 \%$ & $87 \%$ & $68 \%$ & $100 \%$ \\
\hline Ferromanganese production & - & $87 \%$ & $68 \%$ & $87 \%$ \\
\hline Steel coil production & $99 \%$ & - & - & $99 \%$ \\
\hline Component production & $95 \%$ & $87 \%$ & $68 \%$ & $95 \%$ \\
\hline Recycling & - & $87 \%$ & - & $87 \%$ \\
\hline Use phase & - & $87 \%$ & $68 \%$ & $69 \%$ \\
\hline Dismantling & $80 \%$ & $87 \%$ & $68 \%$ & $80 \%$ \\
\hline Shredding & $90 \%$ & $87 \%$ & $68 \%$ & $90 \%$ \\
\hline
\end{tabular}


Table A6. Presentation of working hours, turnover and available social indicators (highlighted in grey) for each process step of the aluminum component.

\begin{tabular}{|c|c|c|c|c|}
\hline Process Step & Material & Electricity & Mineral Oil & $\begin{array}{c}\text { Sum Per } \\
\text { Process Step }\end{array}$ \\
\hline \multicolumn{5}{|l|}{ Working hours (in h) } \\
\hline Ingot production & $1.88 \times 10^{-3}$ & $9.24 \times 10^{-2}$ & $5.02 \times 10^{-3}$ & $9.93 \times 10^{-2}$ \\
\hline Aluminum sheet production & $4.57 \times 10^{-2}$ & $6.69 \times 10^{-3}$ & $1.24 \times 10^{-3}$ & $5.36 \times 10^{-2}$ \\
\hline Component production & $3.51 \times 10^{-1}$ & $1.77 \times 10^{-3}$ & $2.05 \times 10^{-6}$ & $3.52 \times 10^{-1}$ \\
\hline Recycling & - & $4.57 \times 10^{-4}$ & $4.30 \times 10^{-4}$ & $8.86 \times 10^{-4}$ \\
\hline Use phase & - & $2.22 \times 10^{-3}$ & $3.84 \times 10^{-2}$ & $4.06 \times 10^{-2}$ \\
\hline Dismantling & $6.28 \times 10^{-2}$ & $1.88 \times 10^{-5}$ & $2.18 \times 10^{-8}$ & $6.29 \times 10^{-2}$ \\
\hline Shredding & $8.56 \times 10^{-4}$ & $1.15 \times 10^{-4}$ & $1.33 \times 10^{-7}$ & $9.71 \times 10^{-4}$ \\
\hline Floating and sinking plant & - & $3.56 \times 10^{-6}$ & $4.11 \times 10^{-9}$ & $3.56 \times 10^{-6}$ \\
\hline \multicolumn{5}{|l|}{ Turnover (in $€$ ) } \\
\hline Ingot production & $3.24 \times 10^{+2}$ & $6.27 \times 10^{+1}$ & 5.34 & $3.92 \times 10^{+2}$ \\
\hline Aluminum sheet production & $1.69 \times 10^{+1}$ & 4.54 & 1.32 & $2.28 \times 10^{+1}$ \\
\hline Component production & $3.98 \times 10^{+2}$ & 1.20 & $2.18 \times 10^{-3}$ & $3.99 \times 10^{+2}$ \\
\hline Recycling & - & $3.10 \times 10^{-1}$ & $4.57 \times 10^{-1}$ & $7.67 \times 10^{-1}$ \\
\hline Use phase & - & 1.51 & $4.08 \times 10^{+1}$ & $4.23 \times 10^{+1}$ \\
\hline Dismantling & 9.24 & $1.28 \times 10^{-2}$ & $2.31 \times 10^{-5}$ & 9.26 \\
\hline Shredding & $3.70 \times 10^{-1}$ & $7.83 \times 10^{-2}$ & $1.42 \times 10^{-4}$ & $4.49 \times 10^{-1}$ \\
\hline Floating and sinking plant & - & $2.42 \times 10^{-3}$ & $4.37 \times 10^{-6}$ & $2.42 \times 10^{-3}$ \\
\hline \multicolumn{5}{|l|}{ Number of accidents } \\
\hline Ingot production & $3.48 \times 10^{-9}$ & $2.06 \times 10^{-7}$ & $2.51 \times 10^{-8}$ & $2.35 \times 10^{-7}$ \\
\hline Aluminum sheet production & $4.57 \times 10^{-8}$ & $1.50 \times 10^{-8}$ & $6.20 \times 10^{-9}$ & $6.69 \times 10^{-8}$ \\
\hline Component production & $2.66 \times 10^{-6}$ & $3.96 \times 10^{-9}$ & $1.02 \times 10^{-11}$ & $2.67 \times 10^{-6}$ \\
\hline Recycling & - & $1.02 \times 10^{-9}$ & $2.15 \times 10^{-9}$ & $3.17 \times 10^{-9}$ \\
\hline Use phase & - & $4.96 \times 10^{-9}$ & $1.92 \times 10^{-7}$ & $1.97 \times 10^{-7}$ \\
\hline Dismantling & $3.33 \times 10^{-6}$ & $4.21 \times 10^{-11}$ & $1.09 \times 10^{-13}$ & $3.33 \times 10^{-6}$ \\
\hline Shredding & $1.57 \times 10^{-8}$ & $2.58 \times 10^{-10}$ & $6.66 \times 10^{-13}$ & $1.60 \times 10^{-8}$ \\
\hline Floating and sinking plant & - & $7.96 \times 10^{-12}$ & $2.06 \times 10^{-14}$ & $7.98 \times 10^{-12}$ \\
\hline \multicolumn{5}{|l|}{ Number of fatal accidents } \\
\hline Ingot production & $3.00 \times 10^{-11}$ & $6.42 \times 10^{-9}$ & $4.10 \times 10^{-10}$ & $6.86 \times 10^{-9}$ \\
\hline Aluminum sheet production & $2.36 \times 10^{-9}$ & $4.65 \times 10^{-10}$ & $1.01 \times 10^{-10}$ & $2.93 \times 10^{-9}$ \\
\hline Component production & $2.63 \times 10^{-9}$ & $4.65 \times 10^{-10}$ & $1.67 \times 10^{-13}$ & $3.09 \times 10^{-9}$ \\
\hline Recycling & - & $3.17 \times 10^{-11}$ & $3.51 \times 10^{-11}$ & $6.68 \times 10^{-11}$ \\
\hline Use phase & - & $1.54 \times 10^{-10}$ & $3.13 \times 10^{-9}$ & $3.29 \times 10^{-9}$ \\
\hline Dismantling & 0 & $1.31 \times 10^{-12}$ & $1.78 \times 10^{-15}$ & $1.31 \times 10^{-12}$ \\
\hline Shredding & 0 & $8.02 \times 10^{-12}$ & $1.09 \times 10^{-14}$ & $8.03 \times 10^{-12}$ \\
\hline Floating and sinking plant & - & $2.47 \times 10^{-13}$ & $3.36 \times 10^{-16}$ & $2.48 \times 10^{-13}$ \\
\hline \multicolumn{5}{|l|}{ Number of training hours (in h) } \\
\hline Ingot production & Not published & $2.56 \times 10^{-3}$ & $1.25 \times 10^{-4}$ & $2.68 \times 10^{-3}$ \\
\hline Aluminum sheet production & $5.44 \times 10^{-4}$ & $1.85 \times 10^{-4}$ & $3.09 \times 10^{-5}$ & $7.60 \times 10^{-4}$ \\
\hline Component production & $7.74 \times 10^{-3}$ & $4.91 \times 10^{-5}$ & $5.11 \times 10^{-8}$ & $7.79 \times 10^{-3}$ \\
\hline Recycling & - & $1.26 \times 10^{-5}$ & $1.07 \times 10^{-5}$ & $2.34 \times 10^{-5}$ \\
\hline Use phase & - & $6.14 \times 10^{-5}$ & $9.56 \times 10^{-4}$ & $1.02 \times 10^{-3}$ \\
\hline Dismantling & $6.93 \times 10^{-4}$ & $5.22 \times 10^{-7}$ & $5.43 \times 10^{-10}$ & $6.94 \times 10^{-4}$ \\
\hline Shredding & $1.18 \times 10^{-6}$ & $3.19 \times 10^{-6}$ & $3.32 \times 10^{-9}$ & $4.38 \times 10^{-6}$ \\
\hline Floating and sinking plant & $5.44 \times 10^{-4}$ & $9.85 \times 10^{-8}$ & $1.03 \times 10^{-10}$ & $9.86 \times 10^{-8}$ \\
\hline
\end{tabular}


Table A6. Cont.

\begin{tabular}{c|c|c|c|c}
\hline Process Step & Material & Electricity & Mineral Oil & $\begin{array}{c}\text { Sum Per } \\
\text { Process Step }\end{array}$ \\
\hline Working hours with collective agreements \\
\hline Ingot production & $68 \%$ & $87 \%$ & $85 \%$ & $86 \%$ \\
\hline Aluminum sheet production & $68 \%$ & $87 \%$ & $69 \%$ & $71 \%$ \\
\hline Component production & $68 \%$ & $87 \%$ & $95 \%$ & $95 \%$ \\
\hline Recycling & $68 \%$ & $87 \%$ & - & $77 \%$ \\
\hline Use phase & $68 \%$ & $87 \%$ & - & $69 \%$ \\
\hline Dismantling & $68 \%$ & $87 \%$ & $80 \%$ & $80 \%$ \\
\hline Shredding & $68 \%$ & $87 \%$ & $90 \%$ & $90 \%$ \\
\hline Floating and sinking plant & $68 \%$ & $87 \%$ & $85 \%$ & $87 \%$ \\
\hline
\end{tabular}

Table A7. Presentation of the results of the primary data collection of the PDCA indicators. The social aspects of Economic Development (2) and Technological Development (4) do not include PDCA indicators. The nine processes/companies considered in the table are hard coal mining (for electricity), hard coal mining (for coke), hard coal-fired power plant (energy company), fuel (oil company), ingot production, aluminum sheet production, component production, dismantling and shredding. For the steel coil, manganese ore and iron ore company, a set of indicators was determined that did not include PDCA indicators. The social aspects are highlighted in grey.

\begin{tabular}{|c|c|c|c|c|}
\hline & Yes & No & Not Relevant & No Answer \\
\hline \multicolumn{5}{|c|}{ 1. Public Commitment to (Social) Sustainability } \\
\hline PLAN & 9 & & & \\
\hline DO/CHECK & 9 & & & \\
\hline $\mathrm{ACT}$ & 8 & 1 & & \\
\hline \multicolumn{5}{|c|}{ 3. Corruption } \\
\hline PLAN & 8 & 1 & & \\
\hline $\mathrm{DO}$ & 8 & 1 & & \\
\hline CHECK & 8 & 1 & & \\
\hline $\mathrm{ACT}$ & 8 & 1 & & \\
\hline \multicolumn{5}{|c|}{ 5. Armed Conflicts } \\
\hline PLAN & 4 & & 4 & 1 \\
\hline $\mathrm{DO}$ & 2 & & 4 & \\
\hline CHECK & & & 4 & \\
\hline $\mathrm{ACT}$ & 1 & & 4 & \\
\hline \multicolumn{5}{|c|}{ 6. Behavior in Competition } \\
\hline PLAN & 8 & 1 & & \\
\hline $\mathrm{DO}$ & 7 & 1 & & 1 \\
\hline CHECK & 6 & 1 & & 2 \\
\hline $\mathrm{ACT}$ & 8 & 1 & & \\
\hline \multicolumn{5}{|c|}{ 7. Intellectual Property Rights } \\
\hline PLAN & 4 & 1 & & 4 \\
\hline $\mathrm{DO}$ & 3 & 1 & & 5 \\
\hline CHECK & 2 & 2 & & 5 \\
\hline $\mathrm{ACT}$ & 3 & 2 & & 4 \\
\hline
\end{tabular}


Table A7. Cont.

\begin{tabular}{|c|c|c|c|c|}
\hline & Yes & No & Not Relevant & No Answer \\
\hline \multicolumn{5}{|c|}{ 8. Supplier Relationships } \\
\hline PLAN & 8 & 1 & & \\
\hline $\mathrm{DO}$ & 5 & 1 & & 3 \\
\hline CHECK & 6 & 1 & & 2 \\
\hline ACT & 6 & 1 & & 2 \\
\hline \multicolumn{5}{|c|}{ 9. Social Responsibility } \\
\hline PLAN & 7 & 2 & & \\
\hline $\mathrm{DO}$ & 7 & 2 & & \\
\hline CHECK & 5 & 2 & & 2 \\
\hline $\mathrm{ACT}$ & 4 & 2 & & 3 \\
\hline \multicolumn{5}{|c|}{ 10. Freedom of Association and Collective Bargaining } \\
\hline PLAN & 8 & 1 & & \\
\hline $\mathrm{DO}$ & 8 & 1 & & \\
\hline CHECK & 6 & 2 & & 1 \\
\hline $\mathrm{ACT}$ & 7 & 1 & & 1 \\
\hline \multicolumn{5}{|c|}{ 11. Child Labor } \\
\hline PLAN & 6 & 1 & 2 & \\
\hline DO & 6 & 1 & 2 & \\
\hline CHECK & 5 & 1 & 2 & 1 \\
\hline $\mathrm{ACT}$ & 6 & 1 & 2 & \\
\hline \multicolumn{5}{|l|}{ 12. Salary } \\
\hline PLAN & 9 & & & \\
\hline DO & 7 & & & 2 \\
\hline CHECK/ACT & 8 & & & 1 \\
\hline \multicolumn{5}{|c|}{ 13. Hours of Work } \\
\hline PLAN & 6 & & & 3 \\
\hline $\mathrm{DO}$ & 4 & & & 5 \\
\hline CHECK & 4 & & & 5 \\
\hline $\mathrm{ACT}$ & 4 & & & 5 \\
\hline \multicolumn{5}{|c|}{ 14. Forced Labor } \\
\hline PLAN & 6 & 1 & 2 & \\
\hline $\mathrm{DO}$ & 6 & & 2 & 1 \\
\hline CHECK & 5 & 1 & 2 & 1 \\
\hline $\mathrm{ACT}$ & 6 & 1 & 2 & \\
\hline \multicolumn{5}{|c|}{ 15. Equal Opportunities } \\
\hline PLAN & 8 & 1 & & \\
\hline $\mathrm{DO}$ & 7 & 1 & & 1 \\
\hline CHECK & 6 & 2 & & 1 \\
\hline $\mathrm{ACT}$ & 7 & 2 & & \\
\hline \multicolumn{5}{|c|}{ 16. Health and Safety } \\
\hline PLAN & 9 & & & \\
\hline $\mathrm{DO}$ & 8 & 1 & & \\
\hline CHECK & 8 & 1 & & \\
\hline $\mathrm{ACT}$ & 8 & 1 & & \\
\hline
\end{tabular}


Table A7. Cont.

\begin{tabular}{|c|c|c|c|c|}
\hline & Yes & No & Not Relevant & No Answer \\
\hline \multicolumn{5}{|c|}{ 17. Social Benefits/Social Security } \\
\hline PLAN & 5 & 1 & & 3 \\
\hline DO & 4 & 1 & & 4 \\
\hline CHECK & 1 & 2 & & 6 \\
\hline $\mathrm{ACT}$ & 1 & 2 & & 6 \\
\hline \multicolumn{5}{|c|}{ 18. Education and Training } \\
\hline PLAN & 9 & & & \\
\hline DO & 8 & & & 1 \\
\hline CHECK & 6 & & & 3 \\
\hline $\mathrm{ACT}$ & 5 & 1 & & 3 \\
\hline \multicolumn{5}{|c|}{ 19. Job Security } \\
\hline PLAN & 4 & 2 & & 3 \\
\hline \multicolumn{5}{|c|}{ 20. Subjective Job Satisfaction } \\
\hline PLAN & 3 & 2 & & 4 \\
\hline $\mathrm{DO}$ & 4 & 2 & & 3 \\
\hline CHECK & 6 & 1 & & 2 \\
\hline ACT & 3 & 1 & & 5 \\
\hline \multicolumn{5}{|c|}{ 21. Delocalization } \\
\hline PLAN & 7 & 1 & 1 & \\
\hline DO & 6 & 1 & 1 & 1 \\
\hline CHECK & 4 & 1 & 1 & 3 \\
\hline ACT & 5 & 1 & 1 & 2 \\
\hline \multicolumn{5}{|c|}{ 22. Migration } \\
\hline PLAN & 3 & 1 & & 5 \\
\hline DO & 1 & 1 & & 7 \\
\hline CHECK & 1 & 1 & & 7 \\
\hline ACT & 1 & 1 & & 7 \\
\hline \multicolumn{5}{|c|}{ 23. Dialogue with the Local Community } \\
\hline PLAN & 8 & 1 & & \\
\hline $\mathrm{DO}$ & 8 & 1 & & \\
\hline CHECK & 7 & 1 & & 1 \\
\hline ACT & 7 & 1 & & 1 \\
\hline \multicolumn{5}{|c|}{ 24. Local Heritage } \\
\hline PLAN & 3 & 2 & & 4 \\
\hline $\mathrm{DO}$ & 3 & 2 & & 4 \\
\hline CHECK & 2 & 2 & & 5 \\
\hline ACT & 2 & 2 & & 5 \\
\hline \multicolumn{5}{|c|}{ 25. Indigenous Rights } \\
\hline PLAN & 4 & & 5 & \\
\hline DO & 4 & & 5 & \\
\hline CHECK & 2 & & 5 & 2 \\
\hline $\mathrm{ACT}$ & 2 & & 5 & 2 \\
\hline
\end{tabular}


Table A7. Cont.

\begin{tabular}{|c|c|c|c|c|}
\hline & Yes & No & Not Relevant & No Answer \\
\hline \multicolumn{5}{|c|}{ 26. Local Employment } \\
\hline PLAN & 6 & 3 & & \\
\hline DO & 3 & 3 & & 3 \\
\hline CHECK & & 3 & & 6 \\
\hline $\mathrm{ACT}$ & 1 & 2 & & 6 \\
\hline \multicolumn{5}{|c|}{ 27. Access to Immaterial Resources } \\
\hline PLAN & 8 & 1 & & \\
\hline DO & 5 & 1 & & 3 \\
\hline CHECK & 2 & 1 & & 6 \\
\hline $\mathrm{ACT}$ & 2 & 1 & & 6 \\
\hline \multicolumn{5}{|c|}{ 28. Access to Material Resources } \\
\hline PLAN & 7 & & & 2 \\
\hline $\mathrm{DO}$ & 6 & & & 3 \\
\hline CHECK & 2 & 1 & & 6 \\
\hline $\mathrm{ACT}$ & 4 & & & 5 \\
\hline \multicolumn{5}{|c|}{ 29. Safe and Healthy Living Conditions } \\
\hline PLAN & 9 & & & \\
\hline $\mathrm{DO}$ & 9 & & & \\
\hline CHECK & 9 & & & \\
\hline ACT & 8 & 1 & & \\
\hline \multicolumn{5}{|c|}{ 30. Secure Living Conditions } \\
\hline PLAN & 8 & & 1 & \\
\hline $\mathrm{DO}$ & 6 & 1 & & 1 \\
\hline CHECK & 3 & 1 & 1 & 4 \\
\hline $\mathrm{ACT}$ & 3 & 1 & 1 & 4 \\
\hline
\end{tabular}

\section{References}

1. Otto GmbH \& Co KG. Lebensqualität. 4. Otto Group Trendstudie zum ethischen Konsum; Otto GmbH \& Co KG: Hamburg, Germany, 2013. Available online: http://www.ottogroup.com/media/docs/de/trendstudie/1_Otto_ Group_Trendstudie_2013.pdf (accessed on 19 June 2014).

2. Brigitte. BRIGITTE KommunikationsAnalyse 2012: Sozial ist das neue Bio; Brigitte; Gruner + Jahr AG \& Co KG; G+J Media Research Services: Berlin, Germany, 2012. Available online: http://www.gujmedia.de/fileadmin/ redaktion/Print/Deutsch/Portfolio/Titel/brigitte/KA_2012_Druck_V10.pdf (accessed on 4 April 2015).

3. Fiedler, D. Moral am Supermarktregal: Der Kauf von Bier rettet Regenwald, der von Eis hilft Bienen: Sozial-Marketing wird wichtiger. Schwäbisches Tagblatt, 21 May 2012; p. 20.

4. Fairtrade International. Strong Producers, Strong Future. Annual Report 2013-14. 2014. Available online: http:/www.fairtrade.net/fileadmin/user_upload/content/2009/resources/2013-14_AnnualReport_ FairtradeIntl_web.pdf (accessed on 13 December 2014).

5. Chamberlain, G. Monsoon's internal audits reveal suppliers used child labour and underpaid workers. 2010. Available online: http://www.guardian.co.uk/business/2010/nov/21/monsoon-child-labour-india?INTCMP= ILCNETTXT3487 (accessed on 7 December 2011).

6. Tief verstrickt: Deutsche Textilfirmen lassen zu menschenunwürdigen Bedingungen in China und der Dritten Welt produzieren. Der Spiegel, 21 December 1998; pp. 52, 88-89.

7. GLHR. How Can Wal-Mart Sell a Denim Shirt for \$11.67? Institute for Global Labour and Human Rights (GLHR), 2005. Available online: http://www.globallabourrights.org/reports?id=0042 (accessed on 7 December 2011). 
8. Lee, F. Kinderarbeit für Samsung: Südkoreanischer Elektrokonzern wehrt sich gegen Vorwürfe. Schwäbisches Tagblatt, 10 August 2012; p. 15.

9. Perras, A.; Bitala, M. Das Blut an meinem Handy. Natur+Kosmos 2011, 3, 29-33.

10. Robertson, J. Apple Admits Using Child Labor: 15-Year-Olds Worked In Factories. 2010. Available online: http://www.huffingtonpost.com/2010/02/28/apple-child-labor-confess_n_479871.html (accessed on 12 January 2012).

11. Bojanowski, A. Europas Gift verseucht Spielplätze in Afrika: Uno-Studie zu Elektroschrott. 2011. Available online: http://www.spiegel.de/wissenschaft/technik/0,1518,794843,00.html (accessed on 9 January 2012).

12. Kaiser, M. Nigerian Carcycler. 2012. Available online: http://vimeo.com/61253899 (accessed on 17 October 2014)

13. Bock, C. Toxic City. Deutscher Giftschrott für Ghana; ZDF: Mainz, Germany, 2011.

14. Kerkow, U.; Martens, J.; Müller, A. Vom Erz zum Auto. Abbaubedingungen und Lieferketten im Rohstoffsektor und die Verantwortung der deutschen Automobilindustrie. Bischöfliches Hilfswerk MISEREOR e.V., Diakonisches Werk der Evangelischen Kirche in Deutschland e.V für die Aktion “Brot für die Welt", Global Policy Forum Europe, Eds. 2012. Available online: http://www.misereor.de/fileadmin/ redaktion/Vom_Erz_zum_Auto.pdf (accessed on 11 December 2012).

15. Hütz-Adams, F.; Voge, A.-K.; Liese, S.; Hörmann, S.; Bethge, J.P. Nachhaltige Rohstoffe für den deutschen Automobilsektor. Herausforderungen und Lösungswege. SÜDWIND e.V., Collaborating Centre on Sustainable Consumption and Production, Global Nature Fund, Eds. 2014. Available online: http://www.suedwind-institut.de/fileadmin/fuerSuedwind/Publikationen/2014/2014-13_ Nachhaltige_Rohstoffe_fuer_den_deutschen_Automobilsektor.pdf (accessed on 27 June 2014).

16. UNEP/SETAC LCI. Guidelines for Social Life Cycle Assessment of Products. United Nations Environment Programme (UNEP)/Society of Environmental Toxicology and Chemistry (SETAC) Life Cycle Initiative (LCI). 2009. Available online: http://www.unep.fr/shared/publications/pdf/DTIx1164xPA-guidelines_sLCA.pdf (accessed on 20 March 2019).

17. UNEP/SETAC LCI. The Methodological Sheets for Subcategories in Social Life Cycle Assessment (S-LCA). United Nations Environment Programme (UNEP)/Society of Environmental Toxicology and Chemistry (SETAC) Life Cycle Initiative (LCI). 2013. Available online: http://www.lifecycleinitiative.org/wp-content/ uploads/2013/11/S-LCA_methodological_sheets_11.11.13.pdf (accessed on 12 September 2014).

18. Grießhammer, R.; Buchert, M.; Gensch, C.-O.; Hochfeld, C.; Manhart, A.; Rüdenauer, I. PROSA-Product Sustainability Assessment. Endbericht. In cooperation with Ebinger, M. Öko-Institut e.V., Ed. 2007. Available online: http://www.prosa.org/fileadmin/user_upload/pdf/PROSA-gesamt_Finalversion_0407_red. pdf (accessed on 17 January 2011).

19. Manhart, A.; Grießhammer, R. Soziale Auswirkungen der Produktion von Notebooks. Beitrag zur Entwicklung einer Produktnachhaltigkeitsanalyse (PROSA). 2006-010-de. Öko-Institut e.V., Ed. 2006. Available online: https://www.oeko.de/oekodoc/291/2006-010-de.pdf (accessed on 20 March 2019).

20. Kruse, S.A.; Flysjö, A.; Kasperczyk, N.; Scholz, A.J. Socioeconomic indicators as a complement to life cycle assessment-An application to salmon production systems. Int. J. Life Cycle Assess. 2009, 14, 8-18. [CrossRef]

21. Paragahawewa, U.; Blackett, P.; Small, B. Social Life Cycle Analysis (S-LCA): Some Methodological Issues and Potential Application to Cheese Production in New Zealand. AgResearch. 2009. Available online: http://www.saiplatform.org/uploads/Library/SocialLCA-FinalReport_July2009.pdf (accessed on 8 April 2011).

22. Lehmann, A.; Russi, D.; Bala, A.; Finkbeiner, M.; Fullana-i-Palmer, P. Integration of Social Aspects in Decision Support, Based on Life Cycle Thinking. Sustainability 2011, 3, 562-577. [CrossRef]

23. Hunkeler, D. Societal LCA Methodology and Case Study. Int. J. Life Cycle Assess. 2006, 11, 371-382. [CrossRef]

24. Norris, G.A. Social Impacts in Product Life Cycles: Towards Life Cycle Attribute Assessment. Int. J. Life Cycle Assess. 2006, 11, 97-104. [CrossRef]

25. Andrews, E.; Lesage, P.; Benoît, C.; Parent, J.; Norris, G.A.; Revéret, J.-P. Life Cycle Attribute Assessment: Case Study of Quebec Greenhouse Tomatoes. J. Ind. Ecol. 2009, 13, 565-578. [CrossRef]

26. Ekener-Petersen, E.; Finnveden, G. Potential hotspots identified by social LCA: Part 1: A case study of a laptop computer. Int. J. Life Cycle Assess. 2013, 18, 127-143. [CrossRef]

27. Ciroth, A.; Franze, J. LCA of an Ecolabeled Notebook-Consideration of Social and Environmental Impacts along the Entire Life Cycle. GreenDeltaTC, 2011. Available online: https://www.greendelta.com/wp-content/ uploads/2017/03/LCA_laptop_final.pdf (accessed on 20 March 2019). 
28. Prakash, S.U.C.; Manhart, A. Socio-economic assessment and feasibility study on sustainable e-waste management in Ghana. In cooperation with Amoyaw-Osei, Y., Agyekum, O. Opoku. Öko-Institut e.V., Ed. 2010. Available online: http://www.oeko.de/oekodoc/1057/2010-105-en.pdf (accessed on 20 March 2019).

29. Zamani, B.; Sandin, G.; Svanström, M.; Peters, G.M. Hotspot identification in the clothing industry using social life cycle assessment-Opportunities and challenges of input-output modelling. Int. J. Life Cycle Assess. 2018, 23, 536-546. [CrossRef]

30. Blom, M.; Solmar, C. How to Socially Assess Biofuels: A Case Study of the UNEP/SETAC Code of Practice for Socialeconomical LCA. Master's Thesis, Luleå University of Technology, Luleå, Sweden, 2009. Available online: http://tu.diva-portal.org/smash/get/diva2:1019458/FULLTEXT01.pdf (accessed on 20 March 2019).

31. Ekener-Petersen, E.; Höglund, J.; Finnveden, G. Screening potential social impacts of fossil fuels and biofuels for vehicles. Energy Policy 2014, 73, 416-426. [CrossRef]

32. Traverso, M.; Asdrubali, F.; Francia, A.; Finkbeiner, M. Towards life cycle sustainability assessment: An implementation to photovoltaic modules. Int. J. Life Cycle Assess. 2012, 17, 1068-1079. [CrossRef]

33. Souza, A.; Watanabe, M.D.B.; Cavalett, O.; Ugaya, C.M.L.; Bonomi, A. Social life cycle assessment of first and second-generation ethanol production technologies in Brazil. Int. J. Life Cycle Assess. 2018, 23, 617-628. [CrossRef]

34. Hosseinijou, S.A.; Mansour, S.; Akbarpour Shirazi, M. Social life cycle assessment for material selection: A case study of building materials. Int. J. Life Cycle Assess. 2013, 19, 620-645. [CrossRef]

35. Bozhilova-Kisheva, K.; Hu, M.; van Roekel, E. An integrated Life Cycle Inventory for demolition processes in the context of Life Cycle Sustainability Assessment. In International Symposium on Life Cycle Assessment and Construction-Civil Engineering and Buildings; Ventura, A., de La Roche, C., Eds.; CSTB: Nantes, France, 2012; pp. 327-335.

36. Traverso, M. Life Cycle Sustainability Assessment-A tool for supporting decision makers. In Proceedings of the Workshop "Social Aspects of Products along the Whole Life Cycle", Berlin, Germany, 30 May 2011. Available online: http://www.greendeltatc.com/uploads/media/TU_Berlin_Traverso.pdf (accessed on 8 June 2011).

37. Ugaya, C.M.L.; Brones, F.; Corrêa, S. S-LCA: Preliminary results of Natura's cocoa soap bar. In Proceedings of the LCM 2011-Towards Life Cycle Sustainability Management, Berlin, Germany, 28-31 August 2011. Available online: http://www.lcm2011.org/papers.html (accessed on 12 January 2012).

38. Sanchez Ramirez, P.; Petti, L.; Ugaya, C.M.L. Subcategory Assessment Method for Social LCA: A First Application on the Wine Sector. In Pathways to Environmental Sustainability: Methodologies and Experiences; Salomone, R., Saija, G., Eds.; Springer International Publishing: Cham, Switzerland, 2014; pp. 107-116, ISBN 978-3-319-03826-1.

39. Franze, J.; Ciroth, A. Social Life Cycle Assessment of Roses. A Comparison of Cut Roses from Ecuador and the Netherlands. In Proceedings of the SETAC Annual Meeting, Sevilla, Spain, 25 May 2010.

40. Revéret, J.-P.; Couture, J.-M.; Parent, J. Socioeconomic LCA of Milk Production in Canada. In Social Life Cycle Assessment: An Insight; Muthu, S.S., Ed.; Springer: Singapore, 2015; pp. 25-69, ISBN 978-981-287-295-1.

41. Manik, Y.; Leahy, J.; Halog, A. Social life cycle assessment of palm oil biodiesel: A case study in Jambi Province of Indonesia. Int. J. Life Cycle Assess. 2013, 18, 1386-1392. [CrossRef]

42. Nemarumane, T.M.; Mbohwa, C. Social Life Cycle Assessment in the South African Sugar Industry: Issues and Views. In Social Life Cycle Assessment: An Insight; Muthu, S.S., Ed.; Springer: Singapore, 2015; pp. 71-113. ISBN 978-981-287-295-1.

43. Martinéz-Blanco, J.; Lehmann, A.; Muñoz, P.; Antón, A.; Traverso, M.; Rieradevall, J.; Finkbeiner, M. Application challenges for the social LCA of fertilizers within Life Cycle Sustainability Assessment. J. Clean. Prod. 2014, 69, 34-48. [CrossRef]

44. Chang, Y.-J.; Sproesser, G.; Neugebauer, S.; Wolf, K.; Scheumann, R.; Pittner, A.; Rethmeier, M.; Finkbeiner, M. Environmental and Social Life Cycle Assessment of Welding Technologies. Procedia CIRP 2015, 26, $293-298$. [CrossRef]

45. Tsurukawa, N.; Prakash, S.; Manhart, A. Social Impacts of Artisanal Cobalt Mining in Katanga, Democratic Republic of Congo; Öko-Institut e.V., Ed. 2011. Available online: http://www.oeko.de/oekodoc/1294/2011419-en.pdf (accessed on 17 May 2015). 
46. Chang, Y.-J.; Schau, E.M.; Finkbeiner, M. Application of Life Cycle Sustainability Assessment to the bamboo and aluminum bicycles in surveying social risks of developing countries. In Proceedings of the 2nd World Sustainability Forum, 1-30 November 2012. web conference.

47. Lehmann, A. Lebenszyklusbasierte Nachhaltigkeitsanalyse von Technologien: Am Beispiel eines Projekts zum Integrierten Wasserressourcenmanagement. Ph.D. Dissertation, Technical University Berlin, Berlin, Germany, 2013. Available online: http://opus4.kobv.de/opus4-tuberlin/frontdoor/index/index/docId/3759 (accessed on 8 December 2013).

48. Arcese, G.; Lucchetti, M.; Merli, R. Social Life Cycle Assessment as a Management Tool: Methodology for Application in Tourism. Sustainability 2013, 5, 3275-3287. [CrossRef]

49. Foolmaun, R.K.; Ramjeeawon, T. Comparative life cycle assessment and social life cycle assessment of used polyethylene terephthalate (PET) bottles in Mauritius. Int. J. Life Cycle Assess. 2013, 18, 155-171. [CrossRef]

50. Aparcana, S.; Salhofer, S. Application of a methodology for the social life cycle assessment of recycling systems in low income countries: Three Peruvian case studies. Int. J. Life Cycle Assess. 2013, 18, 1116-1128. [CrossRef]

51. Vinyes, E.; Oliver-Solà, J.; Ugaya, C.M.L.; Rieradevall, J.; Gasol, C.M. Application of LCSA to used cooking oil waste management. Int. J. Life Cycle Assess. 2013, 18, 445-455. [CrossRef]

52. Petti, L.; Serreli, M.; Di Cesare, S. Systematic literature review in social life cycle assessment. Int. J. Life Cycle Assess. 2016, 23, 422-431. [CrossRef]

53. Musaazi, M.K.; Mechtenberg, A.R.; Nakibuule, J.; Sensenig, R.; Miyingo, E.; Makanda, J.V.; Hakimian, A.; Eckelman, M.J. Quantification of social equity in life cycle assessment for increased sustainable production of sanitary products in Uganda. J. Clean. Prod. 2015, 96, 569-579. [CrossRef]

54. Weldegiorgis, F.S.; Franks, D.M. Social dimensions of energy supply alternatives in steelmaking: Comparison of biomass and coal production scenarios in Australia. J. Clean. Prod. 2014, 84, 281-288. [CrossRef]

55. Bouzid, A.; Padilla, M. Analysis of social performance of the industrial tomatoes food chain in Algeria. New Medit. 2014, 13, 60-65.

56. Baumann, H.; Arvidsson, R.; Tong, H.; Wang, Y. Does the Production of an Airbag Injure more People than the Airbag Saves in Traffic? J. Ind. Ecol. 2013, 17, 517-527. [CrossRef]

57. Moran, D.; McBain, D.; Kanemoto, K.; Lenzen, M.; Geschke, A. Global Supply Chains of Coltan. J. Ind. Ecol. 2015, 19, 357-365. [CrossRef]

58. Subramanian, V.; Semenzin, E.; Zabeo, A.; Saling, P.; Ligthart, T.; van Harmelen, T.; Malsch, I.; Hristozov, D.; Marcomini, A. Assessing the social impacts of nano-enabled products through the life cycle: The case of nano-enabled biocidal paint. Int. J. Life Cycle Assess. 2018, 23, 348-356. [CrossRef]

59. Finkbeiner, M.; Schau, E.M.; Lehmann, A.; Traverso, M. Towards Life Cycle Sustainability Assessment. Sustainability 2010, 2, 3309-3322. [CrossRef]

60. Parent, J.; Cucuzzella, C.; Revéret, J.-P. Impact assessment in SLCA: Sorting the sLCIA methods according to their outcomes. Int. J. Life Cycle Assess. 2010, 15, 164-171. [CrossRef]

61. Wu, R.; Yang, D.; Chen, J. Social Life Cycle Assessment Revisited. Sustainability 2014, 6, 4200-4226. [CrossRef]

62. Chhipi-Shrestha, G.K.; Hewage, K.; Sadiq, R. 'Socializing' sustainability: A critical review on current development status of social life cycle impact assessment method. Clean Technol. Environ. Policy 2015, 17, 579-596. [CrossRef]

63. Jørgensen, A.; Lai, L.C.H.; Hauschild, M.Z. Assessing the validity of impact pathways for child labour and well-being in social life cycle assessment. Int. J. Life Cycle Assess. 2010, 15, 5-16. [CrossRef]

64. Neugebauer, S.; Traverso, M.; Scheumann, R.; Chang, Y.-J.; Wolf, J.; Finkbeiner, M. Impact Pathways to Address Social Well-Being and Social Justice in SLCA-Fair Wage and Level of Education. Sustainability 2014, 6, 4839-4857. [CrossRef]

65. Benoît Norris, C. Data for social LCA. Int. J. Life Cycle Assess. 2014, 19, 261-265. [CrossRef]

66. Jørgensen, A. Social LCA-A way ahead? Int. J. Life Cycle Assess. 2013, 18, 296-299. [CrossRef]

67. Jørgensen, A.; Dreyer, L.C.; Wangel, A. Addressing the effect of social life cycle assessments. Int. J. Life Cycle Assess. 2012, 17, 828-839. [CrossRef]

68. Macombe, C.; Leskinen, P.; Feschet, P.; Antikainen, R. Social life cycle assessment of biodiesel production at three levels: A literature review and development needs. J. Clean. Prod. 2013, 52, 205-216. [CrossRef] 
69. Zamagni, A.; Buttol, P.; Buonamici, R.; Masoni, P.; Guinée, J.B.; Huppes, G.; Heijungs, R.; van der Voet, E.; Ekvall, T.; Rydberg, T. D20 Blue Paper on Life Cycle Sustainability Analysis. Institute of Environmental Sciences, Leiden University. Proceedings of the CALCAS (Co-ordination Action for innovation in Life-Cycle Analysis for Sustainability). Deliverable 20 of Work Package 7 of the CALCAS project. 2009. Available online: http://www.leidenuniv.nl/cml/ssp/publications/calcas_report_d20.pdf (accessed on 8 June 2015).

70. International Organization for Standardization (ISO). ISO/TS 14072: Environmental Management-Life Cycle Assessment-Requirements and Guidelines for Organizational Life Cycle Assessment; ISO: Geneva, Switzerland, 2014.

71. UNEP/SETAC LCI. Guidance on Organizational Life Cycle Assessment. United Nations Environment Programme (UNEP), Society of Environmental Toxicology and Chemistry (SETAC); Life Cycle Initiative (LCI). 2015. Available online: http://www.lifecycleinitiative.org/wp-content/uploads/2015/04/o-lca_24.4.15-web.pdf (accessed on 15 June 2015).

72. Martínez-Blanco, J.; Inaba, A.; Quiros, A.; Valdivia, S.; Milà-i-Canals, L.; Finkbeiner, M. Organizational LCA: The new member of the LCA family-Introducing the UNEP/SETAC Life Cycle Initiative guidance document. Int. J. Life Cycle Assess. 2015, 20, 1045-1047. [CrossRef]

73. Martínez-Blanco, J.; Lehmann, A.; Chang, Y.-J.; Finkbeiner, M. Social organizational LCA (SOLCA)—A new approach for implementing social LCA. Int. J. Life Cycle Assess. 2015, 20, 1586-1599. [CrossRef]

74. Daimler Communications. Mit Bildung gegen Kinderarbeit-Daimler unterstützt soziales Projekt in der Demokratischen Republik Kongo mit über einer Million Euro. Press Release 12 May 2019. Available online: https://media.daimler.com/marsMediaSite/de/instance/print/Mit-Bildung-gegen-Kinderarbeit-Daimlerunterstu-etzt-soziales-Projekt-in-der-Demokratischen-Republik-Kongo-mit-ueber-einer-Million-Euro.xhtml? oid=42790689\&ls=L3NlYXJjaHJlc3VsdC9zZWFyY2hyZXN1bHQueGh0bWw_c2VhcmNoU3RyaW5nPUhSU lMmc2VhcmNoSWQ9MCZzZWFyY2hUeXBIPWRldGFpbGVkJmJvcmRlcnM9dHJ1ZSZyZXN1bHRJbmZvV HlwZUlkPTE3NSZ2aWV3VHlwZT10aHVtYnMmc29ydERIZmluaXRpb249UFVCTEITSEVEX0FULTImdGh 1bWJTY2FsZUluZGV4PTAmcm93Q291bnRzSW5kZXg9NQ!!\&rs=0 (accessed on 29 March 2019).

75. Kölsch, D.; Saling, P.; Kicherer, A.; Grosse-Sommer, A.; Schmidt, I. How to measure social impacts? A socio-eco-efficiency analysis by the SEEBALANCEßmethod. Int. J. Sustain. Dev. 2008, 11, 1-23. [CrossRef]

76. Schmidt, I.; Meurer, M.; Saling, P.; Kicherer, A.; Reuter, W.; Gensch, C.-O. SEEbalance: Managing Sustainability of Products and Processes with the Socio-Eco-Efficiency Analysis by BASF. Green. Manag. Int. 2004, 45, 79-94.

77. Saling, P. AgBalance-Measuring agricultural sustainability. A clearer view of agricultural sustainability. In Proceedings of the International Workshop "Practical Aspects of Social Life Cycle Assessment", Berlin, Germany, 25 May 2012. Available online: http://www.greendeltatc.com/uploads/media/Saling_AgBalance. pdf (accessed on 4 September 2013).

78. WBCSD. Social Life Cycle Metrics for Chemical Products. The World Business Council for Sustainable Development (WBCSD); Working Group on Life Cycle Metrics. 2016. Available online: https://www. wbcsd.org/Projects/Chemicals/Resources/Social-Life-Cycle-Metrics-for-Chemical-Products (accessed on 16 April 2019).

79. Fontes, J. Handbook for Product Social Impact Assessment. Roundtable for Product Social Metrics, Ed. Version 2.0. 2014. Available online: http://product-social-impact-assessment.com/wp-content/uploads/2014/ 08/Handbook-for-Product-Social-Impact-Assessment.pdf (accessed on 3 September 2014).

80. Goedkoop, M.J.; Indrane, D.; de Beer, I.M. Handbook for Product Social Impact Assessment. Roundtable for Product Social Metrics, Ed. Version 4.0. 2018. Available online: https://product-social-impact-assessment. com/handbook/ (accessed on 6 February 2019).

81. Fontes, J.; Tarne, P.; Traverso, M.; Bernstein, P. Product social impact assessment. Int. J. Life Cycle Assess. 2018, 23, 547-555. [CrossRef]

82. Karlewski, H. Social Life Cycle Assessment in der Automobilindustrie. Ph.D. Thesis, Technical University Berlin, Berlin, Germany, 2016. Available online: https://www.depositonce.tu-berlin.de/bitstream/11303/5286/ 3/karlewski_hannah.pdf (accessed on 6 February 2019).

83. Tarne, P.; Lehmann, A. A comparison of Multi-Regional Input-Output databases regarding transaction structure and supply chain analysis. Int. J. Life Cycle Assess. 2018, 196, 1486-1500. [CrossRef]

84. Tarne, P.; Lehmann, A.; Finkbeiner, M. Introducing weights to life cycle sustainability assessment-How do decision-makers weight sustainability dimensions? Int. J. Life Cycle Assess. 2019, 24, 530-542. [CrossRef] 
85. Tarne, P.; Lehmann, A.; Kantner, M.; Finkbeiner, M. Introducing a product sustainability budget at an automotive company-One option to increase the use of LCSA results in decision-making processes. Int. J. Life Cycle Assess. 2018, 66, 1-19. [CrossRef]

86. Tarne, P.; Traverso, M.; Finkbeiner, M. Review of Life Cycle Sustainability Assessment and Potential for Its Adoption at an Automotive Company. Sustainability 2017, 9, 670. [CrossRef]

87. Schmidt, W.-P.; Taylor, A. Ford of Europe's Product Sustainability Index. In Proceedings of the 13th CIRP International Conference on Life Cycle Engineering, Leuven, Belgium, 31 May-2 June 2006. Available online: http://www.mech.kuleuven.be/lce2006/key2.pdf (accessed on 15 November 2012).

88. Martin, M.; Røyne, F.; Ekvall, T.; Moberg, Å. Life Cycle Sustainability Evaluations of Bio-based Value Chains: Reviewing the Indicators from a Swedish Perspective. Sustainability 2018, 10, 547. [CrossRef]

89. Rafiaani, P.; Kuppens, T.; van Dael, M.; Azadi, H.; Lebailly, P.; van Passel, S. Social sustainability assessments in the biobased economy: Towards a systemic approach. Renew. Sustain. Energy Rev. 2018, 82, 1839-1853. [CrossRef]

90. Di Cesare, S.; Silveri, F.; Sala, S.; Petti, L. Positive impacts in social life cycle assessment: State of the art and the way forward. Int. J. Life Cycle Assess. 2016, 23, 406-421. [CrossRef]

91. Kühnen, M.; Hahn, R. Indicators in Social Life Cycle Assessment: A Review of Frameworks, Theories, and Empirical Experience. J. Ind. Ecol. 2017, 21, 1547-1565. [CrossRef]

92. Jørgensen, A.; Hauschild, M.Z.; Jørgensen, M.S.; Wangel, A. Relevance and feasibility of social life cycle assessment from a company perspective. Int. J. Life Cycle Assess. 2009, 14, 204-214. [CrossRef]

93. New Earth. Social Hotspot Database. 2015. Available online: http://socialhotspot.org (accessed on 15 July 2015).

94. Hauschild, M.; Dreyer, L.C.; Jørgensen, A. Assessing social impacts in a life cycle perspective-Lessons learned. CIRP Ann. Manuf. Technol. 2008, 57, 21-24. [CrossRef]

95. Falcone, P.; Imbert, E. Social Life Cycle Approach as a Tool for Promoting the Market Uptake of Bio-Based Products from a Consumer Perspective. Sustainability 2018, 10, 1031. [CrossRef]

96. GRI. G3. Leitfaden zur Nachhaltigkeitsberichterstattung. Version 3.0. Global Reporting Initiative (GRI). 2006. Available online: https://www.globalreporting.org/resourcelibrary/German-G3-Reporting-Guidelines.pdf (accessed on 12 December 2012).

97. Jørgensen, A.; Le Bocq, A.; Nazarkina, L.; Hauschild, M. Methodologies for Social Life Cycle Assessment. Int. J. Life Cycle Assess. 2008, 13, 96-103. [CrossRef]

98. MBC. Umwelt-Zertifikat Mercedes-Benz S-Klasse. Life Cycle. Mercedes-Benz Cars (MBC), Daimler AG. 2013. Available online: http://www.daimler.com/Projects/c2c/channel/documents/2373356_Umweltzertifikat_ Mercedes_Benz_S_Klasse.pdf (accessed on 12 December 2013).

99. Springer Gabler Verlag. Gabler Wirtschaftslexikon: Stichwort: Unternehmensgrößenstruktur. 2010. Available online: http://wirtschaftslexikon.gabler.de/Archiv/71553/unternehmensgroessenstruktur-v8.html (accessed on 24 April 2014).

100. LBP-GaBi. Documentation of LCWE data in GaBi 4. Abteilung Ganzheitliche Bilanzierung (GaBi); Lehrstuhl für Bauphysik (LBP); Universität Stuttgart. 2010. Available online: http://www.gabi-software.com/fileadmin/ Documents/lcwe.pdf (accessed on 20 February 2011).

101. Ramirez, P.K.S.; Petti, L.; Brones, F.; Ugaya, C.M.L. Subcategory assessment method for social life cycle assessment. Part 2: Application in Natura's cocoa soap. Int. J. Life Cycle Assess. 2016, 21, 106-117. [CrossRef]

102. LBP-GaBi; thinkstep. GaBi Software Homepage. Abteilung Ganzheitliche Bilanzierung (GaBi); Lehrstuhl für Bauphysik (LBP); University of Stuttgart; thinkstep AG, formerly PE International. 2015. Available online: www.gabi-software.com (accessed on 5 May 2015).

103. Ecoinvent Association. ecoinvent database. 2015. Available online: www.ecoinvent.org (accessed on 7 February 2015).

104. EAA. Environmental Profile Report for the European Aluminium Industry. Life Cycle Inventory data for aluminium production and transformation processes in Europe. European Aluminium Association (EAA). 2008. Available online: http://www.alueurope.eu/wp-content/uploads/2011/08/EAA_Environmental_profile_ report-May081.pdf (accessed on 20 April 2014).

105. Wötzel, K. Ökobilanzierung der Altfahrzeugverwertung am Fallbeispiel eines Mittelklassefahrzeuges und Entwicklung einer Allokationsmethodik. Ph.D. Thesis, Technical University of Braunschweig, Braunschweig, Germany, 2007. 
106. Finkbeiner, M.; Ackermann, R.; Bachmann, V.; Berger, M.; Brankatschk, G.; Chang, Y.-J.; Grinberg, M.; Lehmann, A.; Martínez-Blanco, J.; Minkov, N.; et al. Challenges in Life Cycle Assessment: An Overview of Current Gaps and Research Needs. In Background and Future Prospects in Life Cycle Assessment; Klöpffer, W., Ed.; Springer: Dordrecht, The Netherlands, 2014; pp. 207-258.

107. OECD. Average annual hours actually worked per worker. Organisation for Economic Co-operation and Development (OECD). 2014. Available online: http://stats.oecd.org/Index.aspx?DataSetCode=ANHRS (accessed on 24 October 2014).

108. Klöpffer, W.; Grahl, B. Ökobilanz (LCA). Ein Leitfaden für Ausbildung und Beruf; Wiley-VCH Verlag GmbH \& Co. KGaA: Weinheim, Germany, 2009.

109. Deutsches Institut für Normung (DIN) e. V. DIN EN ISO 14044 (2006): Umweltmanagement-ÖkobilanzAnforderungen und Anleitungen (German and English version); Deutsches Institut für Normung (DIN) e. V.: Berlin, Germany, 2006.

110. Jungbluth, N. Erdöl: Teil IV. Sachbilanzen von Energiesystemen: Grundlagen für den ökologischen Vergleich von Energiesystemen und den Einbezug von Energiesystemen in Ökobilanzen für die Schweiz; Dones, R., Bauer, C., Bolliger, R., Burger, B., Faist Emmenegger, M., Frischknecht, R., Heck, T., Jungbluth, N., Röder, A., Eds.; Akademie der Naturwissenschaften Schweiz: Dübendorf, Switzerland, 2007.

111. Burckhardt, G. Soziale Indikatoren in Nachhaltigkeitsberichten. Freiwillig, verlässlich, gut? Abteilung Wirtschafts- und Sozialpolitik der Friedrich-Ebert-Stiftung, Ed. 2012. Available online: http://library.fes.de/ pdf-files/wiso/09459.pdf (accessed on 7 January 2014).

112. Arvidsson, R.; Baumann, H.; Hildenbrand, J. On the scientific justification of the use of working hours, child labour and property rights in social life cycle assessment: Three topical reviews. Int. J. Life Cycle Assess. 2014, 20, 161-173. [CrossRef]

113. HP. IMDS Internationales Material Daten System. Hewlett-Packard GmbH (HP). 2013. Available online: http://www.imds.de/ (accessed on 10 July 2014).

114. Philipp, J.A.; Eyerer, P.; Erve, S.; Schuckert, M.; Theobald, W.; Volkhausen, W. Ökobilanzen für Stahlprodukte: Sachstand und Perspektiven. Stahl und Eisen 1994, 114, 71-77.

115. Endemann, G.; Degner, M.; Fandrich, R. Stahlfibel, veränderter Nachdruck, Originalausgabe 2007; Verlag Stahleisen GmbH: Düsseldorf, Germany, 2011.

116. Classen, M.; Althaus, H.-J.; Blaser, S.; Tuchschmid, M.; Jungbluth, N.; Scharnhorst, W.; Faist Emmenegger, M. Life Cycle Inventories of Metals; Swiss Centre for Life Cycle Inventories. Proceedings of the Final report ecoinvent. No. 10, data v2.1; EMPA: Dübendorf, Switzerland, 2009.

117. Dones, R.; Bauer, C.; Röder, A. Sachbilanzen von Energiesystemen: Grundlagen für den ökologischen Vergleich von Energiesystemen und den Einbezug von Energiesystemen in Ökobilanzen für die Schweiz; Kohle: Teil VI; Dones, R., Bauer, C., Bolliger, R., Burger, B., Faist Emmenegger, M., Frischknecht, R., Heck, T., Jungbluth, N., Röder, A., Eds.; Akademie der Naturwissenschaften Schweiz: Dübendorf, Switzerland, 2007.

(C) 2019 by the authors. Licensee MDPI, Basel, Switzerland. This article is an open access article distributed under the terms and conditions of the Creative Commons Attribution (CC BY) license (http://creativecommons.org/licenses/by/4.0/). 